\title{
Structures and Fabrics in Glacial Ice: A Review
}

PETER J. HUDLESTON

4 Department of Geology and Geophysics, University of Minnesota, Minneapolis, MN

hudle001@umn.edu

\section{Abstract}

10 Glaciers, ice sheets and ice caps represent tectonic systems driven by gravity. Their

11 movement can be studied in real time and the rheological properties and strength of

12 ice determined from laboratory experiments and field measurements. All glacial ice

13 has primary stratification, exhibited by variations in grain size, bubble content and

14 debris content. As it deforms, with deformation dominated by plastic flow and

15 recrystallization, accompanied locally by fracture under tension,, a suite of

16 structures develops that reflects the primary fabric of the ice and the anisotropy

17 that develops as a result of cumulative deformation. Initial variations in solid

18 impurity content and strain dependent anisotropy as a result of a crystallographic

19 fabric give rise to effective viscosity increases or decreases compared to isotropic

20 polycrystalline ice of about a factor of ten. Foliation develops from inherited

21 (mostly stratification) or introduced (mostly ice veins or fracture traces) fabric

22 elements and from dynamic recrystallization. It is largely dependent on the

23 accumulated strain, which is highest at the base and near the margins of glaciers, ice 
24 sheets and ice streams. Folds develop largely passively due to initial amplification of

25 irregularities in the primary stratification, to variations in flow with time or to

26 inhomogeneous flow associated with shear zones and ductile accommodation

27 around open fractures. Buckle folds and boudinage, mostly on a small scale, occur

28 where viscosity contrast is large, mostly in basal ice. Thrusting and wrench faulting

29 are documented in surging glaciers but theoretically most unlikely and rare or

30 absent elsewhere. Many structures interpreted as faults are not due to shear failure

31 but rather result from shear displacements during opening and closing of tensile

32 fractures.

\section{1. Introduction}

35 Glaciers have particular appeal to structural geologists, providing natural 'tectonic'

36 systems in which a variety of brittle and ductile structures develop under known

37 driving forces and at rates that can be directly measured. Analogies between

38 structural development in ice and in rocks have been made by many authors (e.g.

39 Wegmann, 1963; Hambrey and Milnes, 1977; Kamb et al., 1985; Hudleston, 1992;

40 Lawson et al., 1994), and have been drawn from the scale of the crystal - ice in some

41 ways being a good analogue for quartz (e.g. Wilson and Russell Head, 1979; Wilson

42 et al., 2014), to individual structures such as folds (e.g. Hudleston, 1977b) and

43 boudinage (Hambrey and Milnes, 1975), to tectonic systems (e.g. Herbst and

44 Neubauer, 2000). 
46 One benefit of studying structures in ice is that the rheology is relatively well

47 understood, with a well-established flow law for isotropic polycrystalline ice and

48 with recent advances that allow characterization of the rheology at low stresses and

49 with preferred crystallographic orientation (e.g. Pettit et al., 2011; Treverrow et al.,

50 2012; Wilson and Peternell, 2012). Considerable experimental work has also been

51 done on the effect on rheology of solid particles dispersed in ice and behavior of ice-

52 saturated sediment (Moore, 2014). Much recent work has been done on the

53 microstructure of ice and the development of preferred crystallographic orientation

54 with strain (e.g. Duval et al., 2010; Montagnat et al., 2012, 2014), with particular

55 focus on the Greenland and Antarctic ice caps. In those locations, understanding the

56 flow history has important implications for interpreting proxy signals for climate

57 change, since deformation overprints and disrupts stratigraphy deep under ice caps

58 due to the nature of the ice flow.

60 Geophysical methods are employed to determine ice flow and material properties at 61 depth within and over large areas of ice sheets and glaciers. Radio-echo sounding 62 (e.g. Drews et al., 2009) and ground-penetrating radar (e.g. Vaughan et al., 1999;

63 Holschuh et al., 2014) are used to determine ice thickness and elucidate internal 64 structure. Not only can these techniques pick up internal reflectors representing 65 stratification (isochrones), they may also detect changes in crystallographic fabric 66 (Eisen et al., 2007), as may seismic wave velocity analysis (Diez et al., 2104).

67 Interferometric synthetic aperture radar (InSAR), together with optical-image-

68 tracking methods provided by satellite imagery and GPS, are used to measure 
69 surface velocities over large areas and over time frames of from seconds to years

70 (e.g. Joughin et al., 1999, 2010). This is especially useful for studying ice streams in 71 ice sheets.

72

73 Hambrey and Lawson (2000) have provided a comprehensive summary of

74 structural studies on glaciers from the 1950s until the turn of the century. Good

75 examples of detailed studies are those of Allen et al. (1960) on the Lower Blue

76 Glacier, Washington; Meier (1964) on the Athabasca Glacier, Alberta; Hambrey

77 (1976a, 1976b) on Charles Rabots Bre, Norway; Hambrey and Milnes (1977) on

78 Griesgletscher, Switzerland; Hambrey and Müller (1978) on White Glacier, Axel

79 Heiberg Island, Canada; Sharp et al. (1994) and Lawson $(1996,1997)$ on the

80 Variegated Glacier, Alaska; and Goodsell et al. (2005) on Haut Glacier d'Arolla,

81 Switzerland.

82

83 The approach taken in this paper is first to provide brief reviews of ice rheology, the

84 kinematics of flow in glaciers and larger ice bodies (Fig. 1) and the crystallographic

85 fabric that develops as a result of this flow. The bulk of the paper is devoted to

86 descriptions of the various structural and fabric elements found and mapped in

87 glacial ice and a discussion of the processes involved in their development. The

88 paper concludes with a brief section discussing the assembly and sequence of

89 structures and fabrics developed in glacial 'tectonic' systems.

90

$91 \quad$ 2. Rheology 
93 Data from experiments and theoretical considerations suggest that isotropic

94 polycrystalline ice deforms under secondary creep according to a relationship of the 95 form:

96

$97 \quad \cdot i j=A$\begin{tabular}{lll}
$n$ & \multicolumn{1}{l}{1} \\
eff & $i j$
\end{tabular}

99 (cf., Cuffey and Paterson, 2010, eq. 3.22), where ${ }_{i j}$ and ${ }_{i j}$ are components of the

100 strain rate and stress tensors, respectively and eff is the effective stress - the

101 second invariant of the stress tensor. This is the generalized form (Nye, 1953) of

102 Glen's (1955) flow law relating shear strain rate to shear stress. The value of the

103 constant $A$ is affected by various physical and chemical properties of the ice and

104 reported values vary widely (see Cuffey and Paterson, 2010, sect. 3.4.5). It primarily

105 incorporates a strong temperature dependence through an Arrhenius relationship.

106 Reported values of $n$ also vary widely (Weertman, 1983; Cuffey and Paterson, 2010,

107 sect. 3.4.4). A value of $n=3$, reported in many studies, is consistent with theoretical

108 considerations of intracrystalline slip on the basal plane (Weertman, 1983) and is

109 commonly preferred for modeling ice flow. Values of $n<3$ and as low as 1 are

110 reported at low stresses and for fine grain sizes and may reflect a change to grain-

111 size sensitive creep mechanisms (e.g. Goldsby and Kohlstedt, 1997; Montagnat and

112 Duval, 2000). Flow laws that include a term expressing a linear stress-strain 
113 relationship have been successfully applied to low deviatoric stress regions such as

114 near ice divides (e.g. Pettit and Waddington, 2003; Pettit et al., 2011).

115

116 Ice crystallographic fabric evolves during deformation of initially isotropic ice (e.g.

117 Alley, 1992), and secondary creep is in fact transient rather than steady state. It

118 appears that under a constant stress regime of either uniaxial compression or

119 simple shear and with deformation accompanied by dynamic recrystallization, a

120 steady state tertiary creep regime may be achieved after about $10 \%$ strain (Fig. 2,

121 Budd and Jacka, 1989; Treverrow et al., 2012). The nature of the crystallographic

122 fabric and stress-strain rate relationship depend on the kinematics of flow (Duval,

123 1981; Wilson, 2000; Budd et al., 2013). Tertiary creep is characterized by dynamic

124 recrystallization (Duval et al., 2010).

125

126 As crystallographic fabric develops the viscosity becomes anisotropic, with the ice

127 becoming softer in some stress configurations and harder in others. Equation 1

128 then becomes inadequate for describing the rheology. Various ways of modifying

129 the flow law to take anisotropy into effect have been suggested. One way is to

130 introduce an enhancement factor into the equation, which then becomes.

131

$132 \dot{H}_{i j}=E A_{\text {eff }}^{n} i j$

134 (cf., Cuffey and Paterson, 2010, eq. 3.35), where $E$ is the factor by which the strain 135 rate deviates from that predicted by the flow law for isotropic ice. The value of $E$ 
136 depends on the nature and intensity of the fabric, and is about twice as large in

137 simple shear as in uniaxial compression (Treverrow et al., 2012). It can reach a

138 value of about 10 in simple shear (see Fig 3 and the discussion in Cuffey and

139 Paterson, chap. 3).

140

141 In the past twenty years considerable attention has been paid to modeling flow in

142 polycrystalline ice that treats deformation on multiple scales up to that of ice sheets.

143 In these models crystallographic fabric evolves with deformation. Examples are

144 Azuma (1994), Castelnau et al. (1996), Thorsteinsson (2002) and Pettit et al. (2007).

145 A comprehensive review of the various approaches taken to the modeling of ice

146 deformation and fabric evolution at different scales is given by Montagnat et al.

147 (2014).

148

$149 \underline{2.1 \text { Effect of solid impurities }}$

150

151 Glacial ice frequently contains debris, ranging in particle size from dust to boulder,

152 usually well dispersed except near the base of glaciers, ice caps and ice sheets where

153 debris rich layers are frequently found. Debris enters the ice in several ways. It

154 does so as wind born particles on the surface in the accumulation zone, where it

155 occurs in trace amounts that help create annual markers of stratification when the

156 ice is later exposed in the ablation zone. Debris also may also be deposited on the ice

157 surface near the sides of glaciers, as a result of mass wasting processes affecting the

158 rock walls or deposition from supraglacial streams. Rock avalanches may produce 
159 local concentrations of coarse debris. High concentrations of debris are found along

160 the base of glaciers or ice caps, where it may be entrained by several processes.

161 These processes have received much attention by glaciologists, since so much of

162 glacier movement occurs at the base of glaciers, either by slip on the bedrock or

163 shear within the basal ice or sediment below the ice. There is almost a complete

164 range in composition from $100 \%$ ice to close packing of debris particles with ice

165 filling the interstices. Basal ice is typically strongly layered, due either to shear

166 within the ice/debris mixtures or the process by which the debris is entrained, (e.g.

167 Knight, 1995; Samyn et al., 2008).

168

169 A comprehensive review of the effect of debris on ice rheology and strength is given 170 by Moore (2014), who considers the deformational behavior of materials over the

171 complete range of debris-ice mixtures. As expected, the inclusion of solid particles

172 has a pronounced effect on rheology, most typically by strengthening the ice and

173 increasing the viscosity (e.g. Hooke et al., 1972). Under certain conditions, however,

174 as evidenced both in nature (e.g. Echelmeyer and Wang, 1987) and in experiments

175 (e.g. Song et al., 2005, 2008) the presence of dispersed solid particles weakens

176 rather than strengthen the ice, and the reason for this duality of behavior has been

177 much debated (see discussion in Moore, 2014). It appears mainly to be through the

178 influence of the particles on recrystallized grain size and grain-boundary sliding

179 (Durand et al., 2006). Weakening of ice-debris mixtures occurs at relatively high

180 temperatures when unfrozen water exists along crystal and rock-ice interfaces. At

181 concentrations of above about $40 \%$ debris by volume, frictional interaction among 
182 particles becomes important and Mohr-Coulomb (pressure dependent) behavior

183 occurs, modified by the presence of the interstitial ice (Moore, 2014).

184

185 The same mixture of ice and sediment can be stronger than pure ice under some

186 conditions and weaker under others. For example, in experiments by Bray (2013),

187 ice-rich silt at $-1^{\circ} \mathrm{C}$ was weaker than pure ice at low stresses and stronger than pure

188 ice at stresses above a threshold of about $220 \mathrm{kPa}$, Since this threshold stress is at

189 the high end of the range of shear stresses expected for basal glacial ice (Cuffey and

190 Paterson, 2010. Sect.8.2).,it suggests interesting possibilities for structural

191 development where such material is interlayered with pure ice.

192

193 Overall, it appears from the data available (Moore, 2014) that the presence of debris

194 in ice may increase or decease its resistance to shear by up to about a factor of about

19510 , which is also approximately the factor by which viscosity may be increased or

196 lowered as a result of fabric-induced anisotropy (Fig. 3).

198 3. Flow Field and Kinematics

200 Surface velocities can be measured directly on glaciers and ice caps, and internal velocities

201 measured by use of boreholes (see Hooke, 2005, ch. 5). Typical maximum horizontal

202 velocities in valley glaciers are on the order of tens of meters per year, while in surging

203 glaciers and ice streams in Antarctica and Greenland the velocities are one or more orders 
204 of magnitude faster (see Cuffey and Paterson, 2010, table 8.2). Generalized flow patterns

205 for valley glaciers and ice caps are illustrated schematically in Fig. 1.

206

207 Basal ice may slide over or be frozen to its substrate, and basal conditions are different

208 under temperate glaciers than under polar glaciers and ice sheets. Sliding is inhibited if the

209 ice is frozen to the substrate (Hutter and Olunyolo, 1980), although the effect may be

210 limited if the substrate is unlithified (Echelmeyer and Wang, 1987; Moore et al., 2011).

211 Sliding velocities can be measured directly in some instances and the phenomena of local

212 pressure melting and regelation (refreezing) around obstacles observed (Kamb and

213 LaChapelle, 1964; Cohen et al., 2000; Iverson et al., 2007).

215 Velocity profiles in valley glaciers are generally what would be expected for a material

216 deforming according to a non-linear flow law, with high gradients near the margins and the

217 base (Fig. 4, Raymond, 1971a, b), although there may be local complexity even when the

218 overall glacier geometry is straightforward (e.g. Harper et al., 2001). In ice sheets, ice

219 divides may move with time and ice streams change in position and intensity (Voight et al.,

220 2003; Siegert et al., 2004; Jacobson and Waddington, 2005).

221

222 Knowing the velocity field allows strain rates to be calculated. Longitudinal strain rates are 223 generally extensional in the accumulation zone and contractional in the ablation zone of a 224 valley glacier (see Fig. 1). Shear strain rate is high along the margins and at the base of 225 glaciers and in the margins of ice streams (e.g. Clarke, 1987). As an example, the velocity 226 profiles in Fig. 4 imply shear strain rates of about $0.2 \mathrm{a}^{-1}\left(7.0 \times 10^{-9} \mathrm{~s}^{-1}\right)$ and $0.1 \mathrm{a}^{-1}\left(2.5 \times 10^{-9} \mathrm{~s}^{-}\right.$ 
227 1) along the sides and base respectively of the Athabasca glacier. Longitudinal strain rates

228 at the same location are negative and an order of magnitude smaller than these (Raymond, 229 1971b).

230

231 Estimates of shear stress at the base of glaciers and ice caps can be made from ice thickness 232 and surface slope (Cuffey and Paterson, chap. 8). Typical values are 50-200 kPa (Cuffey

233 and Paterson, 2010, table 8.3). Values an order of magnitude lower are found in water-

234 saturated sediment below some ice streams (Joughin et al., 2004) .

235

236 Flow variations occur on all time scales, in part related to changes in weather and climate

237 (e.g. Hooke et al., 1989; Keller and Blatter, 2012) and in part due to seasonal changes and

238 episodic surges, which are discussed later. Steady state is never achieved, but may be

239 approached over certain time intervals and on some scales. It is useful to consider steady

240 state as a reference frame for understanding structural development.

242 Assuming steady state flow, measured or modeled velocities can be used to estimate finite

243 strains within a glacier or ice cap (Figs. 5, 6, 7) (Milnes and Hambrey, 1976; Hambrey and

244 Milnes, 1977; Hambrey et al., 1980; Hudleston and Hooke, 1980; Budd and Jacka, 1989;

245 Hubbard and Hubbard, 2000). In ice caps and ice sheets, cumulative strain changes from

246 uniaxial shortening at the centers of domes or pure shear at divides, with the minimum

247 strain vertical, to being progressively more non-coaxial with depth and distance from the

248 center or divide (Figs. 5,6) (Hudleston and Hooke, 1980). Strongly non-coaxial strain is

249 found in basal ice and along the margins of glaciers and ice streams. In regions where flow 
250 is two-dimensional, basal strain will accumulate under simple shear. In radial flow (as in

251 Fig. 1a), cumulative strain will be of flattening type. In valley glaciers, in general the strains

252 will be close to coaxial along the centerline and strongly non-coaxial along the base and

253 sides, locally approaching simple shear (Fig. 7). The patterns described above are subject

254 to modification when the flow deviates substantially from steady state. The consequences

255 of this for structures are discussed in section 5.

256

257 4. Crystallographic Fabric

258

259 Considerable attention has been paid in recent years to the development of

260 crystallographic fabric (lattice preferred orientation, or LPO), especially in ice sheets, with

261 recognition of the significant effect fabric has on the flow of ice, imparting anisotropy to the

262 viscosity (Azuma, 1994; Alley, 1988; Castlenau et al., 1996). A complete analysis of LPO

263 includes $a$-axes, which can be determined using such techniques as X-ray Laue diffraction

264 (e.g. Weikusat et al., 2011). An excellent treatment of crystallographic fabric, set in a

265 broader discussion of microfabric deformation mechanisms and recrystallization, is given

266 by Faria et al. (2014a, 2014b) in their review of microstructure of polar ice.

267 A brief description of typical $c$-axis fabrics is given here

269 Fabric anisotropy develops due to intracrystalline slip on lattice planes during

270 deformation. In ice, slip on the basal plane is dominant, causing these planes in individual

271 crystals to rotate towards being perpendicular to the maximum shortening direction (e.g.

272 Alley, 1988, 1992). This produces a small circle distribution of $c$-axes around the axis of 
273 uniaxial compression at the center of ice domes (Fig. 8a), a bimodal pattern symmetric

274 about the compression axis in pure shear, as found at ice ridges (Fig. 8b), and an

275 asymmetric bimodal pattern in simple shear, with the maxima lying in a plane

276 perpendicular to the shear plane and parallel to the shear direction, as found in shear zones

277 deep in ice sheets and near the base of polar glaciers (Fig.8c). Fabric strength intensifies

278 with increasing strain (e.g. Hudleston, 1977a; Montagnat et al., 2012) and may achieve

279 steady state with increasing deformation as fabric enhancing lattice rotations are balanced

280 by fabric weakening recrystallization. In simple shear and at large shear strains the weaker

281 maximum may disappear (Fig. 8d) as a result of recrystallization. Debris particles, if

282 present even in small amounts, may weaken the development of a fabric (Song et al., 2005). 283

284 In valley glaciers and in the deeper parts of ice sheets, in coarse-grained ice that has 285 undergone significant recrystallization and often subsequent annealing, multiple maximum 286 fabrics, often with a four-fold diamond arrangement, are common (Fig. 8e) (Kamb, 1959;

287 Budd, 1972; Gow and Williamson, 1976; Hambrey, 1976b). These may result from a 288 modification of a girdle fabric, and several mechanisms have been proposed to account for 289 them, with twinning likely playing a role (Matsuda and Wakahama, 1978; Faria et al., $2902014 b)$.

291

292 The planes and axes of symmetry of the crystallographic fabric may or may not be 293 geometrically related to the foliation with which the fabric is associated (Budd, 1972;

294 Hambrey, 1976b, 1977a). Where it is, the pole to the foliation typically is perpendicular to 
295 a $c$-axis maximum or to the center of a multi-maxima fabric (e.g. Kamb, 1959; Allen et al., 296 1960; Hambrey, 1976b).

\section{5. Mappable Structural and Fabric Elements in Glaciers}

300 Glacial ice contains several distinctive fabric and structural elements that in part are

301 imparted to the ice as it forms and in part develop and are modified as a result of

302 deformation accompanied by recrystallization. These elements are defined by

303 variations in grain size, bubble content, and impurity content. In addition, there

304 may be a grain shape fabric (shape preferred orientation or SPO) and bubble fabric

305 (bubbles with preferred shape and orientation). As in deformed rocks, there are 306 both planar and linear fabric elements.

308 5.1 Primary Stratification

310 Primary stratification or bedding is present in the accumulation zones of all glaciers

311 and ice caps. It is manifest by variations in crystal size and bubble content that

312 reflect the changing conditions related to snow deposition and the transition

313 through firn to glacial ice. The nature of the transition differs in temperate glaciers,

314 where melting and refreezing occur (e.g. Kawashima and Yamada, 1997), and polar

315 glaciers and ice caps, where the transition is largely in a dry state (e.g. Alley et al,

316 1982). In the latter case initial bubble concentration is related to temperature and

317 snow accumulation rate during firnification (Spencer et al., 2006). Dust may be 
318 seasonally concentrated on the surface and often serves to mark annual layering.

319 Also, in valley glaciers debris carried onto the glacier from the valley sides may

320 accumulate locally on the surface in the accumulation zone and this angular

321 englacial material can provide evidence of bedding when later exposed, often folded,

322 in the ablation zone (e.g. Hambrey and Dowdeswell, 1997; Hubbard and Hubbard,

323 2000; Roberson, 2008). Bedding is the only fabric element seen at the front of the

324 smallest glaciers (e.g. Fig. 9a).

325

326 Besides deposition of layers in the upper parts of glaciers and ice caps, irregularities

327 in topography and local conditions mean that net accumulation may occur in other

328 places, giving rising to local unconformities, an example of which is shown in Fig. 9b.

330 Primary stratification may be traced throughout the length of small glaciers (e.g.

331 Hambrey, 1976b), although not necessarily as continuous strata, and its orientation

332 down glacier may be tracked using flow models and compared with surface

333 exposures (Hubbard and Hubbard, 2000). In larger glaciers, it becomes difficult to

334 distinguish primary stratification from foliation (see below). 335

$336 \quad 5.2$ Extensional fractures and veins

338 Brittle failure of ice under extension at the surface of glaciers and ice caps occurs in 339 virtually all glaciers, producing crevasses if the fractures widen enough. These are 340 predominantly mode I fractures (Lawn, 1993) that are initially perpendicular to the ice 
341 surface and perpendicular to the direction of maximum extensional strain rate.

342 Crevasses are typically transverse to valley glaciers where developed at or close to the

343 mid line in regions of longitudinal extensional strain rate and arranged en echelon to the

344 glacier sides close to the ice margins or edges of ice streams (Marmo and Wilson, 1998),

345 reflecting the dominance of shear stress at the glacier margins or edges of ice streams.

346 The classical patterns are illustrated in Fig. 10 (after Nye, 1952). Natural examples are

347 shown in outcrop and on a map in Figs. 11 and 12., and in general they match Nye's

348 predictions well. Deviations of crevasse orientations from perpendicularity to the

349 maximum extensional strain rate, as is the case locally in Fig. 12, occur due to rotation of

350 the crevasses once formed (and before closure). In addition, stresses are reoriented

351 around crevasses once formed, such that further fracture development, if it occurs, may

352 lead to complex patterns. This is especially true in icefalls (Fig. 11c) and in surging

353 glaciers (Lawson et al., 2000). Estimates of extensional strain rates associated with

354 tensile fracturing based on field measurements are quite variable, with values generally

355 being higher in temperate glaciers than in polar glaciers. Meier et al. (1974) estimated

356 values of $0.03 \mathrm{a}^{-1}\left(\mathrm{ca}^{1} 10^{-9} \mathrm{~s}^{-1}\right)$ for the temperate Blue Glacier and Hambrey and Müller

357 (1978) estimated values as low as $0.004 \mathrm{a}^{-1}\left(\right.$ ca. $\left.10^{-10} \mathrm{~s}^{-1}\right)$ for the polar White Glacier,

358 while noting that strain rates locally as high as $0.16 \mathrm{a}^{-1}\left(\mathrm{ca} .5 \times 10^{-9} \mathrm{~s}^{-1}\right)$ were not

359 associated with fracturing. Crevasse patterns have been used to characterize the flow

360 and flow history in fast moving glaciers (Herzfeld et al., 2004)

362 There is still uncertainty about how deep crevasses penetrate in glaciers and ice 363 caps (Hooke, 2005; Mottram and Benn, 2009; Cuffey and Paterson, 2010, p.449). 
364 The vertical normal stress, zero at the surface, increases linearly with depth and

365 thus the difference between the vertical and horizontal normal stresses (the latter

366 being zero - or more correctly atmospheric pressure - perpendicular to a crevasse

367 wall at all depths) also increases and at some depth must be sufficient to close the

368 fracture by plastic flow. The particular circumstances will depend on the rate of

369 propagation of the fracture and tensile strength of the ice. Water filled crevasses

370 can theoretically extend to glacier beds provided water supply is maintained

371 (Weertman, 1973). Evidence of fractures extending deep into glaciers is provided

372 by the presence of veins of clear ice, presumed to be traces of old fractures, far

373 downstream in the ablation zone where ice is exposed (Hambrey, 1976a; Goodsell et

374 al., 2005).

375

376 From the moment of formation onwards, fractures in marginal ice are subject to

377 displacement downstream and rotation induced by the velocity gradients of the flow

378 (see Hubbard and Hubbard, 2000). This displacement or rotation will bring a

379 fracture into a position or orientation such that the strain rate across it becomes

380 compressional, which eventually causes closure and creation of a vein from

381 transformed snow or freezing of melt water entering the fracture. Healed fractures,

382 or 'fracture traces' in the terminology of Hambrey and Milnes (1977), filled with

383 clear ice are the most likely origin for the "blue bands" seen so abundantly in valley

384 glaciers. During rotation, and before the fracture finally heals and becomes a vein or

385 fracture trace, the lack of shear stress along the crevasse walls and consequent

386 modification of the stress and strain rate fields around the fracture causes fracture- 
387 and strike-parallel displacement of one wall with respect to the other. Relative

388 "strike-slip" movement of one wall of an open crevasse with respect to the other has

389 been directly recorded (e.g. Kehle, 1964). It seems most unlikely that such crevasses

390 originated as shear fractures.

391

392 Some fractures may not develop into open crevasses, but rather develop directly as

393 veins in a manner similar to that described as crack-seal in rocks (Durney and

394 Ramsay, 1973; Ramsay, 1980), with elongate crystals of bubble free ice

395 perpendicular to the walls growing in continuity with crystals in the walls,

396 sometimes with a train of bubbles along the center or along the vein margins

397 (Hambrey and Müller, 1978; Hambrey et al., 1980; Lawson et al., 1994; Voigt et al., 398 2003).

400 In marginal ice, generation of new crevasses in ice containing older healed fractures, 401 appearing as veins, leads to younger veins cutting across older ones and the kind of 402 fracture and vein relationships shown in Fig. 13, similar to what is found in rocks

403 (Passchier and Trouw, 1996, fig. 6.11). The crosscutting relationships are

404 systematic, as older veins are rotated and cut by younger ones. Patrick et al. (2003)

405 have described this phenomenon associated with en echelon arrays of sigmoidal

406 fracture traces in the Sørsdal glacier in East Antarctica (Fig. 14). The distribution of

407 orientations of fracture traces and veins in a straight segment of the marginal zone

408 of Storglaciären in Sweden is shown in Fig. 15a. This can be compared with

409 orientation distributions produced by a simple model of fracture generation and 
410 subsequent passive rotation by simple shear. In this case, if the fractures originated

411 either at $45^{\circ}$ to the glacier margin (Fig. 15b) or angles up to $90^{\circ}$ (Fig. 15c) in the

412 region of extensional flow up glacier in the accumulation zone, significant

413 displacement and shear would concentrate the traces at small angles to the glacier

414 margin. The data (Fig. 15a) are consistent with most fractures having formed

415 between $45^{\circ}$ and $90^{\circ}$ to the margin.

416

417 Steep transverse fractures that form along the mid lines of glaciers will tend to have 418 a crescent shape in map view, initially convex up glacier (Fig. 10), and may close to

419 form veins in regions of compressional strain, and become convex down glacier with

420 inward dips that become more gentle downstream, the crescent shape and

421 shallowing dips reflecting the cross-glacier and vertical velocity gradients,

422 respectively. Numerical modeling may be used to predict the three-dimensional

423 form of healed fracture traces down glacier (Hubbard and Hubbard, 2000).

424

425 Shear fractures (mode II or III fractures) (Lawn, 1993) are much rarer than

426 extensional fractures in glaciers, and many of the structures described as faults or

427 thrusts likely have an alternative origin. These will be discussed in a later section. 428

4295.3 Foliation

430

431 The most prominent fabric element visible in the ablation zones of most valley

432 glaciers is a foliation, defined largely by variations in crystal size, crystal shape, and 
433 bubble concentration, often in the form of distinct, typically discontinuous, bands

434 (Fig. 16a, b)(e.g. Allen et al., 1960; Hambrey, 1975; Hambrey, 1976b, 1977a;

435 Hambrey and Milnes, 1977) and on a finer scale by bubble distribution (Fig. 16c, d,

436 Fig.17) and sometimes bubble shape (e.g. Hudleston, 1977a). A crystallographic

437 lattice preferred orientation (LPO) is commonly developed in foliated ice and may

438 or may not have a well-defined geometrical relationship to the foliation (e.g. Kamb,

439 1959; Budd, 1972). The foliation is most strongly developed at the base and along

440 the margins of glaciers and along sutures or septa formed by the joining of two ice

441 streams. Along margins or along septa it is steep to vertical and parallel to the

442 glacier margins. It is common in the literature to refer to foliation in valley glaciers

443 as either being 'longitudinal' or 'transverse,' the latter typically developing at the

444 base of an icefall (Allen et al., 1960; Ragan, 1969; Hambrey and Milnes, 1977;

445 Hambrey et al., 1980). Overall patterns of transverse foliation in valley glaciers have

446 been described as arcuate at the surface with dips inward and up-glacier (e.g.

447 Hambrey, 1977b), with a general appearance of one or more sets of "nested spoons"

448 (Allen et al., 1960; Rutter, 1965). Cross-cutting foliations, often of several

449 generations, have been described in many glaciers (e.g. Ragan, 1969; Hambrey and

450 Milnes, 1977; Hambrey et al., 1980).

452 As in rocks, foliation may take different forms in glacier ice, and a number of

453 processes contribute to its formation. In all cases however, and by definition of how

454 the term 'foliation' is used, deformation is involved, with the most intense foliation

455 found where the deformation is greatest. Early workers looked for a relationship 
456 between foliation and the state of stress in the ice where the foliation was observed;

457 that is, they expected foliation to form perpendicular to the direction of maximum

458 compressive stress (Glen, 1956; Meier, 1960) or parallel to the direction of

459 maximum shear stress (Ragan, 1969). Allen et al. (1960) considered foliation to be

460 a wholly secondary structure formed as a result of ice deformation, and in the Lower

461 Blue Glacier, Washington, they found it to be developed in a vertical orientation in

462 regions of high compressive stress at the base of an ice fall and then to be modified

463 passively to take up the arcuate nested spoon pattern observed downstream.

464 Pfeffer (1992) considered transverse foliation in the terminal lobe of the Variegated

465 glacier, to have formed by bubble migration as a result of high compressive stress

466 during the 1982-1983 surge. Ragan (1969) considered the foliation to be

467 continually reformed parallel to the plane of maximum shearing stress as earlier

468 foliations rotated away from this orientation, producing serial cross-cutting

469 relationships.

470

471 Observations support the view of Hambrey and Milnes (1977), Hooke and

472 Hudleston (1978) and Hambrey et al. (1980) who argued that total strain and strain

473 history, rather than stress, is the most important factor controlling the development

474 of foliation, and they identified several structural or fabric elements that taken

475 together form foliation (Fig. 18), with a composite foliation becoming parallel to the

$476 X Y$ plane $(X \geq Y \geq Z)$ of the cumulative strain after large deformation. Hambrey (1975)

477 considered that foliation was often developed from sedimentary layering, and a

478 number of subsequent studies have borne this out (e.g. Roberson, 2008; Jennings et 
479 al., 2014). Hooke and Hudleston (1978) argued that bedding and veins or fracture

480 traces formed from the closure of fractures were the two principal components that

481 contribute to foliation. Bedding and veins are both manifest largely in the

482 distribution of bubbles, with variations in bubble concentration, often associated

483 with variations in grain size. An example of ice with bedding well preserved and

484 with a foliation expressed on the grain scale by grain shape and bubble

485 concentration, and these both cut by later veins, is shown in outcrop in Fig. 16d. In

486 thin section and on a fine scale the foliation may appear as lenses and diffuse

487 patches of varying bubble concentration. In Fig. 17a such a foliation is cut by a clear

488 ice vein, but deformation and recrystallization accompanied by some reorganization

489 of bubbles since vein formation have modified the vein edges and made them

490 ragged. Azuma et al. (2012) documented the effect of bubbles impeding grain

491 growth and being swept by moving grain boundaries. In crossed polars, a shape

492 preferred orientation of the ice crystals, parallel to the foliation, can be seen (Fig.

493 17b). In this sample the bubbles themselves are small and remain spherical. In

494 other cases, especially in cold glaciers, the bubbles themselves may be elongate and

495 their alignment may contribute to the foliation (Gow, 1968; Hudleston, 1977a).

497 If different fabric elements contribute to foliation, cross-cutting foliations may

498 indicate: 1) a strain insufficiently large to bring all elements into parallelism (e.g.

499 Fig. 16d); 2) additional cross-cutting elements being introduced after a strong fabric

500 has already developed (e.g. Fig. 16c); or 3) in non-coaxial deformation, the existence

501 of fabric elements that are sensitive to only the most recent part of the strain history 
502 (see section 5.5 on ductile shear zones) and thus forming a foliation oblique to those

503 elements reflecting the total strain. Another way of expressing this is to say that

504 different fabric elements will reflect different segments of the strain history.

505 Primary stratification or bedding is a feature, as long as it is preserved, whose

506 orientation reflects the total strain experienced by the ice, whereas veins record

507 only the strain accumulated since vein formation. Ice crystal size and shape (SPO)

508 and small-scale distribution of bubbles, being modified continuously by dynamic

509 recrystallization, reflect the latest part of the strain history, and thus may form

510 fabric elements oblique to a foliation defined otherwise by variations in bubble

511 concentration due to stratification and vein fillings. In addition, as a result of

512 recrystallization, bubbles may be redistributed on the grain scale by grain boundary

513 migration (Azuma et al., 2012), and this may lead to an alignment of bubble clusters

514 parallel to the SPO and oblique to the dominant early foliation formed by a

515 combination of bedding and rotated veins (e.g. 16c). It is possible also that bubbles

516 may become reorganized by migration is response to stress, creating a foliation

517 perpendicular to the maximum compressive stress (Pfeffer, 1992). In the case

518 studied by Pfeffer at the terminus of the Variegated glacier, after the 1982-83 surge,

519 bubble migration might also have been associated with reorganization of bubbles

520 due to grain boundary migration during dynamic recrystallization associated with

521 the final increment of compressional strain, i.e., incremental strain related rather

522 than directly related to stress.

523 
524 Bubble elongation develops as ice deforms, as has been demonstrated

525 experimentally (Nakawo and Wakahama, 1981) and in natural ice (Hudleston,

526 1977a; Russell-Head and Budd, 1979; Russell-Head, 1982) and elongate bubbles

527 may constitute a fabric element, especially in polar glaciers (e.g. Hambrey, 1977a;

528 Hudleston, 1977a, and section 5.5). Bubble elongation, however, may not always

529 reflect a coherent fabric component. Hambrey (1976b) reported bubbles in coarse-

530 grained ice flattened in the plane of the foliation in a Norwegian valley glacier.

531 Viewed in the plane perpendicular to foliation, however the bubbles were elongate

532 in different directions in adjacent crystals, reflecting control by lattice orientation.

533 Hambrey attributed this as an effect related to recrystallization under stagnant ice

534 conditions (annealing).

535

5365.4 Folds

537

538 Primary stratification, veins, and foliation all locally become folded, and folds have

539 been described in all types of glaciers. Fold shape and style are quite variable (e.g.

540 see Fig. 5 in Hambrey, 1977a), reflecting different mechanisms responsible for their

541 formation. The most common folds visible at the surface have similar (Class 2 ,

542 Ramsay's 1967 classification) or sub-similar shapes (Fig. 19) (Hambrey, 1977a;

543 Calvet and Santanach, 1992), indicating little on no rheological contrast among the

544 layers involved. These occur on many scales from kilometer (Fig. 19a) to centimeter

545 (Fig. 19d). They are the consequence of non-uniform flow on different time scales

546 and spatial scales, resulting in the passive transformation of planar markers such as 
547 bedding, veins, or the banded form of foliation into folds. Alternatively, they may

548 result from a more homogenous strain affecting stratification with originally non-

549 planar form (see Hudleston, 1977b), for example inherited from the topography of

550 the accumulation zone (Figs. 20, 21) (Fig. 10 in Hambrey and Glasser, 2003). In

551 either case the folds are amplified kinematically by intense horizontal shortening or

552 shear strain at various positions within the glacier. The upright folds with hinges

553 plunging mostly gently at various angles up glacier are examples of this. They are

554 commonly found in the ablation zone of valley glaciers, especially in the strongly

555 foliated ice along glacier margins or internal longitudinal septa (resulting from the

556 joining of two ice streams) and are typically associated with an axial planar foliation

557 (Figs. 19c, 20-22, 23a) (Figs. 5,6 in Allen et al., 1960; Fig. 16 in Hambrey et al., 1999;

558 Fig. 10 in Hambrey and Glasser, 2003). Significant horizontal shortening across the

559 glacier suggested by these folds and associated foliation is to be expected

560 considering the reduction in width of glaciers formed by the merging of ice streams

561 of collectively much greater width (Fig. 20) (Lawson et al., 1994; Fig. 15 in Hambrey

562 et al., 1999; Goodsell et al., 2005). Similar or sub-similar (Class 2) folds with steeply

563 plunging hinges affecting the foliation (Fig. 19d, 23b) are younger than the folds just

564 described and have a different origin, connected to the creation of the axial planar

565 ice veins with which they are associated. They are a variety of flanking structure, 566 discussed below.

567

568 Recumbent isoclinal or near isoclinal folds with similar (Class 2) geometry are often 569 exposed at the termini of valley glaciers and ice caps (Fig. 19b). The planar fabric 
570 element folded in this situation is a composite foliation produced by intense shear

571 near then base of the ice, and these folds can be explained as follows (Hudleston,

572 1976, 1977b). Under steady state flow this planar fabric will tend to become

573 parallel with the particle paths and folds will not form. If flow is non steady over

574 sufficiently long time periods, such as is produced by secular variations in

575 accumulation and ablation of ice along the glacier profile, the stress state and

576 resulting strain rate may change sufficiently such that slight changes in the particle

577 paths result in gentle undulations in foliation over bedrock irregularities becoming

578 kinematically amplified following ice movement down glacier to form recumbent

579 folds, as shown in Fig. 24. This way of producing folds requires no rheological

580 contrast in the ice; the foliation can behave in a completely passive way. In the

581 example shown in Fig. 19b that provided the impetus for the model fold of Fig. 24,

582 the crystallographic fabric is the same in the two fold limbs and the hinge

583 (Hudleston, 1976), consistent with homogenous flow on the scale of the fold. This is

584 an example of non-steady laminar flow. At any instant in time and location near the

585 glacier bed the deformation is very close to simple shearing. If there are small

586 rheological contrasts produced by variations in bubble content, crystallographic

587 fabric or dirt content, these may introduce secondary weak perturbations that result

588 in non-perfect similar geometry, as in Fig. 19b. The total strain associated with

589 these folds is large; the strain and strain rate variation around the folds small, and

590 thus the crystallographic fabric is expected to be independent of position around

591 them (Hudleston, 1976). 
593 In passive folding where the perturbation is non-two dimensional, under large

594 displacements and high strains the folds will tend to become sheath like. In such

595 folds the hinges will rotate towards parallelism with the flow direction. The folds in

596 the white Pleistocene ice at the base of the Barnes Ice cap are likely examples of this.

597 In profile, parallel to the flow, they are most likely as illustrated in Fig. 24, similar to

598 the style of folding seen in the superimposed ice in Fig. 9b. In plan view, they

599 appear as in Fig. 25, an aerial photograph of the ice cap margin. The distinctive band

600 of white ice is repeated by folding, in places up to three or four times. The process

601 by which fold hinges rotate towards the shear direction is illustrated schematically

602 in Fig, 26. In the case of the white ice folds in Fig. 25, the rotation likely has not been

603 great, as the closed outcrops of white ice are drawn out parallel to the ice cap

604 margin. Although no inner closed loops of layering can be discerned within the

605 white loops of Fig. 25, these folds certainly belong to the "cat's eye" category of

606 sheath folds (Alsop et al., 2007) given the geometry of folds exposed elsewhere in

607 marginal ice. This is expected where rheological contrast is small and where the

608 kinematics is on the flattening side of plane strain, as is the case for the ice cap

609 margin in Fig. 25.

610

611 A similar process of fold production to that operating near glacier beds, caused by

612 annual or longer variations in ice flow in valley glaciers and their tributaries,

613 produces folds with initially presumably steep plunges near glacier sides where

614 tributaries join, clearly marked by medial moraines (e.g. Rutter, 1965) and

615 especially pronounced in periodically surging glaciers (Post, 1972; Driscoll, 1980; 
616 Lawson et al., 1994; Lawson, 1996; Hambrey and Lawson, 2000). This phenomenon

617 is responsible for the spectacular folds seen on aerial photographs of many valley

618 glaciers, and folds of this type have are found most dramatically in the piedmont

619 Malaspina glacier (Fig. 19a) (Sharp, 1958). Folds in the Malaspina have been

620 modeled effectively by Ramberg (1964).

621

622 Folding of passive type may also develop deep in ice caps under ice divides, even 623 under steady-state flow. Such flow produces low-amplitude folds over highs and

624 lows in a basal decollement (Whillans and Jezek, 1987) and a "Raymond bump"

625 (Jacobson and Waddington, 2005), an anticline in layering centered at the divide

626 reflecting vertical velocities being lower close to the divide than several ice

627 thicknesses horizontally away from it (Raymond, 1983). The bump, however, does

628 not develop if the flow is Newtonian, as might be the case if deviatoric stresses are

629 sufficiently low (Pettit and Waddington, 2003) and is less pronounced if there is

630 sliding at the base (Pettit et al., 2003). It is enhanced with the development of a

631 vertically oriented $c$-axis fabric (Pettit et al., 2007), and in this case. the anisotropic

632 rheology may cause the bump to develop a central syncline and flanking synclines

633 (Martin et al., 2009). If a bump develops and there is migration of the divide under

634 non-steady flow, a common situation, it can be transformed into a recumbent

635 structure (Jacobson and Waddington, 2005), not unlike that illustrated in Fig. 24.

636 Significant folding in ice deep within ice cores of Antarctica and Greenland has been

637 inferred from borehole observations and from radio echo sounding images (Dahl-

638 Jensen et al., 2013). These folds may originate from the effect described by Jacobson 
639 and Waddington, by anomalies in accumulation rate (Vaughan et al., 1999), or from

640 lateral flow over irregular topography, with enhancement due to the significant

641 difference in viscosity between 'cold' glacial-period ice and 'warm' interglacial ice.

642 Note that there is only a weak folding instability in a layered sequence of varying

643 viscosity due to simple shear alone parallel to the layering, and a strong instability if

644 there is combined compression and shear (Fletcher, 2005). Small-scale folding of

645 kink style is observed in the highly anisotropic ice of the GISP2 ice core in Greenland

646 (Alley et al., 1997b), consistent with Fletcher's theoretical results, although it

647 appears that the longitudinal strain rate in this case may be extensional rather than

648 compressional. Thorsteinsson and Waddington (2002) presented an analysis to

649 indicate that the tendency to produce passive recumbent folding of irregularities in

650 layering under the combined influence of pure shear and simple shear near a divide

651 is enhanced by the development of $c$-axis anisotropy. Recumbent passive folds

652 produced by flow associated with migration of a dome have the potential to be of

653 sheath type.

654

655 Low amplitude flow-parallel folds in stratigraphy noted on satellite images across

656 fast flowing ice streams with high basal flow velocities in Antarctica are similar in

657 some respects to sheath folds, likely being caused by flow over irregularities in the

658 bedrock or anomalies in accumulation rate, often accentuated by constrictional flow

659 (Gudmundsson et al., 1998; Siegert et al., 2004; Campbell et al., 2008). Unlike

660 sheath folds, which rotate to become parallel to the flow direction, these folds

661 initiate in the flow direction, affect much of the ice column and are effectively 
662 transmitted by advection to the surface, where they are called flow stripes

663 (Gudmundsson et al., 1998; Campbell et al., 2008). These large scale stripes are not

664 the same as grain scale features described as stripes by Alley et al. (1997b).

665

666 Another type of passive folding is produced in association with the opening and

667 closing of extensional fractures developed in foliated ice in the marginal zones of

668 valley glaciers. In this case, the perturbation of the stress field around a crack from

669 the time of opening until closure and sealing causes folding of the adjacent foliation

670 (Figs. 27, 28) (Hudleston, 1989). Such folds are called flanking structures in current

671 terminology (Passchier, 2001). A characteristic of the type developed here is that

672 the sense of offset of a marker layer is opposite to the sense of shear in the glacier

673 associated with the glacier flow or by the vergence of the folds (Fig. 28). Closely

674 spaced crevasses may produce folds of more complex geometry. Fig. 23b is an

675 example of this.

676

677 The examples of folds discussed so far do not necessitate any rheological differences

678 between layers; they are all examples of (mostly) passive folding. By contrast, there

679 are examples of folds in glaciers clearly produced by a buckling instability, in which

680 perturbations in the layering become dynamically amplified when subjected to

681 layer-parallel stress (Fletcher, 1974; Smith, 1975, 1977; Johnson and Fletcher,

682 1994). Characteristics of buckling are the development of folds with a characteristic

683 wavelength that depends on the rheological contrast between the buckled layer and

684 its matrix and the tendency of the buckling layer to maintain constant thickness 
685 during folding (e.g. Hudleston and Treagus, 2010). High concentrations of debris or

686 volcanic ash may produce a sufficient rheological contrast to lead to buckling.

687 Excellent small-scale examples have been described by Ximenis et al. (2000) and

688 Fitzsimons (2006), as illustrated in Fig. 29. Buckling may play a role in the folds

689 developed in sediment layers in ice found near the terminuses of many glaciers (e.g.

690 Glasser and Hambrey, 2002). Small-scale folds with buckling characteristics have

691 been produced experimentally in ice in which an initial anisotropy due to grain size

692 and layer-separating thin plastic sheets was employed (Wilson and Russell-Head,

693 1979; Wilson, 1981).

694

695 Increased concentration of debris in medial moraines may produce sufficient

696 rheological contrast to enhance the kinematic amplification of perturbations in the

697 folding of moraines during strong longitudinal shortening. Ramberg (1964)

698 demonstrated experimentally this effect in modeling folding in piedmont glaciers.

699 Any such amplification implies a departure from similar fold geometry; modest

700 evidence of this is seen in the dark bands (medial moraines) in Fig. 19a and in the

701 darker debris rich bans in the hinge of the recumbent fold in Fig. 19b.

702

7035.5 Ductile Shear Zones

704

705 Zones of high shear strain are found along the margins and at the base of all glaciers

706 and ice caps where the velocity gradient is highest. They are also found bounding

707 ice streams in ice sheets - regions of faster flow than in the surrounding ice (e.g. 
708 Marmo and Wilson, 1998). Zones of high finite strain - typically manifest as strong

709 longitudinal foliation - are also associated with medial moraines in valley glaciers

710 downstream of where two tributaries merge. In such cases the finite strain will be

711 large, but the strain rate small once the two marginal zones merge to become more

712 centrally located in the glacier. In the case of the Urumqi Glacier No. 1 in China,

713 Echelmeyer and Wang (1987) documented enhanced deformation within the frozen

714 subglacial drift and discrete shear zones within the frozen drift or at the drift-ice

715 interface. Within basal ice, strain localization may occur at rheological interfaces

716 and strain rate, the nature of recrystallization and crystallographic fabric may all

717 vary from layer to layer (Samyn et al., 2008). Hambrey et al. (1999) described

718 steeply up-glacier dipping shear zones near the terminus of the surging glacier

719 Bakaninbreen in Svalbard. Shear localized in alternating limbs of folds likely

720 enhances folding in sediment interlayered with basal ice, as in the folds described by

721 Glasser and Hambrey (2002).

722

723 Other locally discrete zones of high strain also exist within the body of glaciers.

724 These have been described deep in the Antarctica and Greenland ice caps, and may

725 be characterized by finer grain size and a strong single-maximum vertical $c$-axis

726 fabric (e.g. Gow and Williamson, 1976; Gow and Meese, 2007). The vertical

727 shortening strains developed near the center of an ice cap lead to the basal planes

728 rotating towards being perpendicular to the shortening direction and a vertical $c$ -

729 axis maximum. This effect is better developed in glacial-period ice than in

730 interglacial ice. Glacial-period ice is thus in a more favorable orientation to deform 
731 by horizontal shear, and shear zones and folds may develop under these conditions

732 (Dahl-Jensen et al., 2013).

733

734 Examples of such zones on a small scale are provided in the margin of the Barnes Ice

735 Cap where superimposed ice is overridden during an ice advance (Fig. 9b), Hooke,

736 1973). The shear zones are marked by a sigmoidal pattern of elongate air bubbles

737 and bubbles (Fig. 30) and the development of a strong single-maximum preferred $c$ -

738 axis orientation (Fig. 31).

739

$740 \quad 5.6$ Linear Fabric Elements

741

742 Fold hinges are discrete linear fabric elements in glaciers, and their orientations

743 depend on the position of the folds in the glacier and the strain history of the ice

744 containing the fold. The recumbent folds formed near the base of a glacier or ice

745 cap will generally have hinges that are initially perpendicular to the flow direction.

746 If the topography in the bedrock surface seeding these folds is irregular, the fold

747 hinges will locally be drawn towards parallelism with the flow direction and sheath

748 folds will form, as described above (see Figs. 24-26).

749

750 Folds in foliation formed by variations in horizontal flow velocity in the plane

751 parallel to the ice surface in marginal ice, or as flanking folds associated with

752 fracturing, will initially have vertical hinges. These in general will become

753 reoriented to plunge up-glacier at increasingly lower angles, due to the vertical 
754 gradient in horizontal down glacier velocity. Sheath folds could potentially form

755 here, too, with hinges horizontal and parallel to the flow direction.

756

757 Along the midline of valley glaciers, variations in attitude of primary stratification

758 inherited from the accumulation zone may become passively amplified to form folds

759 down glacier as a result of longitudinal shortening strain. The hinges of these folds

760 will tend to be horizontal or gently plunging and perpendicular to the flow direction

761 if the longitudinal strain rate is compressional, or parallel to the flow direction if

762 there is convergent flow where ice streams merge (Figs. 19c, 22, 23a).

763

764 Locally, bubble elongation forms a penetrative linear fabric in glacial ice, with the

765 direction of maximum elongation of the bubbles indicating a direction of maximum

766 stretch in the enclosing ice (Hudleston, 1977a), modified by effects of surface

767 energy, which tends to return bubbles to a spherical shape. The intensity of this

768 effect depends on temperature and bubble size. The smallest bubbles maintain a

769 spherical shape regardless of strain (Hudleston, 1977a). In coarse-grained

770 temperate ice, bubble elongation may vary from crystal to crystal, either reflecting a

771 difference in strain in adjacent crystals or lattice control of the bubble elongation

772 (Hambrey, 1976b). At best, bubbles can be used as qualitative indications of strain

773 and not as strain markers with shapes reflecting the strain ellipsoid (see Hudleston,

774 1977a).

775

$776 \quad 5.7$ Boudinage 
778 Boudinage has been described in glaciers at different scales and with different

779 characteristics of the ice in which it is developed (Hambrey and Milnes, 1975, 1977;

780 Hambrey and Dowdeswell, 1994). The most distinctive examples are ones in which

781 the boudinaged layer is either of debris-rich ice (or frozen sand layers) embedded in

782 cleaner ice, or of clear ice embedded in debris rich ice (Fig. 32). This contrast in

783 behavior is interesting for two reasons. The first is that, depending on several

784 factors including debris concentration, temperature, and the presence or absence of

785 water at the ice particle interfaces, the debris rich ice can act either as the stiffer

786 layer or as the softer layer, behavior consistent with other observational data and

787 experimental data (see section 2.1; Moore, 2014). The second is because the pinch

788 and swell phenomenon that may precede boudinage is a weak dynamic instability

789 (Smith, 1977) with the dynamic growth rate exceeding the kinematic dampening

790 effect associated with the extension only for strongly non-linear viscosity (Smith,

791 1977; Schmalholz et al., 2008). Rheological data suggest that variations in debris

792 content may lead to differences in viscosity of up to about a factor of around 10 (Fig.

793 3). The pinch and swell instability is very weak with $n \leq 5$ for such a viscosity

794 difference. Strain softening significantly enhances the growth rate of the instability

795 (Neurath and Smith, 1982) and this may well be a factor in the development of

796 boudinage in ice, with the softening in this case being a result of fabric development.

797 A combination of theoretical and numerical modeling considerations led Schmalholz

798 et al. (2008) to suggest that vales of $n \geq 5$ and viscosity ratio of $\geq 20$ are sufficient for

799 the development of pinch and swell without the need for other enhancing 
800 mechanisms such as strain softening. Such values are at the high end of what might

801 be expected for glacial ice containing debris versus debris free ice.

802

803 Some of the structures described by Hambrey and Milnes $(1975,1977)$ as foliation

804 boudinage in strongly foliated ice appear to be the same as flanking folds associated

805 with veins described by Hudleston (1989) (Fig. 27), and likely have the same origin,

806 especially since the sense of offset associated with the vein or shear zone that

807 separates the two parts of the structure is opposite to that suggested by the

808 symmetry of the folds. Such flanking folds are in fact one end member of types of

809 foliation boudinage described by Arslan et al. (2008). In contrast, the symmetric

810 structures also described by Hambrey and Milnes as foliation boudinage (and

811 similar structures described as confluent structures by Taylor, 1963) could not have

812 originated as flanking folds and must represent foliation-parallel extension, with

813 localized necking or fracture to produce the boudinage.

814

815 The most unambiguous examples of boudinage occur in basal ice with layers of

816 strongly contrasting debris content (Fig. 32) (Hambrey and Fitzsimons, 2010, Fig.

817 13B). Less unambiguous examples have been invoked to explain or predict

818 structures in ice in which variation in debris content is not a factor. Cunningham

819 and Waddington (1990) applied the analysis of Smith (1977) and Neurath and

820 Smith (1982) to predict that pinch and swell instability would lead to localized

821 enhancement of variations in the thickness of the Sangamon interglacial ice below

822 the Summit divide of the Greenland ice cap. This is by assuming the interglacial ice 
823 to have an effective viscosity about three times that of the glacial-age ice above and

824 below. Theory indicates the kinematic dampening effect on initial thickness

825 variations is just about balanced by the dynamic growth of these variations due to

826 the pinch and swell instability with this viscosity contrast, leading to potentially

827 significant enhancing of the relative total thickness variations in the interglacial ice,

828 since the overall thinning exceeded 90\%. In another situation, Marmo and Wilson

829 (2000) described segmented veins defined by coarse-grained columnar ice infilling

830 tensile fractures in an outlet glacier of the Framnes Mountains, east Antarctica (Fig.

$83132 \mathrm{~d}$ ). They attributed the segmentation to boudinage of an originally continuous ice

832 vein under the influence of stresses during subsequent ice flow and used a finite

833 difference numerical model to explore the conditions under which this might occur.

834 The initial crystallographic fabric of the ice forming the veins is one of $c$-axes

835 parallel to the vein walls, which put this ice in an orientation unfavorable for basal

836 glide during extension of the vein and thus made the vein ice stiffer than the

837 surrounding ice, which had a more isotropic fabric, by a factor of up to about five.

838 The dynamic growth rate of perturbations in the vein margins is very small under

839 these conditions such that a strong softening mechanism would be needed to

840 produce the observed structures through a pinch and swell instability. An

841 alternative origin for these structures seems possible; they may have originated as

842 en echelon fractures rather than as a single continuous fracture, with the

843 segmentation being primary rather than the result of boudinage.

844

$845 \quad 5.8$ Faults 
847 Many examples of thrusts or shear planes in glaciers have been described in the

848 literature (e.g. Boulton, 1970; Glasser et al., 1998; Hambrey et al., 1999; Herbst and

849 Neubauer, 2000; Herbst et al., 2006), and the general concept and a specific example

850 are shown in Fig. 33. However, the evidence for discrete surfaces across which

851 there is a displacement discontinuity produced by faulting is indirect, except in the

852 case of surging glaciers (Sharp et al., 1988). In some studies, structures with clear

853 sense of offset of markers have been interpreted as crevasse traces reactivated as

854 thrusts (e.g. Goodsell et al., 2005; Appleby et al., 2010).

855

856 There is a serious problem in interpreting the structures described as faults or

857 thrusts as the result of shear fracturing, in that the stresses required to produce

858 shear fractures in ice are much larger than the stresses usually inferred throughout

859 glaciers (Moore et al, 2013). Estimates of shear stresses near the base of glaciers

860 are typically in the order of 50-200 kPa (Cuffey and Paterson, 2010, table 8.3). In

861 compressional tests, shear failure of ice other than by plastic flow is of Mohr-

862 Coulomb type, with failure stress dependent on pressure. In uniaxial compressive

863 tests on polycrystalline fresh water ice of about a millimeter grain size, the

864 transition in failure mode from ductile to brittle occurs at an applied stress of about

$8659 \mathrm{MPa}$ (Schulson, 1999), about an order of magnitude greater than the uniaxial

866 tensile strength of about $1 \mathrm{MPa}$. In compression tests at strain rates of less than

867 about $10^{-3} \mathrm{~s}^{-1}$, ice fails by ductile flow before shear fracture occurs under confining

868 pressures of greater than about 1 MPa (Rist and Murrell, 1994; Schulson, 1999). 
869 The fastest strain rate measured in the Variegated glacier under surge conditions 870 was about $2 \times 10^{-6} \mathrm{~s}^{-1}(0.2$ per day) (Kamb et al., 1985). Thus even in the case of a

871 surging glacier where the highest stress are encountered, conditions generally

872 appear not to favor thrusting (Moore et al., 2010).

873

874 Evidence cited for thrusting and more generally of faulting in glaciers includes the 875 offset of markers across planar structural features (Fig. 34) (Hambrey, 1976;

876 Hambrey et al., 1996; Goodsell et al., 2005). Many of these features likely arise from

877 the same process that leads to the flanking structures described earlier (Figs. 27, 28).

878 That is, the 'fault' originates as a tensile fracture that is later closed to become a vein, 879 and that between its opening and closing there is rotation of the fracture due to the 880 velocity gradient in the embedding ice. The walls of the fracture can sustain no shear 881 stress until the fracture is closed and sealed. The strain in the surrounding ice that 882 must accommodate the rotation in a varying stress field results in relative 883 displacement of markers cut by the fracture and leads to the appearance of faulting, 884 as in Fig. 34. Such structures might still be called faults, but they are of a peculiar 885 kind and are not indicative of shear failure. In regions of heavy crevassing, the 886 process just described can lead to a complicated pattern of veining and folding (Fig. 887 34b) (see also Ragan, 1969, Fig. 7). 888

889 The structures most commonly interpreted as thrusts or shear planes in glaciers are 890 located near the termini where the ice is subjected to longitudinal compression.

891 What is indisputable in such cases is that coarse and fine-grained debris from the 
892 base of ice caps and some valley glaciers finds its way to the surface in ablation

893 zones upstream from the glacier front (Hambrey et al., 1999). There must therefore

894 be some mechanism or mechanisms by which basal sediment becomes entrained in

895 glaciers and then moved upwards, and possibilities for this have been much

896 discussed in the literature. Historically, one of the most popular such processes

897 involves shearing or thrusting originating from the bed (Goldthwait, 1951; Swinzow,

898 1962; Tison et al., 1993; Alley et al., 1997a). Not all structures so described involve

899 discrete planes of movement. The structure envisioned by Tison et al. is not actually

900 a thrust fault, but rather a ductile shear zone containing debris, localized between

901 active glacial ice and "dead" ice near the ice-sheet margin. Thus shear failure is not

902 required in this case. Enhanced deformation in the debris-rich basal ice, as

903 described by Echelmeyer and Wang (1987), would facilitate development of such a

904 shear zone.

905

906 Several mechanisms to account for sediment entrainment that do not involve

907 thrusting, and that may eventually lead to emergence of the sediment at the surface

908 along what appears to be a thrust, have been described. These include regelation

909 associated with flow around obstacles in wet-based glaciers (Weertman, 1964) and

910 other mechanisms associated with freezing of water at the base of wet-based or

911 polar glaciers (e.g. Hooke, 1973, 2005; Hubbard and Sharp, 1989; Shoemaker, 1990;

912 Iverson and Semmons, 1995). In polar glaciers, such mechanisms may be facilitated

913 by the glacier being frozen to a deformable bed of sediment at the ice front, and

914 unfrozen some distance upstream, with the boundary between frozen and unfrozen 
915 shifting with time. The upward vertical component of velocity in the zone of

916 longitudinal compressive strain at the terminuses of glaciers may bring ice

917 containing debris to the surface once entrained. The overriding of clean

918 superimposed ice by debris-bearing ice during an ice advance provides a good

919 explanation for the ice-cored moraines at the margin of the Barnes Ice Cap (Hooke,

$9201973,2005)$ and an alternative to a thrust origin for the material that outcrops at

921 the surface.

922

923 Folding originating at the junction between frozen and unfrozen bed has been

924 suggested as a possible alternative to thrusting as a mechanism for bringing debris

925 to the surface (Clarke and Blake, 1991; Moore et al., 2013). In general the complex

926 interplay of glacier sliding with melting and regelation over an irregular topography

927 produces highly variable stresses and complex structural features including folds,

928 boudinage and localized zones of shear, in particular in cold-based glaciers (e.g.

929 Hubbard and Sharp, 1989; Sharp et al., 1994; Fitzsimons et al., 1999; Hambrey and

930 Fitzsimons, 2010.) Elevated pore pressure is likely to be important in these

931 processes and may be sufficient to induce extensional fracturing.

932

933 For a specific example of evaluating the hypothesis of thrusting, consider the case of

934 Storglaciären, where the sediment in an up-glacier dipping debris band near the ice

935 front of has a basal source (Jansson et al., 2000). Thrusting and folding are two

936 possible explanations for this feature (Glasser et al., 2003). By use of numerical

937 modeling and application of fracture mechanics, informed by empirical data on the 
938 rheology and fracture of ice, Moore et al. (2010) showed that the strain rates are six

939 orders of magnitude too small to induce shear fracturing and thus to produce a

940 thrust that could bring debris to the surface along a thrust plane. They did,

941 however, show that frictional slip on a preexisting fracture is possible, if the fracture

942 is large enough, properly oriented, and there is high fluid pressure along the fault

943 surface. They further considered these conditions most likely to be met on surfaces

944 containing sediment. That is, if a sediment-bearing thrust already exists, movement

945 on it by frictional slip is possible under the right conditions. Emplacement of the

946 debris into the ice and elevation above the base, however, must be by some other

947 mechanism. Moore et al. (2013) suggest folding as the most likely process for this. If

948 fractures are involved, they are most likely to have originated as tensile cracks and

949 not by shear. In the case of Variegated glacier, the observed thrusts during the

$950 \quad 1982-1983$ surge were likely to have been the result of folding and tensile fracturing

951 as the surge passed (Raymond et al., 1987; Sharp et al., 1988; Moore et al., 2010).

952

\section{6. Surging Glaciers}

954

955 Surging glaciers are ones that periodically go into a phase of movement in which

956 velocities increase by up to two orders of magnitude over their non-surging state,

957 triggered by a build up of water pressure at the base of the ice (Kamb et al., 1985;

958 Raymond et al., 1987; Eisen et al., 2005). They result in a net transfer of a large

959 volume of ice from the accumulation zone to the ablation zone over a period of a

960 year or two. They may be preceded by mini surges last a day or two (Kamb and 
961 Engelhardt, 1987). The fluctuations in flow from different tributary ice streams

962 associated with surges typically leads to folding of the medial moraines, with the

963 folds becoming tight to isoclinal downstream along the valley sides and in the region

964 of high longitudinal compressive strains near the glacier front (Post, 1969, 1972;

965 Clarke, 1987). The geometry of the folds suggests this folding is largely passive. 966

967 The surge of the Variegated glacier in Alaska was closely monitored from start to 968 finish in 1982-83 (Kamb et al., 1985). The surge started in the upper reaches of the 969 glacier and moved downstream in a kinematic wave. Ice thickened following the 970 passage of the surge front, with extremely high compressional strain rates as the 971 front passed, as large as 0.2 per day $\left(2 \times 10^{-6} \mathrm{~s}^{-1}\right)$. The velocity gradient was small 972 after passage of the front and longitudinal stresses locally changed from 973 compressional to extensional as the wave passed. This behavior led to a distinctive 974 suite of structures (Fig. 35) (Lawson et al, 1994; Lawson, 1997; Sharp et al., 1988;

975 Lawson et al., 2000), including both lateral and frontal faults. During the surge, the 976 surface velocity profile changed from the classical parabolic shape to almost plug 977 flow, with two strike-slip fault zones containing brecciated ice on either side (Kamb 978 et al., 1985). Folding and thrusting developed at the front of the glacier as the surge 979 encountered stagnant ice. Folding of the ice in the case of the Variegated glacier 980 was observed at the surface, involving both ductile and brittle behavior, the latter 981 producing what Sharp et al. (1988) called exfoliation buckle folds. Sharp et al. 982 (1988) traced some thrust faults to roots at the glacier bed - which therefore acted 983 as a decollement - and to lateral terminations in bulge folds, suggesting a ductile 
984 precursor to the passage of the shear fracture and development of the structures in

985 the style of fault-propagation folding (Suppe, 1985). Although clearly active as

986 thrust faults, Lawson et al. (1994) suggested that because of the considerable

987 variation in dip, they may have originated as transverse tensile fractures and later

988 become activated as thrusts. Such an origin would be consistent with the

989 calculations of Moore et al. (2013) who found the compressional stresses too small

990 to initiate shear fractures during the surge. In their propagation as thrusts, the

991 Variegated structures developed in classic piggyback style and slickensides

992 developed on the fault surfaces.

993

994 Thrusting has been inferred to occur at the fronts of other surging glaciers (e.g.

995 Hambrey et al., 1996; Hambrey and Dowdeswell, 1997; Porter et al., 1997; Hambrey

996 et al., 1999), although the only case in which thrusting appears to have been directly

997 observed is that of the Variegated. Hambrey and Dowdeswell (1997) found foliation

998 in the surging Hessbreen glacier in Svalbard to be overall less intense than that in

999 non-surging glaciers, indicating lower strain over most of the ice and slip or

1000 concentration of strain in narrow zones at the glacier sides and base. The

1001 identification of debris-filled planar structures as thrusts by previous workers in

1002 surging glaciers in Svalbard has been questioned by Woodward et al. (2002), who

1003 considered most of these features to have originated as sediment-filled crevasses

1004 that become later deformed and reoriented into attitudes suggesting thrusting. 1005 
1006 Crevassing was intense during the surge of the Variegated glacier and followed an 1007 interesting pattern (Fig. 35). At the surge front, longitudinal compression and

1008 divergent flow produced longitudinal crevasses, and subsequent longitudinal 1009 extension produced transverse crevasses, leading to a blocky crevassed surface 1010 (Lawson et al., 1994). In general, fracturing was much more extensive in the surge 1011 phase than in the quiescent phase. At the end of the surge, a threefold pattern of 1012 crevassed regions was noted; an upper region with transverse crevasses, a long mid 1013 region with superimposed longitudinal and transvers crevasses, and a lower region 1014 with longitudinal crevasses (Fig. 35, Lawson, 1996). This pattern also apparently 1015 followed earlier surges also (Lawson, 1996).

1016

\section{7. Progressive deformation}

1018

1019 A particle of glacial ice may experience a complex history of stresses during its 1020 passage from formation in the accumulation zone - or accretion at the base, front or 1021 elsewhere on a glacier - to its eventual removal by ablation in the frontal zone or 1022 melting elsewhere, and a glacier as a whole might be considered its own tectonic 1023 entity. As such, glaciers provide possible analogs for some tectonic settings in rocks.

1024 For instance, Coward (1982) interpreted parts of the Moine thrust zone as 1025 representing local surges, analogous to glacial surges, and Herbst and Neubauer 1026 (2000) compared structural development in the Pasterze glacier in Austria with 1027 structural development in an extensional allochthon. 
1029 Two different modes of ice 'tectonism' might be distinguished, one in which the 1030 glacier is more or less in steady state, and the other in which there is great variation 1031 with time, as in surging glaciers. In the first, ice particles follow their given paths 1032 through the glacier and experience their particular stress histories depending on the 1033 initial starting point of each particle. Measurements of ice velocity and structures 1034 and fabrics at any fixed geographic point on the glacier would be similar from year

1035 to year. Schematic examples of this are shown in Figs. 5 and 6. In the second mode, 1036 as in surging glaciers, the deformational history experienced by the ice varies

1037 greatly both in space and time. In this case measurements taken at a fixed 1038 geographic point will show great variation depending on when they are taken and 1039 overall structural development will change with time (Fig. 35, Lawson, 1997).

1040 There are similarities in the structure developed near the fronts of surging glaciers

1041 with structures in fold-and-thrust belts, as noted by Kamb et al. (1959) and Sharp et 1042 al. (1988). The role of fluids is critical in both cases, and the sequential development 1043 of linked folds and thrusts is also similar in the toe regions of strong compressional 1044 strain.

1046 In both steady and non steady state glaciers, structures and fabrics can be mapped 1047 following the classical techniques of structural geology, identifying bedding $\left(\mathrm{S}_{0}\right)$ and 1048 then sequentially developed planar fabrics, designated, $S_{1}, S_{2}$, etc. and generations of 1049 folds, $F_{1}, F_{2}$ etc. (Hambrey and Milnes, 1977; Lawson et al., 1994; Hambrey and 1050 Dowdeswell, 1997; Roberson, 2008; Jennings et al., 2014). The sequence generally 1051 follows the progression of ice down glacier or down flow lines, where particles of ice 
1052 will be subjected to different stress states and structural regimes. As in rocks, as

1053 nicely demonstrated for example in the Pennsylvanian Appalachian Valley and

1054 Ridge province by Gray and Mitra (1993), the designation $D_{1}$ and $D_{2}$ (or $S_{1}$ and $S_{2}$ )

1055 does not mean that $D_{1}$ is everywhere earlier than $D_{2}$, only that in one location this is

1056 the case. $D_{2}$ structures may develop at one location a glacier at the same time as $D_{1}$

1057 structures are forming upstream.

1058

1059 In all glaciers and ice caps, moving from source to terminus involves moving from

1060 an accumulation zone of generally longitudinal tensile stresses to an ablation zone

1061 of generally longitudinal compressive stresses, with local fluctuations depending on

1062 valley geometry. The structures that develop reflect this overall change in

1063 longitudinal stress regime, as well as the shear stresses developed along the base

1064 and sides. As climate changes and many glaciers recede, the dynamics of ice flow

1065 may change and with it the nature of structural development (Hambrey et al., 2005).

1066

1067 In valley glaciers, extension in the accumulation zone leads to extensive transverse

1068 crevassing, providing the likely principal source for transverse foliation

1069 downstream following closure of the crevasses. Shear along the sides of valley

1070 glaciers gives rise to en echelon crevasses and subsequent strong near vertical

1071 longitudinal foliation as the crevasse rotate and become veins. Depending on where

1072 in the glacier the foliation develops, transverse foliation may crosscut longitudinal

1073 foliation or vice versa. Hambrey and Milnes (1977) mapped an early longitudinal $S_{1}$, 
1074 cut by a transverse $S_{2}$, with a later longitudinal $S_{3}$ developed near the glacier

1075 terminus. Folds developed with axial surfaces parallel to both $S_{1}$ and $S_{2}$.

1076

1077 Folds develop in bedding and in foliation and frequently are associated with an axial

1078 planar foliation (Figs. 19c, 21, 22 and 23b) (e.g. Hambrey et al., 1996; Hambrey et al.,

1079 1999; Goodsell et al., 2005). The orientation of folds within even a simple glacier

1080 can be highly variable. This is illustrated with folds in either bedding or foliation in

1081 Storglaciären (Fig. 36). Depending on location, fold hinges can be considered to have

1082 three 'end member' orientations: sub horizontal perpendicular to the flow direction

1083 (with vertical axial surface); sub vertical (with axial surface parallel to the flow

1084 direction); sub horizontal parallel to flow (with variable axial surface dips). Two

1085 end members are shown in Fig. 23. Intermediate orientations are also found. This

1086 is all in a small region of overall tectonic simplicity with a single eastward flow

1087 direction.

1088

1089 8. Conclusions

1090 Deformation in glaciers and ice caps often leads to a complex suite of structures, 1091 even when the flow field is apparently simple. This is due to the combination of 1092 brittle fracture and plastic flow affecting ice with inherited and induced 1093 heterogeneities, largely visible through variations in bubble content. Primary 1094 stratification, $\mathrm{S}_{0}$, is preserved to large strains and becomes folded, largely passively, 1095 for various reasons, including irregularities in the accumulation zone, changes in 1096 flow responding to climate, localized shear, and deformation accommodating the 
1097 opening and closing of tensile fractures, often involving fracture rotation. In the

1098 most strongly deformed ice along the margins of valley glaciers and near the base of

1099 all glaciers and ice caps $\mathrm{S}_{0}$ contributes to a composite foliation in which other fabric

1100 elements, in particular fracture fillings, play an essential role. This foliation can itself

1101 become folded. Dynamic recrystallization on the grain scale also contributes to

1102 foliation, leading to a reorganization of bubbles and grain boundaries. The different

1103 fabric elements contributing to foliation commonly result in crosscutting

1104 relationships, with a younger foliation $\left(S_{2}\right)$ cross-cutting an older one $\left(S_{1}\right)$, with a

1105 possibility of several generations progressing down glacier. Rheological contrasts,

1106 with viscosity variations of up to about an order of magnitude, due to grain size and

1107 bubble content, crystallographic-fabric induced anisotropy or debris content, may

1108 give rise to dynamic instabilities of buckle folding and boudinage, usually on a small

1109 scale. Faulting by shear failure in ice is theoretically unlikely and has been directly

1110 observed only in surging glaciers. The commonly observed fault-like discontinuities

1111 in glaciers are mostly the result of displacement occurring between the opening and

1112 closure of extensional fractures. Structures and fabrics at any location in a glacier or

1113 ice cap must be interpreted in terms of the flow history the ice has experienced.

1114

\section{Acknowledgments}

1116 Field work in the 1970s an 1980s was supported by grants from the National

1117 Science Foundation, and this is gratefully acknowledged, as is support in various

1118 ways from the University of Minnesota. My interest in structures in ice was sparked

1119 by Roger Hooke, who has provided much advice, support and companionship in the 
1120 field over the years. I thank Holger Stunitz for helpful comments and suggestions on

1121 the manuscript and Chris Wilson and Carl Stevenson for their thorough and

1122 thoughtful reviews.

1123

1124

1125

1126

1127

1128

1129

1130

1131

1132

1133

1134

1135

1136

1137

1138

1139

1140

1141

1142

1143

1144

1145

1146

1147

1148

1149

1150

1151

\section{References}

Allen, C.R., Kamb, W.B., Meier, M.F., Sharp, R.P., 1960. Structure of the lower Blue Glacier, Washington. Journal of Geology 68, 601-625.

Alley, R.B., 1988. Fabrics in polar ice sheets; development and prediction. Science 240, 493-495.

Alley, R.B., 1992. Flow-law hypotheses for ice-sheet modeling. Journal of Glaciology $38,245-256$.

Alley, R.B., Bolzan, J.F., Whillans, I.M. 1982. Polar firn densification and grain growth. Annals of Glaciology 3, 7-11.

Alley, R.B., Cuffey, K.M., Evenson, E.B., Strasser, J.C., Lawson, D.E., Larson, G.J., 1997a. How glaciers entrain and transport basal sediment; physical constraints. Quaternary Science Reviews 16, 1017-1038.

Alley R.B., Gow A.J., Meese D.A., Fitzpatrick J.J., Waddington E.D., Bolzan J.F., 1997b. Grain-scale processes, folding, and stratigraphic disturbance in the GISP2 ice core. Journal of Geophysical Research 102, 26,819-26,830.

Alsop, G.I., Holdsworth, R.E., McCaffrey, K.J.W., 2007. Scale invariant sheath folds in salt, sediments and shear zones. Journal of Structural Geology 29, 1585-1604.

Appleby, J.R., Brook, M.S., Vale S.S., Macdonald-Creevey, A.M., 2010. Structural glaciology of a temperate maritime glacier; Lower Fox Glacier, New Zealand. Geografiska Annaler.Series A: Physical Geography 92A, 451-467.

Arslan, A., Passchier, C.W., Koehn, D., 2008. Foliation boudinage. Journal of Structural Geology 30, 291-301.

Azuma, N., 1994. A flow law for anisotropic ice and its application to ice sheets. Earth and Planetary Science Letters 128, 601-614.

Azuma, N., Miyakoshi, T., Yokoyama, S., Takata, M., 2012. Impeding effect of air bubbles on normal grain growth of ice. Journal of Structural Geology 42, 184193.

1152 Bouchez, J.L., Duval, P., 1982. The fabric of polycrystalline ice deformed in simple 
1153

1154

1155

1156

1157

1158

1159

1160

1161

1162

1163

1164

1165

1166

1167

1168

1169

1170

1171

1172

1173

1174

1175

1176

1177

1178

1179

1180

1181

1182

1183

1184

1185

1186

shear; experiments in torsion, natural deformation and geometrical interpretation. Textures and Microstructures 5, 171-190.

Boulton, G.S., 1970. On the deposition of subglacial and melt-out tills at the margins of certain Svalbard glaciers. Journal of Glaciology 9, 231-245.

Bray, M.T., 2013. Secondary creep approximations of ice-rich soils and ice using transient relaxation tests. Cold Regions Science and Technology 88, 17-36.

Budd, W.F., 1972. The development of crystal orientation fabrics in moving ice: Zeitschrift fuer Gletscherkunde und Glazialgeologie, v. 8, p. 65-105.

Budd, W.F., Jacka, T.H., 1989. A review of ice rheology for ice-sheet modeling. Cold Regions Science and Technology 16, 107-144.

Budd, W.F., Warner, R.C., Jacka, T.H., Li J., Treverrow, A., 2013. Ice flow relations for stress and strain-rate components from combined shear and compression laboratory experiments. Journal of Glaciology 59, 374-392.

Calvet J., Santanach P., 1992. Grietas y pliegues en el glaciar de la ensenada Johnsons, borde del casquete glaciar de la Isla Livingston, islas Shetland del Sur. Actas del Congreso Latinoamericano de Geologia 8, 153-161.

Campbell, I., Jacobel, R., Welch, B., Pettersson, R., 2008. The evolution of surface flow stripes and stratigraphic folds within Kamb Ice Stream: why don't they match? Journal of Glaciology 54, 421-427.

Castelnau, O., Duval, P., Lebensohn, R.A., Canova, G.R., 1996. Viscoplastic modeling of texture development in polycrystalline ice with a self-consistent approach; comparison with bound estimates. Journal of Geophysical Research 101, 1313,868 .

Clarke, G.K.C., 1987, Fast glacier flow: Ice streams, surging, and tidewater glaciers. Journal of Geophysical Research 92, B9, 8835-8841.

Clarke, G.K.C., Blake, E.W., 1991. Geometric and thermal evolution of a surge-type glacier in its quiescent state - Trapridge Glacier, Yukon-Territory, Canada, 1969-89. Journal of Glaciology 37, 158-169.

Cohen D., Hooke R.L., Iverson N.R., Kohler J., 2000. Sliding of ice past an obstacle at Engabreen, Norway. Journal of Glaciology 46, 599-610.

Coward, M.P., 1982. Surge zones in the Moine thrust zone of NW Scotland. Journal of Structural Geology 4, 247-256.

Cuffey, K.M., Paterson, W.S.B., 2010. The Physics of Glaciers. Elsevier, Amsterdam, Amsterdam, Netherlands (NLD). 
1187

1188

1189

1190

1191

1192

1193

1194

1195

1196

1197

1198

1199

1200

1201

1202

1203

1204

1205

1206

1207

1208

1209

1210

1211

1212

1213

1214

1215

1216

1217

1218

1219

1220

1221

1222

1223

1224

1225
Cunningham, J., Waddington, E.D., 1990. Boudinage; a source of stratigraphic disturbance in glacial ice in central Greenland. Journal of Glaciology 36, 269272.

Dahl-Jensen, D., Albert, M.R., Aldahan, A., Azuma, N., Balslev-Clausen, D., Baumgartner, M., Berggren, A., Bigler, M., Binder, T., Blunier, T., Bourgeois, J.C., Brook, E.J., Buchardt, S.L., Buizert, C., Capron, E., Chappellaz, J., Chung, J., Clausen, H.B., Cvijanovic, I., Davies, S.M., Ditlevsen, P., Eicher, O., Fischer, H., Fisher, D., Fleet, L.G., Gfeller, G., Gkinis, V., Gogineni, S., Goto-Azuma, K., Grinsted, A., Gudlaugsdottir, H., Guillevic, M., Hansen, S.B., Hansson, M., Hirabayashi, M., Hong, S., Hur, S.D., Huybrechts, P., Hvidberg, C.S., Iizuka, Y., Jenk, T., Johnsen, S.J., Jones, T.R., Jouzel, J., Karlsson, N.B., Kawamura, K., Keegan, K., Kettner, E., Kipfstuhl, S., Kjaer, H., et. al., 2013. Eemian interglacial reconstructed from a Greenland folded ice core. Nature 493, 489-494.

Dahl-Jensen, D., Thorsteinsson, T., Alley, R., Shoji, H., 1997. Flow properties of the ice from the Greenland Ice Core Project ice core: The reason for folds? Journal of Geophysical Research.C.Oceans 102, 26-26,840.

Diez, A., Eisen, O., Weikusat, I., Eichler, J., Hofstede, C., Bohleber, P., Bohlen, T., Polom, U., 2014. Influence of ice crystal anisotropy on seismic velocity analysis. Annals of Glaciology 55, 97-106.

Drews, R., Eisen, O., Weikusat, I., Kipfstuhl, S., Lambrecht, A., Steinhage, D., Wilhelms, F., Miller, H., 2009. Layer disturbances and the radio-echo free zone in ice sheets. The Cryosphere 3, 195-203.

Driscoll, F.G.Jr., 1980. Formation of the Neoglacial surge moraines of the Klutlan Glacier, Yukon Territory, Canada. Quaternary Research 14, 19-30.

Durand, G., Weiss, J., Lipenkov, V., Barnola, J.M., Krinner, G., Parrenin, F., Delmonte, B., Ritz, C., Duval, P., Roethlisberger, R., Bigler, M., 2006. Effect of impurities on grain growth in cold ice sheets. Journal of Geophysical Research 111., F01015, doi:10.1029/2005JF000320.

Durney, D.W., Ramsay, J.G., 1973. Incremental Strains Measured by Syntectonic Crystal Growths. In: In: De Jong, K. A., Scholten, R. (eds.), Gravity and Tectonics. John Wiley \& Sons, New York, United States (USA).

Duval, P., 1981. Creep and fabrics of polycrystalline ice under shear and compression. Journal of Glaciology 27, 129-140.

Duval, P., Montagnat, M., Grennerat, F., Weiss, J., Meyssonnier, J., Philip, A., 2010. Creep and plasticity of glacier ice: a material science perspective. Journal of Glaciology 56, 1059-1068.

Echelmeyer, K., Wang, Z., 1987. Direct observation of basal sliding and deformation 
of basal drift at subfreezing temperatures: Journal of Glaciology 33, 81-98.

1227

1228

1229

1230

1231

1232

1233

1234

1235

1236

1237

1238

1239

1240

1241

1242

1243

1244

1245

1246

1247

1248

1249

1250

1251

1252

1253

1254

1255

1256

1257

1258

1259

1260

1261
Eisen, O., Harrison, W.D., Raymond, C.F., Echelmeyer, K.A., Bender, G.A., Gorda, J.L.D., 2005. Variegated Glacier, Alaska, USA: a century of surges. Journal of Glaciology 51, 399-406.

Eisen, O., Hamann, I., Kipfstuhl, S., Steinhage, D., Wilhelms, F., 2007. Direct evidence for continuous radar reflector originating from changes in crystal-orientation fabric. Cryosphere 1,1-10.

Faria, S.H., Weikusat, I., Azuma, N., 2014a. The microstructure of polar ice. Part I: Highlights from ice core research. Journal of Structural Geology 61, 2-20.

Faria, S.H., Weikusat, I., Azuma, N., 2014b. The microstructure of polar ice. Part II: State of the art. Journal of Structural Geology 61, 21-49.

Fitzsimons, S., 2006. Mechanical behaviour and structure of the debris-rich basal ice layer. In: Knight, P.G. (Ed.), Glacier Science and Environmental Change. Blackwell Publishing, Oxford, Oxford, United Kingdom (GBR), 329-335.

Fitzsimons, S.J., McManus, K.J., Lorrain, R.D., 1999. Structure and strength of basal ice and substrate of a dry-based glacier: evidence for substrate deformation at sub-freezing temperatures. Annals of Glaciology 28, 236-240.

Fletcher, R.C., 1974. Wavelength selection in the folding of a single layer with powerlaw rheology. American Journal of Science 274, 1029-1043.

Fletcher, R.C., 2005. Instability of an anisotropic power-law fluid in a basic state of plane flow. Journal of Structural Geology, 27, 1155-1167.

Gao, X.Q., Jacka, T.H, 1987. The approach to similar tertiary creep rates for Antarctic core ice and laboratory prepared ice. Journal de Physique Colloques 48(3), C1, 289-295 (Supplément au 3).

Glasser, N.F., Hambrey, M.J., 2002. Sedimentary facies and landform genesis at a temperate outlet glacier: Soler Glacier, North Patagonian Icefield. Sedimentology 49, 43-64.

Glasser, N.F., Hambrey, M., Crawford, K.R., Bennett, M.R., Huddart, D., 1998. The structural glaciology of Kongsvegen, Svalbard, and its role in landform genesis. Journal of Glaciology 44, 136-148.

Glasser, N.F., Hambrey, M.J., Etienne, J.L., Jansson, P., Pettersson, R., 2003. The origin and significance of debris-charged ridges at the surface of Storglaciären, northern Sweden. Geografiska Annaler.Series A: Physical Geography 85, 127147. 
1262 Glen, J. W., 1955. The creep of polycrystalline ice. Proceedings of the Royal Society 1263 London, A, 228, 519-538.

1264 Glen, J.W., 1956. Measurement of the deformation of ice in a tunnel at the foot of an 1265 1266 ice fall; Cambridge University Austerdalsbre Expedition 1955, paper no. 1. Journal of Glaciology 2, 735-745.

1267 Goldsby, D.L., Kohlstedt, D.L., 1997. Grain boundary sliding in fine-grained Ice I. $1268 \quad$ Scripta Materialia 37, 1399-1406.

1269 Goldthwait, R.P., 1951. Development of end moraines in east-central Baffin Island. 1270 Journal of Geology 59, 567-577.

1271 Goodsell, B., Hambrey, M.J., Glasser, N.F., Nienow, P., Mair, D., 2005. The structural

1272

1273

1274

1275

1276

1277

1278

1279

1280

1281

1282

1283

1284

1285

1286

1287

1288

1289

1290

1291

1292

1293

1294

1295

1296

1297

1298 glaciology of a temperate valley glacier: Haut Glacier d-'Arolla, Valais, Switzerland. Arctic Antarctic and Alpine Research 37, 218-232.

Gow, A.J., 1968. Bubbles and bubble pressures in Antarctic glacier ice. Journal of Glaciology, 7, 167-182.

Gow, A.J., Meese, D.A., 2007. Physical properties, crystalline textures and $c$-axis fabrics of the Siple Dome (Antarctica) ice core. Journal of Glaciology 53, 573584.

Gow, A.J., Williamson, T., 1976. Rheological implications of the internal structure and crystal fabrics of the West Antarctic ice sheet as revealed by deep core drilling at Byrd Station. Geological Society of America Bulletin 87, 1665-1677.

Gray, M.B., Mitra, G., 1993. Migration of deformation fronts during progressive deformation; evidence from detailed structural studies in the Pennsylvania Anthracite region, U.S.A; The geometry of naturally deformed rocks. Journal of Structural Geology 15, 435-449.

Gudmundsson, G.H., Raymond, C.F., Bindschadler, R., 1998. The origin and longevity of flow stripes on Antarctic ice streams. Annals of Glaciology, Vol 27, 1998 27, 145-152.

Hambrey, M.J., 1975. The origin of foliation in glaciers; evidence from some Norwegian examples. Journal of Glaciology 14, 181-185.

Hambrey, M., 1976a. Structure of the Glacier Charles Rabots Bre, Norway. Geological Society of America Bulletin 87, 1629-1637.

Hambrey, M.J.., 1976b. Debris, bubble, and crystal fabric characteristics of foliated glacier ice, Charles Rabots Bre, Okstindan, Norway. Arctic and Alpine Research 8, 49-60. 
1299

Hambrey, M.J., 1977a. Foliation, minor folds and strain in glacier ice. Tectonophysics 39, 397-416.

Hambrey, M.J., 1977b. Structures in ice cliffs at the snouts of three Swiss glaciers. Journal of Glaciology 18, 407-414.

Hambrey, M., Bennett, M.R., Dowdeswell, J., Glasser, N.F., Huddart, D., 1999. Debris entrainment and transfer in polythermal valley glaciers. Journal of Glaciology $45,69-86$.

Hambrey, M.J., Dowdeswell, J.A., 1994. Flow regime of the Lambert Glacier-Amery Ice Shelf system, Antarctica - structural evidence from Landsat imagery. Annals of Glaciology 20, 401-406.

Hambrey, M.J., Dowdeswell, J.A., 1997. Structural evolution of a surge-type polythermal glacier; Hessbreen, Svalbard. Annals of Glaciology 24, 375-381.

Hambrey, M.J., Fitzsimons, S.J., 2010. Development of sediment-landform associations at cold glacier margins, Dry Valleys, Antarctica. Sedimentology $57,857-882$.

Hambrey, M.J., Glasser, N.F., 2003. The role of folding and foliation development in the genesis of medial moraines: Examples from Svalbard glaciers. Journal of Geology 111, 471-485.

Hambrey, M.J., Lawson, W.J., 2000. Structural styles and deformation fields in glaciers; a review. In: Maltman, A.J., Hubbard, B., Hambrey, M.J. (Eds.), Deformation of Glacial Materials. Geological Society Special Publications 176, 59-83.

Hambrey, M.J., Milnes, A.G., 1975. Boudinage in glacier ice; some examples. Journal of Glaciology 14, 383-393.

Hambrey, M.J., Milnes, A.G., 1977. Structural geology of an Alpine glacier (Griesgletscher, Valais, Switzerland). Eclogae Geologicae Helvetiae 70, 667684.

Hambrey, M.J., Milnes,A.G., Siegenthaler, H., 1980. Dynamics and structure of Griesgletscher, Switzerland. Journal of Glaciology 25, 215-228.

Hambrey, M.J., Müeller, F., 1978. Structures and ice deformation in the White Glacier, Axel Heiberg Island, Northwest Territories, Canada. Journal of Glaciology 20, 41-66.

Hambrey, M.J., Murray, T., Glasser, N.F., Hubbard, A., Hubbard, B., Stuart G., Hansen, S., Kohler, J., 2005. Structure and changing dynamics of a polythermal valley glacier on a centennial timescale; Midre Lovenbreen, Svalbard. Journal of 
Geophysical Research 110, F01006, doi:10.1029/2004JF000128.

1336

1337

1338

1339

1340

1341

1342

1343

1344

1345

1346

1347

1348

1349

1350

1351

1352

1353

1354

1355

1356

1357

1358

1359

1360

1361

1362

1363

1364

1365

1366

1367

1368
Harper, J.T., Humphrey, N.F., Pfeffer, W.T., Huzurbazar, S.V., Bahr, D.B., Welch, B.C., 2001. Spatial variability in the flow of a valley glacier; deformation of a large array of boreholes. Journal of Geophysical Research 106, 8547-8562.

Herbst, P., Neubauer, F., 2000. The Pasterze Glacier, Austria; an analogue of an extensional allochthon. In: Maltman, A.J., Hubbard, B., Hambrey, M.J. (Eds.), Deformation of Glacial Materials. Geological Society Special Publications 176, 159-168.

Herbst, P., Neubauer, F., Schoepfer, M.P.J., 2006. The development of brittle structures in an Alpine valley glacier; Pasterzenkees, Austria, 1887-1997. Journal of Glaciology 52, 128-136.

Herzfeld, U.C., Clarke G.K.C., Mayer H., Greve R., 2004. Derivation of deformation characteristics in fast-moving glaciers. Computers \& Geosciences 30, 291302.

Holschuh, N., Christianson, K., Anandakrishnan, S., 2014. Power loss in dipping internal reflectors, imaged using ice-penetrating radar. Annals of Glaciology $55,49-56$.

Hooke, R.L., 1973. Structure and flow in the margin of the Barnes Ice Cap, Baffin Island, N.W.T., Canada. Journal of Glaciology 12, 423-438.

Hooke, R.L., 2005. Principles of Glacier Mechanics. $2^{\text {nd }}$ Edition, Cambridge University Press, Cambridge, United Kingdom.

Hooke, R.L., Calla, P., Holmlund, P., Nilsson, M., Stroeven, A., 1989. A 3 year record of seasonal variations in surface velocity, Storglaciären, Sweden. Journal of Glaciology 35, 235-247.

Hooke, R.L., Dahlin, B.B., Kauper, M.T., 1972. Creep of ice containing dispersed fine sand. Journal of Glaciology 11, 327-336.

Hooke, R.L., Hudleston P.J., 1978. Origin of foliation in glaciers. Journal of Glaciology 20, 285-299.

Hubbard, A., Hubbard, B., 2000. The potential contribution of high-resolution glacier flow modelling to structural glaciology. In: Maltman, A.J., Hubbard, B., Hambrey, M.J. (Eds.), Deformation of Glacial Materials. Geological Society Special Publications 176, 135-146.

Hubbard, B., Sharp, M., 1989. Basal ice formation and deformation: a review. Progress in Physical Geography 13, 529-558. 
1369

1370

1371

1372

1373

1374

1375

1376

1377

1378

1379

1380

1381

1382

1383

1384

1385

1386

1387

1388

1389

1390

1391

1392

1393

1394

1395

1396

1397

1398

1399

1400

1401

1402

1403

1404

1405

1406

1407

1408
Hudleston, P.J., 1976. Recumbent folding in the base of the Barnes Ice Cap, Baffin Island, Northwest Territories, Canada. Geological Society of America Bulletin 87, 1684-1692.

Hudleston, P.J., 1977a. Progressive deformation and development of fabric across zones of shear in glacial ice. In: S. Saxena and S. Bhattacharji (eds.). Energetics of Geological Processes, Springer, Verlag, New York, 121-150.

Hudleston, P.J., 1977b. Similar folds, recumbent folds, and gravity tectonics in ice and rocks. Journal of Geology 85, 113-122.

Hudleston, P.J., 1980. The progressive development of inhomogeneous shear and crystallographic fabric in glacial ice. Journal of Structural Geology 2, 189-196

Hudleston, P.J., 1986. Extracting information from folds in rocks. Journal of Geological Education 34, 237-245.

Hudleston, P.J., 1989. The association of folds and veins in shear zones. Journal of Structural Geology 11, 949-957.

Hudleston, P.J., 1992. A comparison between glacial movement and thrust sheet or nappe emplacement and associated structures. In: Mitra, S., Fisher, G.W., Phillips, O.M., Stanley, S.M., Strobel, D.F. (Eds.), Structural Geology of Fold and Thrust Belts. Johns Hopkins Univ. Press, Baltimore, MD, United States (USA).

Hudleston, P.J., Hooke, R.L., 1980. Cumulative deformation in the Barnes ice cap and implications for the development of foliation; Analytical studies in structural geology. Tectonophysics 66, 127-146.

Hudleston, P.J., Treagus, S.H., 2010. Information from folds: A review. Journal of Structural Geology 32, 2042-2071.

Hutter, K., Olunloyo, V., 1980. On the distribution of stress and velocity in an ice strip, which is partly sliding over and partly adhering to its bed, by using a newtonian viscous approximation. Proceedings of the Royal Society of London Series A-Mathematical Physical and Engineering Sciences 373, 385403.

Iverson, N.R., Hooyer, T.S., Fischer, U.H., Cohen, D., Moore, P.L., Jackson, M., Lappegard, G., Kohler, J., 2007. Soft-bed experiments beneath Engabreen, Norway: regelation infiltration, basal slip and bed deformation. Journal of Glaciology 53, 323-340.

Iverson, N.R., Semmens, D.J., 1995. Intrusion of ice into porous-media by regelation a mechanism of sediment entrainment by glaciers. Journal of Geophysical Research-Solid Earth 100, 10219-10230. 
1409

1410

1411

1412

1413

1414

1415

1416

1417

1418

1419

1420

1421

1422

1423

1424

1425

1426

1427

1428

1429

1430

1431

1432

1433

1434

1435

1436

1437

1438

1439

1440

1441

1442

1443

1444

1445

1446

Jacobson, H.P., Waddington, E.D., 2005. Recumbent folding of divide arches in response to unsteady ice-divide migration. Journal of Glaciology 51, 201-209.

Jansson, P., Naslund, J., Pettersson, R., Richardson-Naslund, C., Holmlund, P., 2000. Debris entrainment and polythermal structure in the terminus of Storglaciären. IAHS-AISH Publication 264, 143-151.

Jennings, S.J.A., Hambrey, M.J., Glasser, N.F., 2014. Ice flow-unit influence on glacier structure, debris entrainment and transport. Earth Surface Processes and Landforms 39, 1279-1292.

Johnson, A.M., Fletcher, R.C., 1994. Folding of Viscous Layers. Columbia University Press, New York.

Joughin, I., Gray, L., Bindschadler, R., Price, S., Morse, D., Hulbe, C., Mattar, K., Werner, C., 1999. Tributaries of West Antarctic ice streams revealed by RADARSAT interferometry. Science 286, 283-286.

Joughin, I., MacAyeal, D., Tulaczyk, S., 2004. Basal shear stress of the Ross ice streams from control method inversions. Journal of Geophysical Research-Solid Earth 109, B09405.

Joughin, I., Smith, B.E., Howat, I.M., Scambos, T., Moon, T., 2010. Greenland flow variability from ice-sheet-wide velocity mapping. Journal of Glaciology 56, 415430.

Kamb, W.B., 1959. Ice petrofabric observations from Blue Glacier, Washington, in relation to theory and experiment. Journal of Geophysical Research 64, 18911909.

Kamb, B., 1972. Experimental recrystallization of ice under stress. In: Heard, H.C., Borg, I.Y., Carter, N.C., Raleigh, C.B. (eds.), Flow and Fracture of Rocks. Geophysical Monograph 16, 211-241.

Kamb, B., Engelhardt, H., 1987. Waves of accelerated motion in a glacier approaching surge: the mini-surges of Variegated Glacier, Alaska, U.S.A. Journal of Glaciology $33,27-46$.

Kamb, B., LaChapelle, E., 1964. Direct observation of the mechanism of glacier sliding over bedrock. Journal of Glaciology 5, 159-172.

Kamb, B., Raymond, C.F., Harrison, W.D., Engelhardt, H., Echelmeyer, K.A., Humphrey, N., Brugman, M.M., Pfeffer, T., 1985. Glacier surge mechanism; 1982-1983 surge of Variegated Glacier, Alaska. Science 227, 469-479. 
1447 Kawashima, K., Yamada, T., 1997. Experimental studies on the transformation from

1448

1449

1450

1451

1452

1453

1454

1455

1456

1457

1458

1459

1460

1461

1462

1463

1464

1465

1466

1467

1468

1469

1470

1471

1472

1473

1474

1475

1476

1477

1478

1479

1480

1481

1482

firn to ice in the wet-snow zone of temperate glaciers. Annals of Glaciology 24, 181-185.

Kehle, R.O., 1964. Deformation of the Ross ice shelf, Antarctica. Geological Society of America Bulletin 75, 259-286.

Keller, A., Blatter, H., 2012. Measurement of strain-rate components in a glacier with embedded inclinometers. Journal of Glaciology 58, 692-698.

Knight, P.G., 1995. Debris structures in basal ice exposed at the margin of the Greenland ice sheet. Boreas 24, 11-12.

Lawn, B.R., 1993. Fracture of Brittle Solids. Cambridge ; New York : Cambridge University Press, Cambridge ; New York.

Lawson, W., 1996. Structural evolution of Variegated Glacier, Alaska, U.S.A., since 1948. Journal of Glaciology 42, 261-270.

Lawson, W., 1997. Spatial, temporal and kinematic characteristics of surges of Variegated Glacier, Alaska. Annals of Glaciology 24, 95-101.

Lawson, W.J., Sharp, M., Hambrey, M., 1994. The structural geology of a surge-type glacier. Journal of Structural Geology 16, 1447-1462.

Lawson, W.J., Sharp, M.J., Hambrey, M.J., 2000. Deformation histories and structural assemblages of glacier ice in a non-steady flow regime. In: Maltman, A.J., Hubbard, B., Hambrey, M.J. (Eds.), Deformation of Glacial Materials. Geological Society Special Publications 176 176, 85-96.

Marmo, B.A., Wilson, C.J.L., 1998. Strain localisation and incremental deformation within ice masses, Framnes Mountains, east Antarctica. Journal of Structural Geology 20, 149-162.

Marmo, B.A., Wilson, C.J.L., 2000. The stress distribution related to the boudinage of a visco-elastic material; examples from a polar outlet glacier; Deformation of glacial materials. In: Maltman, A.J., Hubbard, B., Hambrey, M.J. (Eds.), Deformation of Glacial Materials. Geological Society Special Publications 176, 115-134.

Martin, C., Gudmundsson, G.H., Pritchard, H.D., Gagliardini, O., 2009. On the effects of anisotropic rheology on ice flow, internal structure, and the age-depth relationship at ice divides. Journal of Geophysical Research 114, F04001. doi:10.1029/2008JF001204

Matsuda, M., Wakahama, G., 1978. Crystallographic structure of polycrystalline ice. Journal of Glaciology, 21, 607-620. 
1483

Meier, M.F., 1960. Mode of flow of Saskatchewan Glacier, Alberta, Canada. U.S.Geological Survey Professional Paper 351.

Meier, M.F., Kamb, W.B., Allen, C.R., Sharp, R.P., 1974. Flow of Blue Glacier, Olympic Mountains, Washington, U.S.A. Journal of Glaciology, 13, 187-212.

Milnes, A.G., Hambrey, M.J., 1976. A method of estimating approximate cumulative strains in glacier ice. Tectonophysics 34, T23-T27.

Montagnat, M., Buiron, D., Arnaud, L., Broquet, A., Schlitz, P., Jacob, R., Kipfstuhl, S., 2012. Measurements and numerical simulation of fabric evolution along the Tabs Dome ice core, Antarctica. Earth and Planetary Science Letters 357, 168-178.

Montagnat, M., Castelnau, O., Bons, P.D., Faria, S.H., Gagliardini, O., Gillet-Chaulet, F., Grennerat, F., Griera, A., Lebensohn, R.A., Moulinec, H., Roessiger, J., Suquet, P., 2014. Multiscale modeling of ice deformation behavior. Journal of Structural Geology 61, 78-108.

Montagnat, M., Duval, P., 2000. Rate controlling processes in the creep of polar ice, influence of grain boundary migration associated with recrystallization. Earth and Planetary Science Letters 183, 179-186.

Moore, P.L., 2014. Deformation of debris-ice mixtures. Reviews of Geophysics 52, 435-467.

Moore, P.L., Iverson, N.R., Brugger, K.A., Cohen, D., Hooyer, T.S., Jansson, P., 2011. Effect of a cold margin on ice flow at the terminus of Storglaciaren, Sweden: implications for sediment transport. Journal of Glaciology 57, 77-87.

Moore, P.L., Iverson, N.R., Cohen, D., 2010. Conditions for thrust faulting in a glacier. Journal of Geophysical Research-Earth Surface 115, F02005, doi:10.1029/2009JF001307.

Moore, P.L., Iverson, N.R., Uno, K.T., Dettinger, M.P., Brugger, K.A., Jansson, P., 2013. Entrainment and emplacement of englacial debris bands near the margin of Storglaciären, Sweden. Boreas 42, 71-83.

Mottram, R.H., Benn, D.I., 2009. Testing crevasse-depth models; a field study at Breidamerkurjokull, Iceland. Journal of Glaciology 55, 746-752.

Murray, T., Gooch, D.L., Stuart, G.W., 1997. Structures within the surge front at Bakaninbreen, Svalbard, using ground-penetrating radar. Annals of Glaciology 24, 122-129.

Nakawo, M., Wakahama, G., 1981. Preliminary experiments on the formation of 
1521

1522

1523

1524

1525

1526

1527

1528

1529

1530

1531

1532

1533

1534

1535

1536

1537

1538

1539

1540

1541

1542

1543

1544 1545

1546

1547

1548

1549

1550

1551

1552

1553

1554

1555

1556 elongated air bubbles in glacier ice by stress. Journal of Glaciology 27, 141146.

Neurath, C., Smith, R.B., 1982. The effect of material properties on growth rates of folding and boudinage; experiments with wax models. Journal of Structural Geology 4, 215-229.

Nye, J.F., 1952. The mechanics of glacier flow. Journal of Glaciology 2, 82-93.

Nye, J.F., 1953. The flow law of ice from measurements in glacier tunnels, laboratory experiments and the Jungfraufirn borehole experiment. Proceedings of the Royal Society London, A 219, 477-489.

Passchier, C.W., 2001. Flanking structures. Journal of Structural Geology 23, 951962.

Passchier, C.W., Trouw, R.A.J., 1996. Microtectonics. Springer-Verlag, Berlin, Berlin, Federal Republic of Germany (DEU).

Patrick, B.A., Corvino, A.F., Wilson, C.J.L., 2003. Ice-flow measurements and deformation at marginal shear zones on Sorsdal Glacier, Ingrid Christensen Coast, East Antarctica. Annals of Glaciology 37, 60-68.

Pettit, E.C., Jacobson, H.P., Waddington, E.D., 2003. Effects of basal sliding on isochrones and flow near an ice divide. Annals of Glaciology, Vol 37 37, 370376.

Pettit, E., Thorsteinsson, T., Jacobson, H., Waddington, E., 2007. The role of crystal fabric in flow near an ice divide. Journal of Glaciology 53, 277-288.

Pettit, E.C., Waddington, E., 2003. Ice flow at low deviatoric stress. Journal of Glaciology 49, 359-369.

Pettit, E.C., Waddington, E., Harrison, W.D., Thorsteinsson, T., Elsberg, D., Morack, J., Zumberge, M., 2011. The crossover stress, anisotropy and the ice flow law at Siple Dome, West Antarctica. Journal of Glaciology 57, 39-52.

Porter, P.R., Murray , T., Dowdeswell, J.A., 1997. Sediment deformation and basal dynamics beneath a glacier surge front; Bakaninbreen, Svalbard. Annals of Glaciology 24, 21-26.

Pfeffer, W.T., 1992. Stress-induced foliation in the terminus of Variegated Glacier, Alaska, USA, formed during the 1982-83 surge. Journal of Glaciology 38, 213222.

Post, A., 1969. Distribution of surging glaciers in western North America. Journal of Glaciology 8, 229-240. 
Post, A., 1972. Periodic surge origin of folded medial moraines on Bering piedmont glacier, Alaska. Journal of Glaciology 11, 219-226.

Ragan, D.M., 1969. Structures at the base of an ice fall. Journal of Geology 77, 647667.

Ramberg, H., 1964. Note on model studies of folding of moraines in piedmont glaciers. Journal of Glaciology 5, 207-218.

Ramsay, J.G., 1967. Folding and Fracturing of Rocks. McGraw Hill, New York.

Ramsay, J.G., 1980. The crack-seal mechanism of rock deformation. Nature (London) 284, 135-139.

Raymond, C.F., 1971a. Determination of the three-dimensional velocity field in a glacier. Journal of Glaciology 10, 39-53.

Raymond, C.F., 1971b. Flow in a transverse section of Athabasca glacier, Alberta, Canada. Journal of Glaciology 10, 55-58.

Raymond, C.F., 1983. Deformation in the vicinity of ice divides. Journal of Glaciology 29, 357-373.

Raymond, C., Johannesson, T., Pfeffer, T., Sharp, M., 1987. Propagation of a glacier surge into stagnant ice. Journal of Geophysical Research 92, 9037-9049.

Rignot, E., Mouginot, J., Scheucht, B., 2011. Ice flow of the Antarctic ice sheet. Science $333,1427-1430$.

Rist, M.A., Murrell, S.A.F., 1994. Ice triaxial deformation and fracture. Journal of Glaciology 40, 305-318.

Roberson, S., 2008. Structural composition and sediment transfer in a composite cirque glacier: Glacier de St. Sorlin, France. Earth Surface Processes and Landforms 33, 1931-1947.

Russell-Head, D.S., Budd, W.F., 1979. Ice-sheet flow properties derived from borehole shear measurements combined with ice-core studies. Journal of Glaciology 24, 90, 117-130.

Russell-Head, D.S., 1982. Cleavage structure in Antarctic ice. In: Borradaile, G.J., Bayly, M.B., Powell, C.M. (eds.), Atlas of Deformational and Metamorphic Rock Fabrics. Springer-Verlag, Berlin, pp. 76-77.

Rutter, N.W., 1965. Foliation pattern of Gulkana Glacier, Alaska Range, Alaska. Journal of Glaciology 5, 711-718.

Samyn, D., Svensson, A., Fitzsimons, S.J., 2008. Dynamic implications of 
1590

1591

1592

1593

1594

1595

1596

1597

1598

1599

1600

1601

1602

1603

1604

1605

1606

1607

1608

1609

1610

1611

1612

1613

1614

1615

1616

1617

1618

1619

1620

1621

1622

1623 discontinuous recrystallization in cold basal ice; Taylor Glacier, Antarctica. Journal of Geophysical Research 113, F03S90, doi:10.1029/2006JF000600.

Schmalholz, S.M., Schmid, D.W., Fletcher, R.C., 2008. Evolution of pinch-and-swell structures in a power-law layer. Journal of Structural Geology 30, 649-663.

Schulson, E.M., 1999. The structure and mechanical behavior of ice. Journal of the Minerals Metals and Materials Society 51, 21-27.

Seddik, H., Greve, R., Zwinger, T., Placidi, L., 2011. A full Stokes ice flow model for the vicinity of Dome Fuji, Antarctica, with induced anisotropy and fabric evolution. Cryosphere 5, 495-508.

Sharp, M., Lawson, W., Anderson, R.S., 1988. Tectonic processes in a surge-type glacier. Journal of Structural Geology 10, 499-515.

Sharp, M., Jouzel, J., Hubbard, B., Lawson, W., 1994. The character, structure and origin of the basal ice layer of a surge-type glacier. Journal of Glaciology 40, 327-340.

Sharp, R.P., 1958. Malaspina Glacier, Alaska. Geological Society of America Bulletin 69, 617-646.

Shoemaker, E.M., 1990. A subglacial boundary-layer regelation mechanism. Journal of Glaciology 36, 263-272.

Siegert, M.J., Welch, B., Morse, D., Vieli, A., Blankenship, D.D., Joughin, I., King, E.C., Vieli, G.J., Payne, A.J., Jacobel, R., 2004. Ice flow direction change in interior West Antarctica. Science 305, 1948-1951.

Smith, R.B., 1975. Unified theory of the onset of folding, boudinage, and mullion structure. Geological Society of America Bulletin 86, 1601-1609.

Smith,R.B., 1977. Formation of folds, boudinage, and mullions in non-Newtonian materials. Geological Society of America Bulletin 88, 312-320.

Song, M., Baker, I., Cole, D.M., 2005. The effect of particles on dynamic recrystallization and fabric development of granular ice during creep. Journal of Glaciology 51, 377-382.

Song, M., Baker, I., Cole, D., 2008. The effect of particles on creep rate and microstructures of granular ice. Journal of Glaciology 54, 533-537.

Spencer, M.K., Alley, R.B., Fitzpatrick, J.J., 2006. Developing a bubble number-density paleoclimatic indicator for glacier ice. Journal of Glaciology 52, 358-364.

Suppe, J., 1985. Principles of Structural Geology. Prentice-Hall, Englewood Cliffs, NJ, Englewood Cliffs, NJ, United States (USA). 
1624 Swinzow, G.K., 1962. Investigation of shear zones in the ice sheet margin, Thule area, Greenland. Journal of Glaciology 4, 215-229.

1626

1627

1628

1629

1630

1631

1632

1633

1634

1635

1636

1637

1638

1639

1640

1641

1642

1643

1644

1645

1646

1647

1648

1649

1650

1651

1652

1653

1654

1655

1656

1657

Taylor, L.D., 1963. Structure and fabric on the Burroughs Glacier, south-east Alaska. Journal of Glaciology 4, 731-752.

Thorsteinsson, T., 2002. Fabric development with nearest-neighbor interaction and dynamic recrystallization. Journal of Geophysical Research 107, 13. doi:http://dx.doi.org/10.1029/2000JB000244

Thorsteinsson, T., Waddington, E.D., 2002. Folding in strongly anisotropic layers near ice-sheet centers. Annals of Glaciology 35, 480-486.

Tison, J., Petit, J., Barnola, J., Mahaney, W.C., 1993. Debris entrainment at the icebedrock interface in sub-freezing temperature conditions (Terre Adelie, Antarctica). Journal of Glaciology 39, 303-315.

Treverrow, A., Budd, W.F., Jacka, T.H., Warner, R.C., 2012. The tertiary creep of polycrystalline ice: experimental evidence for stress-dependent levels of strain-rate enhancement. Journal of Glaciology 58, 301-314.

Vaughan, D.G., Corr, H., Doake, C., Waddington, E., 1999. Distortion of isochronous layers in ice revealed by ground-penetrating radar. Nature 398, 323-326.

Voigt, D.E., Alley, R.B., Anandakrishnan, S., Spencer, M.K., 2003. Ice-core insights into the flow and shut-down of Ice Stream C, West Antarctica. Annals of Glaciology 37, 123-128.

Weertman, J., 1964. The theory of glacier sliding. Journal of Glaciology 5, 287-303.

Weertman, J., 1973. Can a water-filled crevasse reach the bottom surface of a glacier? International Association of Scientific Hydrology Publication 95 (Symposium at Cambridge 1969 - Hydrology of Glaciers), 139-145.

Weertman, J., 1983. Creep deformation of ice. Annual Review of Earth and Planetary Sciences 11, 215-240.

Wegmann, C.E., 1963. Tectonic patterns at different levels. The Geological Society of South Africa Annex to Volume 66, 1-73.

Weikusat, I., Miyamoto, A., Faria, S., Kipfstuhl, S., Azuma, N., Hondoh, T., 2011. Subgrain boundaries in Antarctic ice quantified by X-ray Laue diffraction. Journal of Glaciology 57, 111-120.

Whillans, I.M., Jezek, K.C., 1987. Folding in the Greenland ice sheet. Journal of Geophysical Research 92, 485-493.

Wilson, C.J.L., 1981. Experimental folding and fabric development in multilayered 
ice. Tectonophysics 78, 139-159.

1659

1660

1661

1662

1663

1664

1665

1666

1667

1668

1669

1670

1671

1672

1673

1674

1675

1676

1677

1678

1679

1680

1681

1682

1683

1684 ablation exceeds accumulation in the ablation zone $\left({ }^{\circ}<0\right)$. If basal temperature is at

1685 the pressure-melting point there will be a component of basal slip (not shown). Ice

1686 sheets (not shown) are much larger than ice caps and possess ice divides separating

1687 flow basins; they possess outlet glaciers and ice streams at their margins in which

1688 the velocity is much higher than in the surrounding ice (see Rignot et al., 2011).

1689 Otherwise, the basic flow pattern in an ice sheet resembles that of an ice cap. 
1691 Fig. 2. a) Curves of log strain rate versus log strain for creep tests on polycrystalline 1692 ice under unconfined compression, illustrating the difference between starting with 1693 an isotropic $c$-axis fabric and an initially compatible anisotropic fabric - a small 1694 circle of $c$-axes centered on the compression axis. In the initially isotropic case, the 1695 strain rate passes through a minimum (secondary creep) and tends towards a stable 1696 value (tertiary creep) as a small circle $c$-axis fabric develops. The fabric after about

$169710 \%$ strain is similar in both cases and similar to the starting anisotropic fabric. b)

1698 Same data on a traditional creep plot of strain against time. After Treverrow et al.

1699 (2012) and experiments of Gao and Jacka (1987).

1700

1701 Fig. 3. Numerical model results of stress-strain rate relationships in a

1702 polycrystalline aggregate to show softening or hardening of ice due to lattice

1703 preferred orientation of $c$-axes (after Cuffey and Peterson, 2010, fig. 3-20). The plot

1704 shows enhancement of shear strain rate in simple shear and of compressive strain

1705 rate in uniaxial compression (vertical axis) against strength of fabric for simple

1706 shear and cone angle of girdle distribution for uniaxial compression (horizontal

1707 axis). The characteristic angle delimits the distribution of $c$-axes as shown. The

1708 width of the band in compression is $30^{\circ}$.

1709

1710 Fig. 4. Measured and calculated (based on measurements) velocities in a cross

1711 section of the Athabasca Glacier, from Raymond (1971a, 1971b). a) Contours of

1712 longitudinal velocity, in $\mathrm{m} \mathrm{a}^{-1}$. Positions of boreholes are indicated. b) Difference 
1713 between surface longitudinal velocity and longitudinal velocity at depth at position

1714 1A. c) Longitudinal velocity variation across the glacier, same location. Positions of

1715 markers or boreholes shown by black dots. Velocity at open circle estimated from

1716 adjacent stakes and tape measure.

1717

1718 Fig. 5. Schematic particle paths (light solid blue lines), isochrons (red dashed lines)

1719 and strain pattern in an ice cap at steady state (from Hooke and Hudleston, 1978).

1720 E.L. is equilibrium line; $\mathrm{D}$ is ice divide. If there is extension in the third dimension,

1721 as in radial flow, the strains will all be of flattening type; otherwise this is plane

1722 strain.

1723

1724 Fig. 6. Flow and strain regimes in a cross section of the Law Dome, Antarctica, from

1725 the summit to Cape Folger (after Budd and Jacka, 1989). Bedrock topography from

1726 radio echo sounding. a) Particle paths and isochrons in thousands of years;

1727 locations of boreholes shown by grey lines. b) Contours of cumulative compressive

1728 strain. c) Contours of cumulative shear strain.

1729

1730 Fig. 7. Estimated surface finite strain field accumulated in flow starting below an

1731 icefall in Griesgletscher, Switzerland based on displacement of stakes over several

1732 years and assuming steady state (from Hambrey and Milnes, 1977). Five separate

1733 particle paths are followed, with the time interval in years associated with each

1734 strain state noted. The estimates are realistic in as much as flow does not vary much 
1735 with time and ice velocities do not change significantly with depth. See Hambrey

1736 and Milnes for discussion.

1737

1738 Fig. 8. Schematic crystallographic $c$-axis patterns in found in ice caps and in

1739 experiments (after Budd, 1972; Hudleston, 1977a; Duval, 1981; Bouchez and Duval,

1740 1982; Budd and Jacka, 1989). Axes are with reference to ice caps or experimental

1741 tests: $x$, flow direction, $z$, vertical, $y$, perpendicular to the 'flow plane.' a) Small circle

1742 girdle about the vertical at domes and in uniaxial compression. The opening angle

1743 of the cone gets smaller as strain increases. b) Bimodal pattern at a divide, and in

1744 pure shear experiments. c) One strong and one weak maximum in simple shear at

1745 low shear strain. d) A strong single maximum in simple shear at higher strain. e)

1746 Four-maxima 'diamond' pattern found in coarse-grained ice in valley glaciers and

1747 deep in ice caps.

1748

1749 Fig. 9. a) Sedimentary layering is the only fabric element evident (apart from a few

1750 fracture traces at the left) at the terminus of Southeast Kaskasatjåkkaglaciären, a

1751 small cirque glacier in northern Sweden. The field of view is about $100 \mathrm{~m} . \mathrm{b}$ )

1752 Sedimentary layering in superimposed (post Pleistocene) ice at the edge of the

1753 Barnes Ice Cap, Canada, with older layers folded, overturned and unconformably

1754 overlain by younger ice. The cliff is about $15 \mathrm{~m}$ high.

1755

1756 Fig. 10. Classic pattern of crevasses in a valley glacier according to Nye (1952).

1757 Marginal crevasses form at $45^{\circ}$ to the valley sides in the absence of longitudinal 
1758 stress $\left(\sigma_{x}=0\right)$, and at angles either less than or greater than $45^{\circ}$ in the presence of a

1759 longitudinal stress, depending on whether this is compressive or tensile. Transverse

1760 crevasses form under longitudinal tensile stresses and curve as the longitudinal

1761 stress is modified by shear stress approaching the margins. A second set of

1762 crevasses may form (dashed lines) if both principal stresses become tensile. Arrows

1763 represent directions, sense and magnitude of principal stresses. a) compressive

1764 flow, b) no longitudinal stress, c) extensional flow

1765

1766 Fig. 11. Natural crevasse patterns in three glaciers in Swedish Lapland. a) En

1767 echelon marginal crevasses, as in Fig. 10b, affecting ice of Rabotsglaciären with an

1768 arcuate trace of primary stratification, the center of the arc corresponding to the

1769 position of maximum horizontal velocity. (Distance from the near margin to the

1770 center of the glacier ca. $200 \mathrm{~m}$ ). b) En echelon crevasses with the pattern shown in

1771 Fig. 10a, just below the equilibrium line in Storglaciären, with primary stratification

1772 as in a). In this case the active crevasses cross cut older rotated crevasse traces. .

1773 (Distance from the near margin to the center of the glacier ca. $400 \mathrm{~m}$ ). c)

1774 Isfallsglaciären, with transverse crevasses, for which the pattern becomes more

1775 complex with flow over rough bedrock topography. There are marginal en echelon

1776 crevasses in the superimposed snow/ice in the foreground. (Width of the glacier ca.

$1777800 \mathrm{~m})$.

1778

1779 Fig. 12. Pattern of crevasses (red lines) in a stretch of the Blue Glacier, Washington, 1780 and relationship to surface principal strain rates (from Meier et al., 1974). 
1782 Fig. 13. Pattern of closed crevasses, veins or fracture traces, along the south margin 1783 of Storglaciären, Sweden, with cross-cutting relationships consistent with formation

1784 and subsequent rotation before older crevasses are crosscut by younger. The

1785 arcuate trace of sedimentary layering, combined with closed transverse crevasse

1786 traces, is prominent in the center of the glacier, which is about $1 \mathrm{~km}$ wide. There is a

1787 secondary partial arc of sedimentary layering in the near part of the glacier,

1788 originating from a subsidiary accumulation basin. Flow is to the right. 1789

1790 Fig. 14. Sequence of structures developed in the marginal ice of Sörsdal Glacier, East 1791 Antarctica as a result of crevassing, from Patrick et al. (2003). a) Open crevasse 1792 cutting ice with numerous veins/fracture traces (shaded blue) formed by closure of 1793 older crevasses and showing cross-cutting relations consistent with rotation after 1794 formation in a zone of dextral shear, as indicated by the inset, with veins in $\mathrm{S}_{1}$

1795 orientation being the oldest, and $S_{5}$ being the youngest. b) Sequence of deformation 1796 of vein after formation from a crevasse, involving closure, rotation and differential 1797 shear to form folds. 1798

1799 Fig. 15. a) Histogram of orientations, defined by angle, $\alpha$, of ice veins/fracture traces 1800 formed from closed crevasses along the north margin of Storglaciären, Sweden, in 1801 the ablation zone just below the equilibrium line b) Simulated distribution of 1802 orientations of fracture traces forming at regular intervals (values of shear strain) 1803 and then being rotated passively by subsequent flow, modeled as simple shear; 
1804 initial orientation of fractures is $135^{\circ}$. The average shear strain, $\gamma$, required to

1805 produce the rotations for each $20^{\circ}$ range of orientations is shown above the

1806 histogram. c) The same as b) except that the initial orientation of the fractures is

$180790^{\circ}$. The initial fractures sub-vertical; this is also true of the natural fracture traces

1808 and veins.

1809

1810 Fig. 16. a) Strong steeply dipping longitudinal foliation between two ice streams

1811 from separate accumulation zones on Rabotsglaciären, Sweden. b) Strong composite

1812 longitudinal foliation along the south side of Storglaciären, Sweden, associated with

1813 a large shear strain. The relatively bubble-free ice is interpreted to have originated

1814 as veins filling fractures, now parallel to primary stratification and bubble

1815 clustering. c) Strong longitudinal foliation (marked by the pencil) near the front of

1816 Storglaciären cross cut by clear ice veins forming a second planar fabric element,

1817 with significant deformation and rotation post vein emplacement. d) Three

1818 distinctly different planar features near the center of Storglaciären: black: primary

1819 stratification $\left(\mathrm{S}_{0}\right)$, blue: two veins, one composite, infilling fractures, and red: a near

1820 vertical longitudinal foliation defined by slight variations in grain size and bubble

1821 clustering on the grain scale. The foliation affects both $\mathrm{S}_{0}$ and, to a lesser extent, the 1822 veins.

1823

1824 Fig. 17. a) Vertical slab of ice about $4 \mathrm{~mm}$ thick in a transverse orientation from the

1825 north side of Storglaciären to show steeply dipping longitudinal foliation defined by

1826 bubble clustering, and a vein of clear ice, with irregular edges due to deformation. b) 
1827 The same slab, thinned to $2 \mathrm{~mm}$, under crossed polarizers to show large

1828 recrystallized grains with a shape-preferred orientation generally parallel to the

1829 foliation.

1830

1831 Fig. 18. Schematic diagram to illustrate how a) various components of foliation in

1832 ice become modified by b) pure shear and c) simple shear. d) Strain alone for shear

1833 strain of $\gamma=10$. (after Hooke and Hudleston, 1978). With very large strains,

1834 especially in simple shear, often exceeding $\gamma=10$, a composite planar fabric will

1835 form from these components.

1836

1837 Fig. 19. Folds at very different scales seen on the surface (a,c,d) and in an ice cliff (b)

1838 of different glaciers. a) Similar style folds in medial moraines on the east edge of the

1839 Seward Glacier lobe of Malaspina Glacier (from Sharp, 1958). The field of view is

1840 several km. b) Recumbent fold in debris-containing superimposed ice exposed in an

1841 ice cliff at the edge of the Barnes Ice Cap, Canada (see Hudleston, 1976). Dirt coats

1842 the surface of the cliff and the debris content of the ice is much smaller than appears

1843 from the picture. Ice axe for scale in center of picture. c) Sharp-hinged folds with

1844 axial planar foliation in primary stratification midre Lovénbreen, Svalbard (Fig. 5B

1845 in Hambrey and Glasser, 2003). Ice axe (circled) lies along the fold axial surface

1846 trace. d) Fold of subsimilar style affecting composite foliation at the edge of

1847 Storglaciären, Sweden. Axial surface is parallel to the glacial margin and the hinge

1848 plunges steeply. This fold does not have an axial planar foliation. Penknife (circled)

1849 for scale is $9 \mathrm{~cm}$ long. 
1851 Fig. 20. Convergent flow from an accumulation basin produces folds in irregularities 1852 in primary stratification and a longitudinal foliation (as in Fig. 19c), most intense 1853 along the valley sides due to combination of shear with lateral shortening. Based on 1854 Fig. 7 of Lawson et al. (1994) for structures developed in Variegated Glacier, Alaska.

1855 Note that the deformation history as the glacier narrows is basically one of 1856 transpression, with opposite sense of shear on either side. 1857

1858 Fig. 21. Schematic diagram to show progressive development of folds in the 1859 situation illustrated in Fig. 20, as seen in a transverse section, with horizontal 1860 shortening across the glacier eventually producing transposition of primary 1861 stratification and development of a strong longitudinal foliation in marginal ice 1862 (modified from Hambrey and Lawson, 2000). 1863

1864 Fig. 22. Schematic illustration of structures and fabrics developed in valley glaciers 1865 due to lateral shortening associated with flow from two or more accumulation 1866 basins. Folds in stratification have sub horizontal hinges parallel to the flow 1867 direction and an axial planar foliation. The figure is after Hambrey et al. (1999), 1868 based on observations on several glaciers in Svalbard. 1869

1870 Fig. 23. Examples of folds with different origins and orientations in Storglaciären, 1871 Sweden. a) Folds of the type illustrated in Fig. 21 and 22 exposed in the walls of 1872 closely spaced closed crevasses in marginal ice of Storglaciären, Sweden, with sub 
1873 horizontal hinges and vertical longitudinal axial planar foliation. b) Steeply plunging

1874 fold of foliation in marginal ice, with vertical ice veins parallel to the axial plane and

1875 at a small angle to the glacier margin.

1876

1877 Fig. 24. Numerical model of passive recumbent folding in stratification at the base of 1878 the Barnes Ice Cap. The fold is generated by a small perturbation of flow over

1879 bedrock topography (to the right of what is shown here) and amplified

1880 kinematically. The direction and magnitude of the maximum extensional strain

1881 accumulated since the perturbation occurred are indicated by the short lines with

1882 numbers beside them (after Hudleston, 1977).

1883

1884 Fig. 25. Aerial photograph of the SE margin of the Barnes Ice Cap to show band of 1885 white Pleistocene ice repeated by folding of the kind illustrated in Fig. 24. See 1886 Hooke (1973) for explanation of how the Pleistocene age is both overlain and 1887 underlain by younger ice. Original photograph supplied by Department of Energy, 1888 Mines and Resources, Ottawa, Canada. Field of view is $5 \mathrm{~km}$ wide. 1889

1890 Fig. 26. Schematic diagram to show how recumbent folds of the kind shown in Fig. 189124 can become sheath folds, with conical closures drawn out in the flow direction 1892 (after Hudleston, 1986). The layer designated by heavy black line outcrops on the 1893 glacier surface (shaded plane) as shown by the dashed lines. 1894 
1895 Fig. 27. Flanking fold in marginal ice of Storglaciären associated with the creation, 1896 closure and rotation of a crevasse, now a vein, shown in blue (after Hudleston, 1897 1989).

1898

1899 Fig. 28. Simple model, based on experiments on clay, to show development of a 1900 flanking fold (after Hudleston, 1989), with shear strain values associated with 1901 rotation of the fracture as it fills in - indicated with blue shading - and becomes a 1902 vein, with initial orientation at $45^{\circ}$ to the shear plane (glacier margin). An initially 1903 continuous planar marker cut by the fracture is shown to be folded and displaced to 1904 form a flanking structure - double hook shaped fold - while the rotation occurs. The 1905 strain ellipse at $\gamma=10$ is truncated.

1906

1907 Fig. 29. Examples of small-scale buckle folds in glacial ice. a) In a thin tephra layer 1908 near the terminus of Johnsons Glacier, Livingston Island, Antarctica, with hinges

1909 parallel to the flow direction (from Ximenis et al., 2000). The folds indicate

1910 shortening perpendicular to this direction. The difference in shape of the inner arcs

1911 of the anticlines and synclines in the tephra layer indicates that the ice above and

1912 below the layer have different viscosities, with that above being higher than that

1913 below. b) In a layer of gravelly sand about $1 \mathrm{~m}$ above the base of Suess Glacier,

1914 Antarctica (from Fitzsimons, 2006). 
1916 Fig. 30. Small-scale shear zone in superimposed ice at the margin of the Barnes, Ice 1917 Cap, Baffin Island, Canada, defined by stretched bubbles. Seen in a vertical slab of 1918 ice $0.3 \mathrm{~cm}$ thick. See Hudleston (1980) for location and setting. 1919

1920 Fig. 31. Small-scale shear zone from the same location as Fig. 30, in crossed 1921 polarizers to show the grain shape fabric and extremely strong $c$-axis preferred 1922 orientation in coarsely recrystallized ice within the shear zone, with the maximum 1923 perpendicular to the shear zone boundaries. In both this and Fig. 30 the shear zones 1924 are sub horizontal and shear direction is perpendicular to the ice cap margin. a)

1925 Oriented with shear zone grains showing brightest. b) Oriented with nearly all shear 1926 zone grains in extinction. Section about $1 \mathrm{~mm}$ thick. Centimeter grid in a) gives 1927 scale. 1928

1929 Fig. 32. Examples of boudinage in glaciers. a) Line drawing from photograph by 1930 Lawson in Hubbard and Sharp (1989, Fig. 5) of boudins in debris-free ice (blue) 1931 embedded in debris-rich ice at the base of Variegated Glacier, Alaska. b) Boudins in 1932 sand layers within clean and bubbly ice on Sandy Glacier, Victoria Land, Antarctica 1933 (Dort, 1967, Fig. 5). c) Boudins in 10mm thick layer of sand near the base of Suess 1934 Glacier, Antarctica (Fitzsimons, 2006, Fig. 65.3). Penknife blade for scale. d) Results 1935 of numerical model to simulated boudins developed in ice-filled crevasses observed 1936 on the surface of an outlet glacier of the Framnes Mountains, Antarctica (Marmo and 1937 Wilson, 2000). The individual modeled boudins are about $1 \mathrm{~m}$ long and have this 
1938 form about $1000 \mathrm{~m}$ from the crevasse field, with estimated strains since flow over

1939 that distance of $\varepsilon_{\mathrm{y}}=1.6$ and a shear strain, $\gamma_{\mathrm{xy}}$, of 0.6 .

1940

1941 Fig. 33. a) Schematic illustration of the common concept of thrust faults bringing

1942 basal debris to the surface at the front of glaciers (after Moore et al., 2010). b)

1943 Interpretation of structures including thrusts and folds at the front of Bakaninbreen,

1944 Svalbard, following a surge in 1985-86; based on ground-penetrating radar (after

1945 Murray et al., 1997).

1946

1947 Fig. 34. a) Fold in longitudinal foliation with steep plunge, cut by ice vein, in

1948 marginal ice of Storglaciären. There is no new axial planar foliation here. The fold is

1949 displaced across the ice vein by an apparent strike-slip fault, but not by shear along

1950 a fault or shear zone. b) Folds in primary stratification and multiple axial planar

1951 fracture traces with offsets of stratification, exposed on a crevasse face on

1952 Kebnepakteglaciären, Sweden. Displacement was not caused by shear fracturing.

1953

1954 Fig. 35. Schematic diagram to illustrate the structures at the end of the 1982-1983

1955 surge of the Variegated Glacier, Alaska, showing strain rate histories during the

1956 surge at three locations with different histories (after Lawson et al., 1994).

1957

1958 Fig. 36. Map of the ablation zone of Storglaciären, Sweden, to show generalized

1959 variation in orientation of fold hinges depending on location in ice flowing with a

1960 single "tectonic transport" direction. Horizontal hinges are for folds in primary 
1961 stratification, with axial planar foliation in the marginal ice; at the front of the 1962 glacier the hinges are for folds in a composite foliation that may be of sheath type.

1963 Vertical hinges are for folds affecting composite foliation in marginal ice. The 1964 foliation is everywhere steep to vertical. Based on data collected in 1979, 1980. 1965 

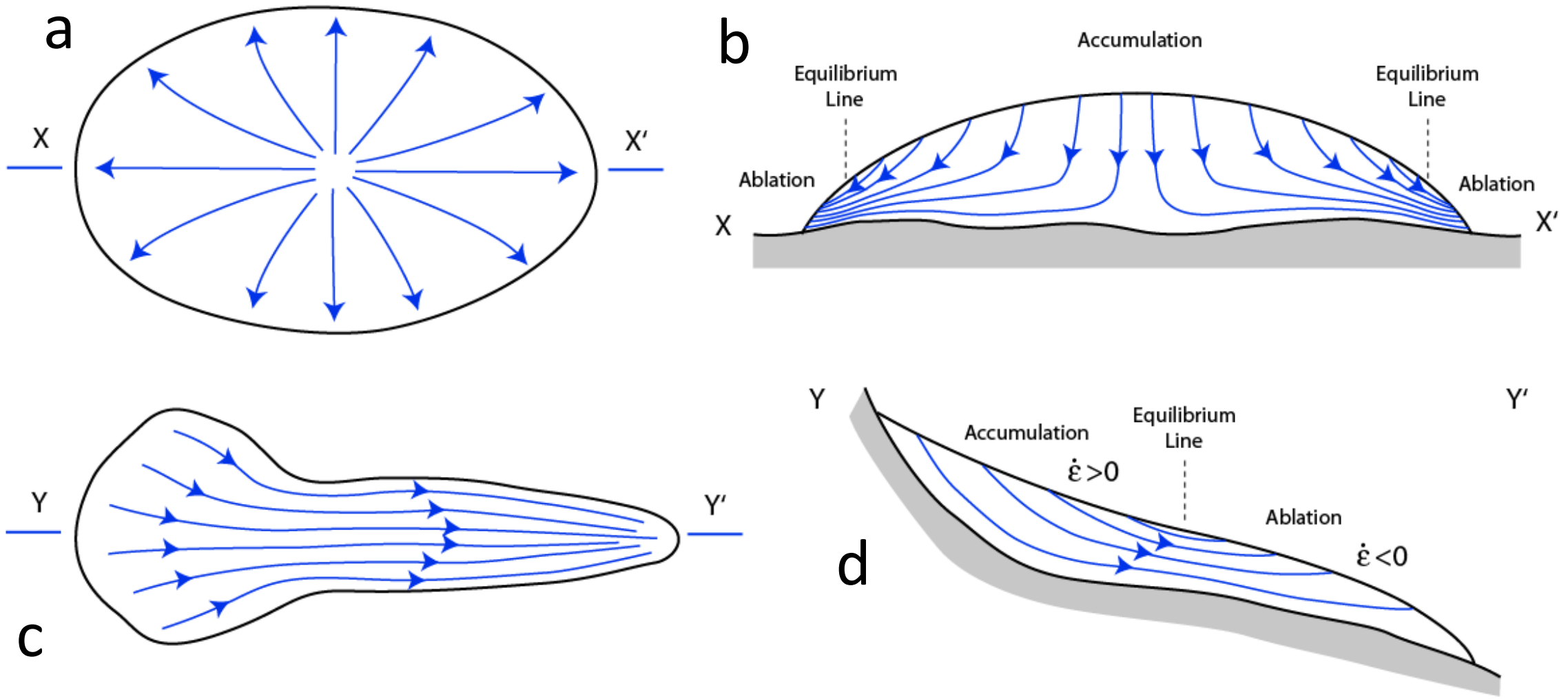

Fig. 1 

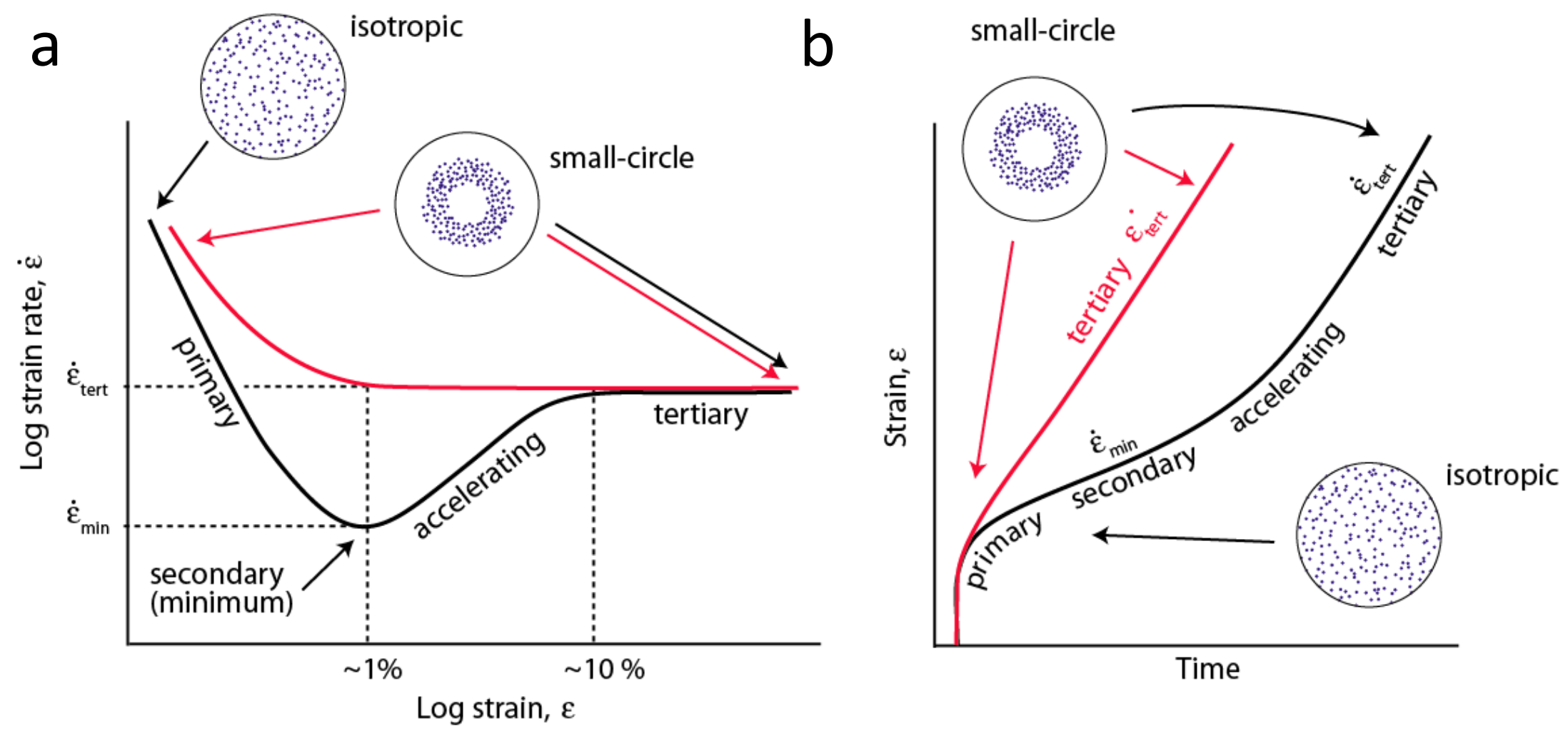

Fig. 2 


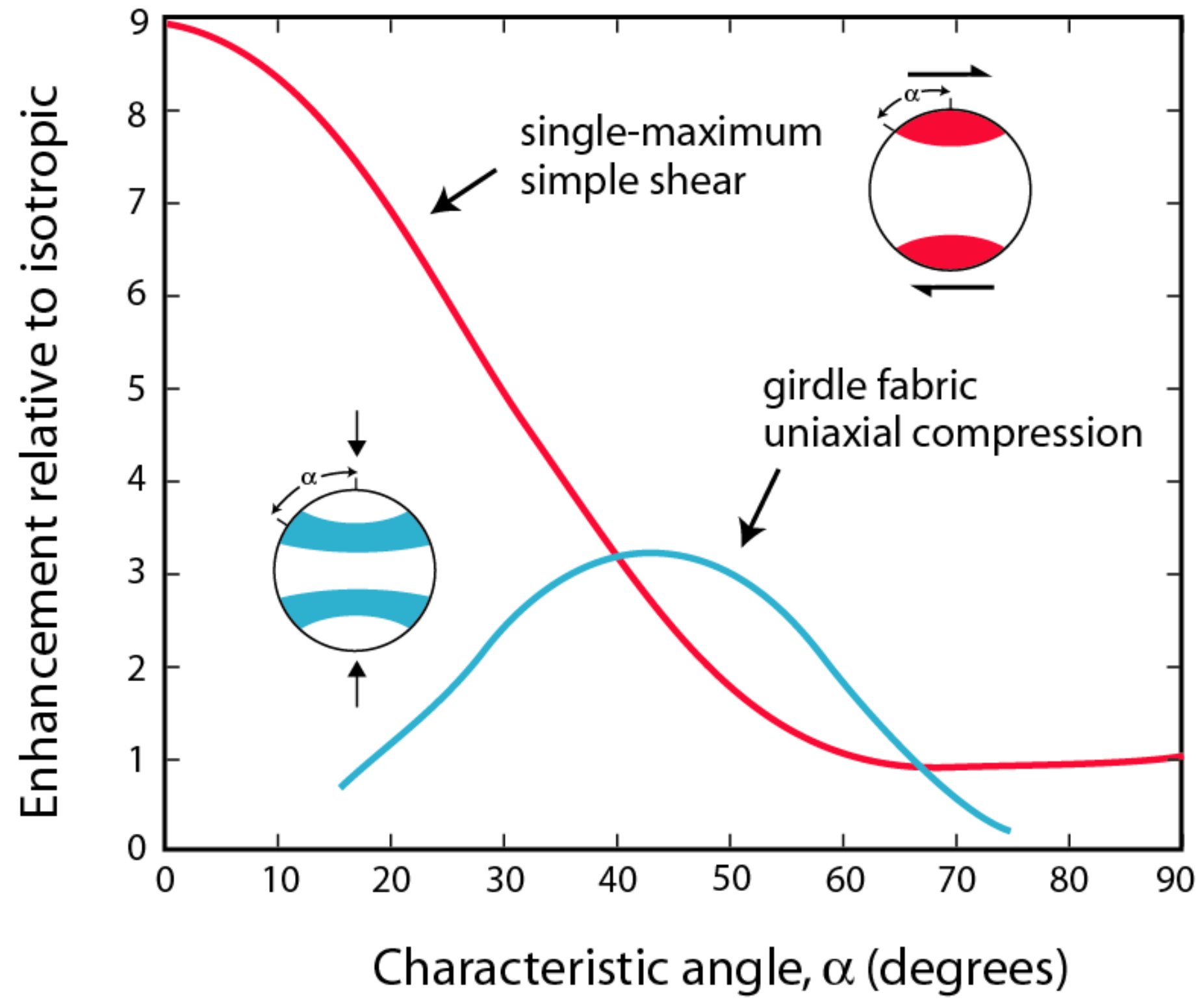

Fig. 3 

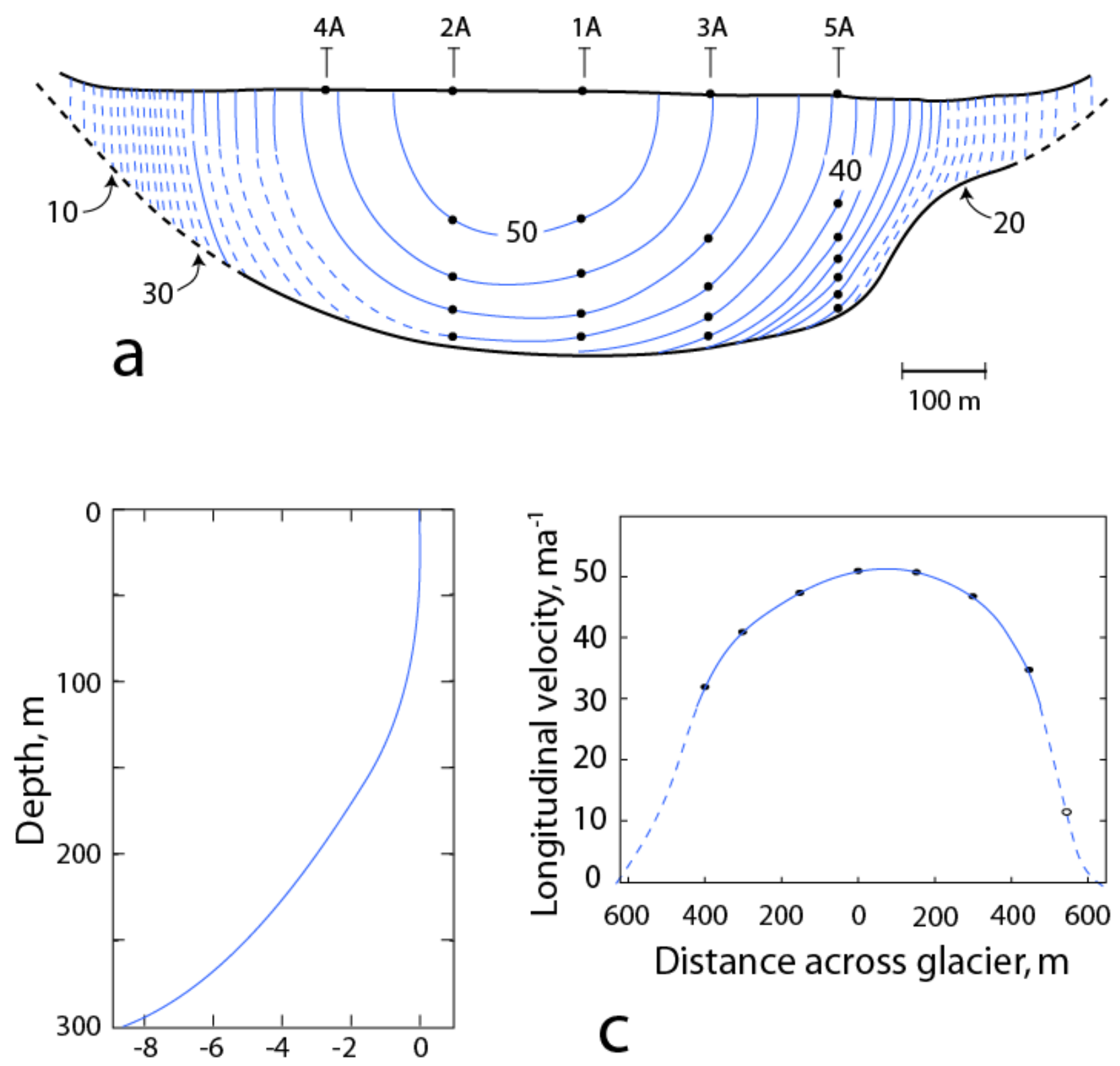

b velocity with depth, $\mathrm{ma}^{-1}$

Fig. 4 
D
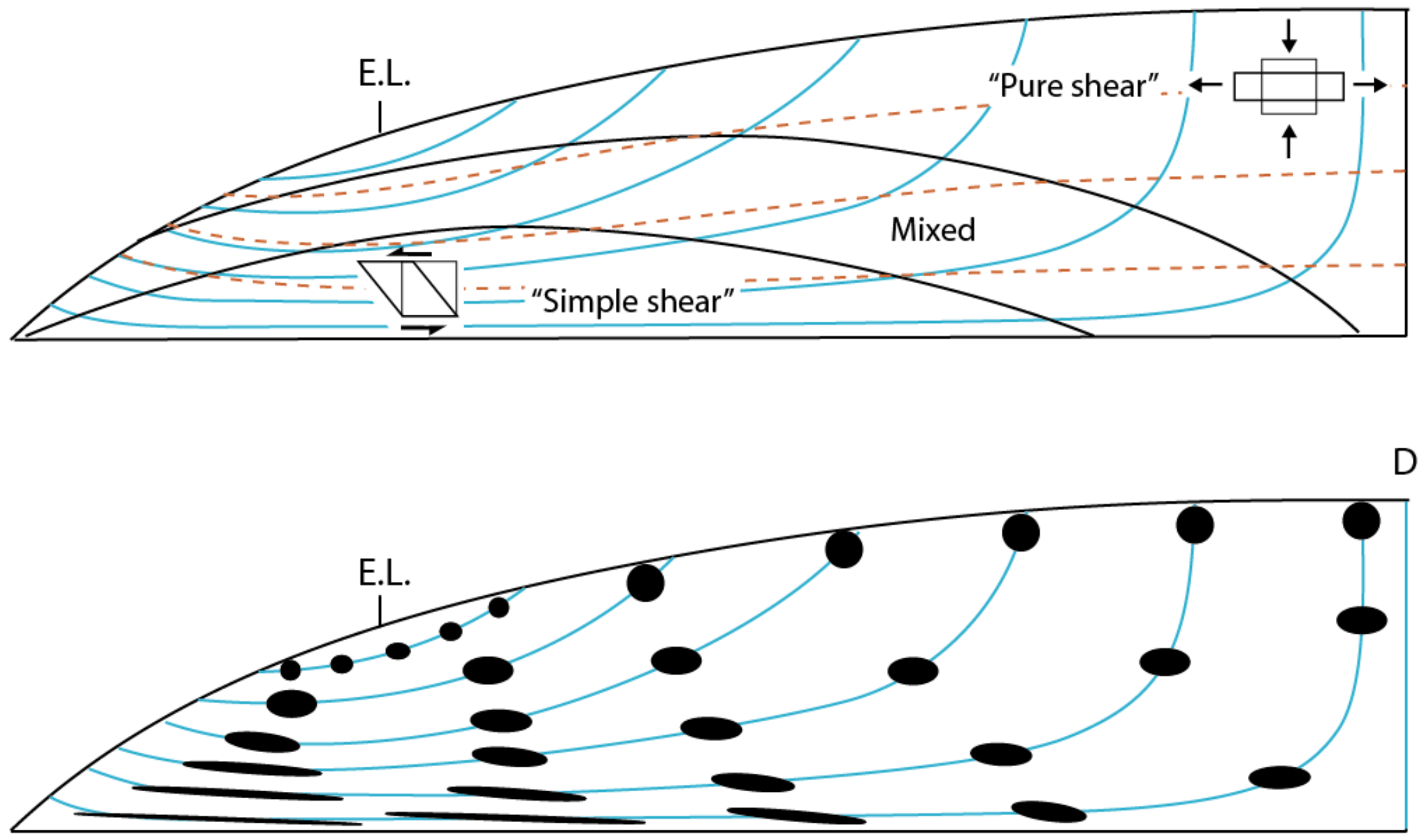

Fig. 5 


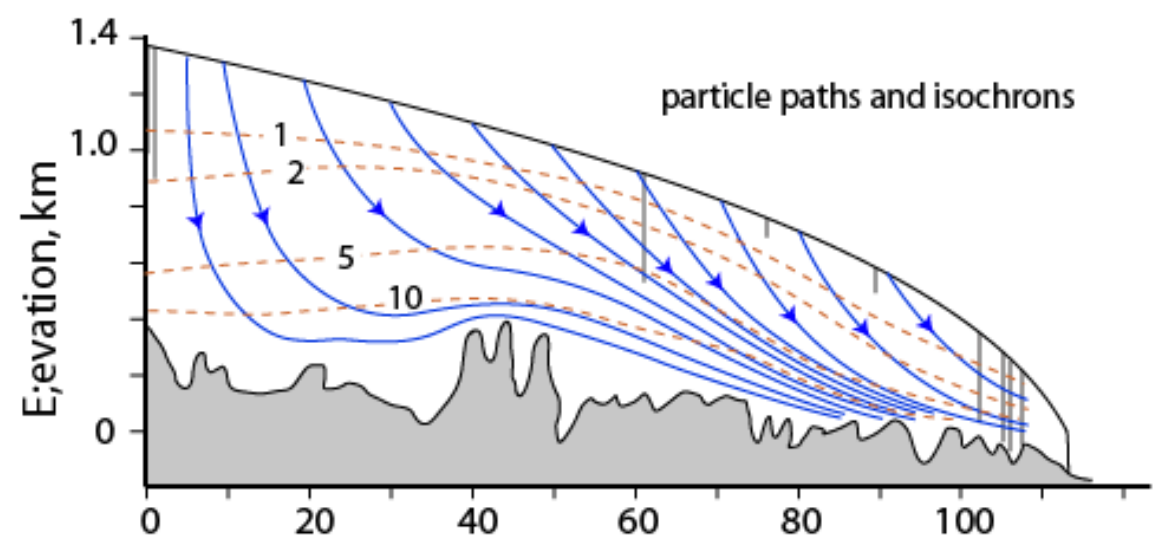

a

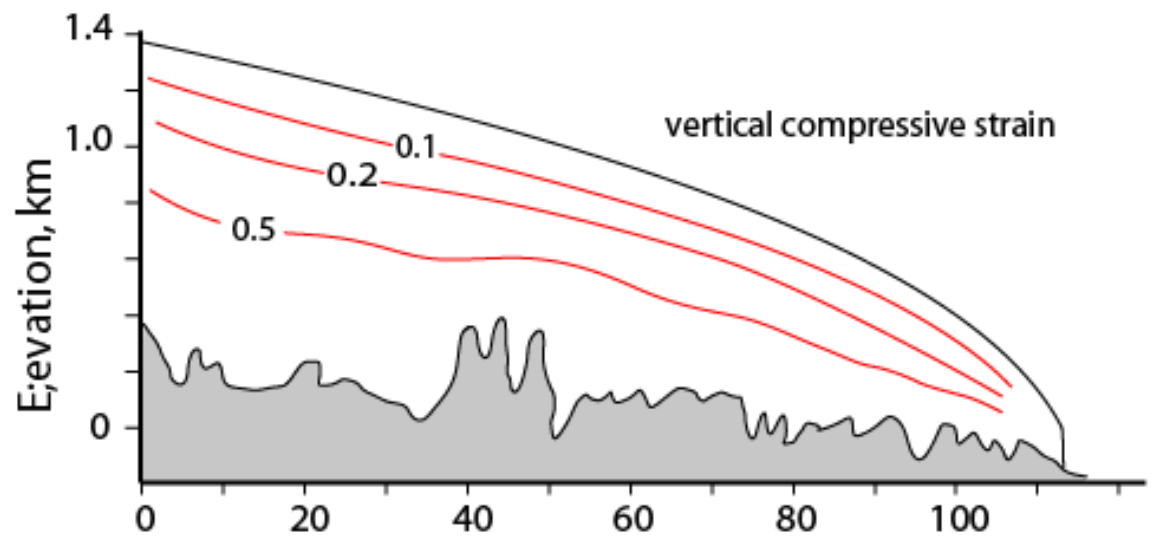

b

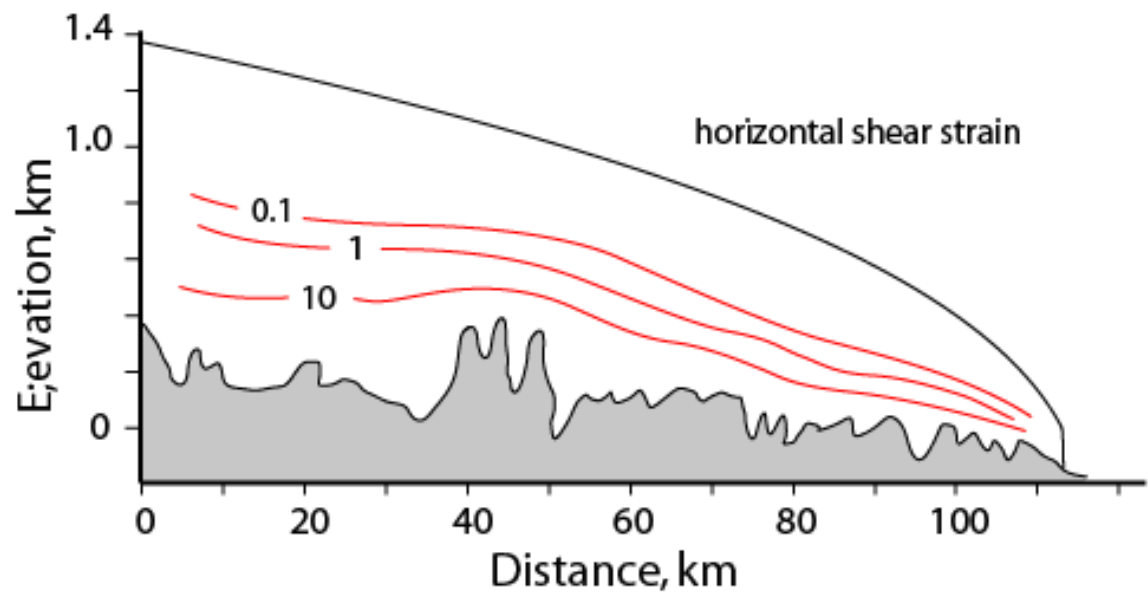

C

Fig. 6 


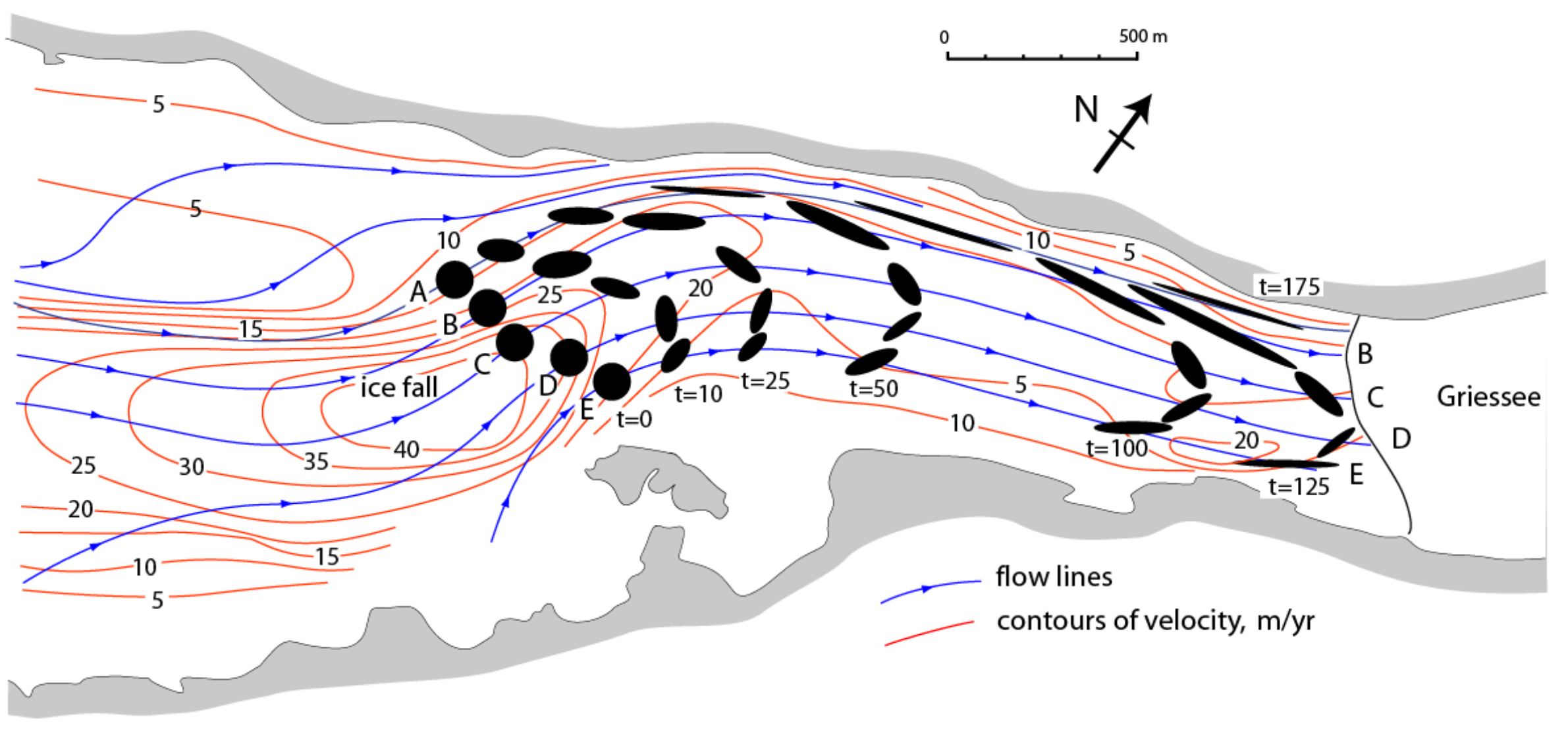

Fig. 7 


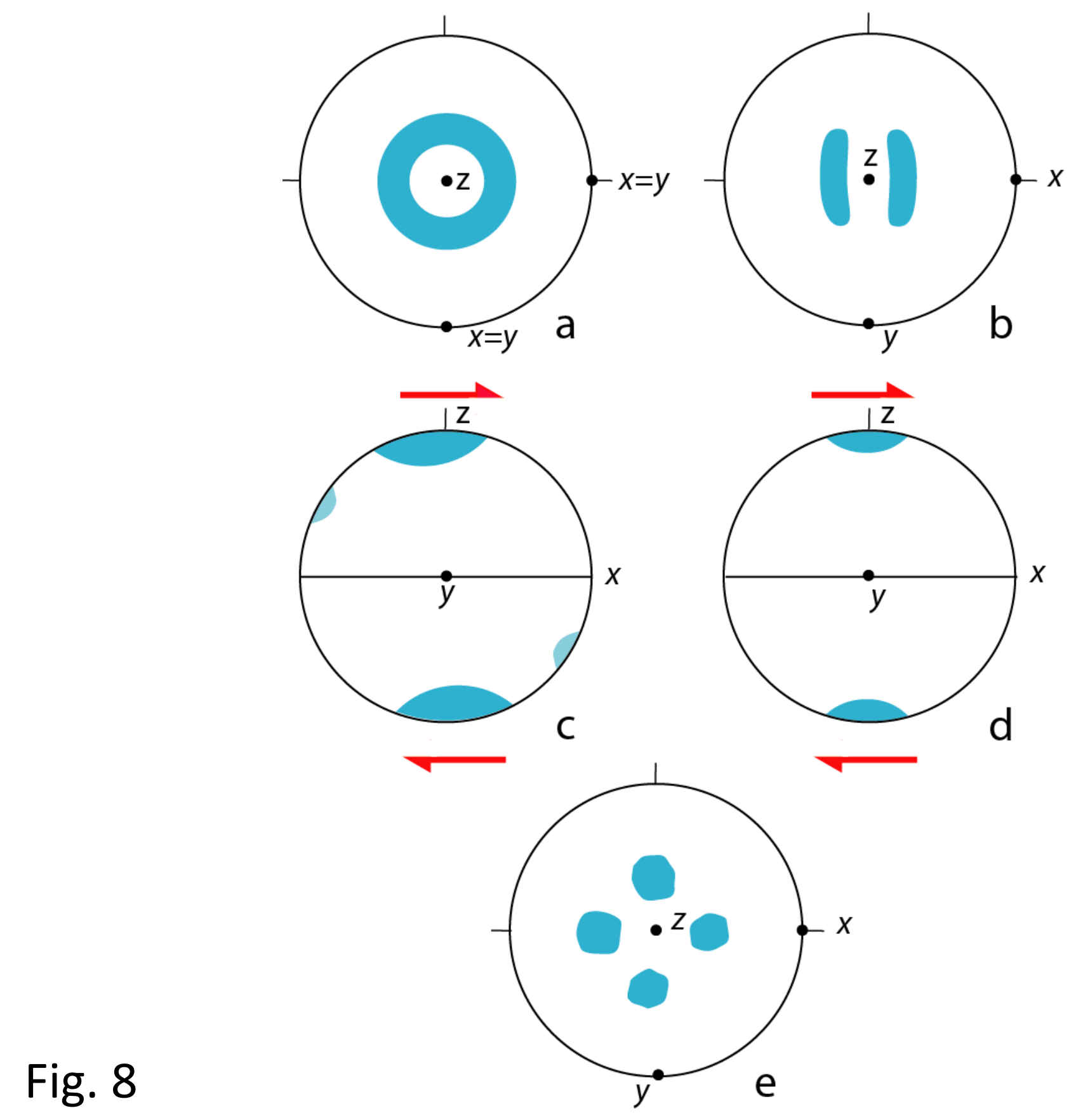



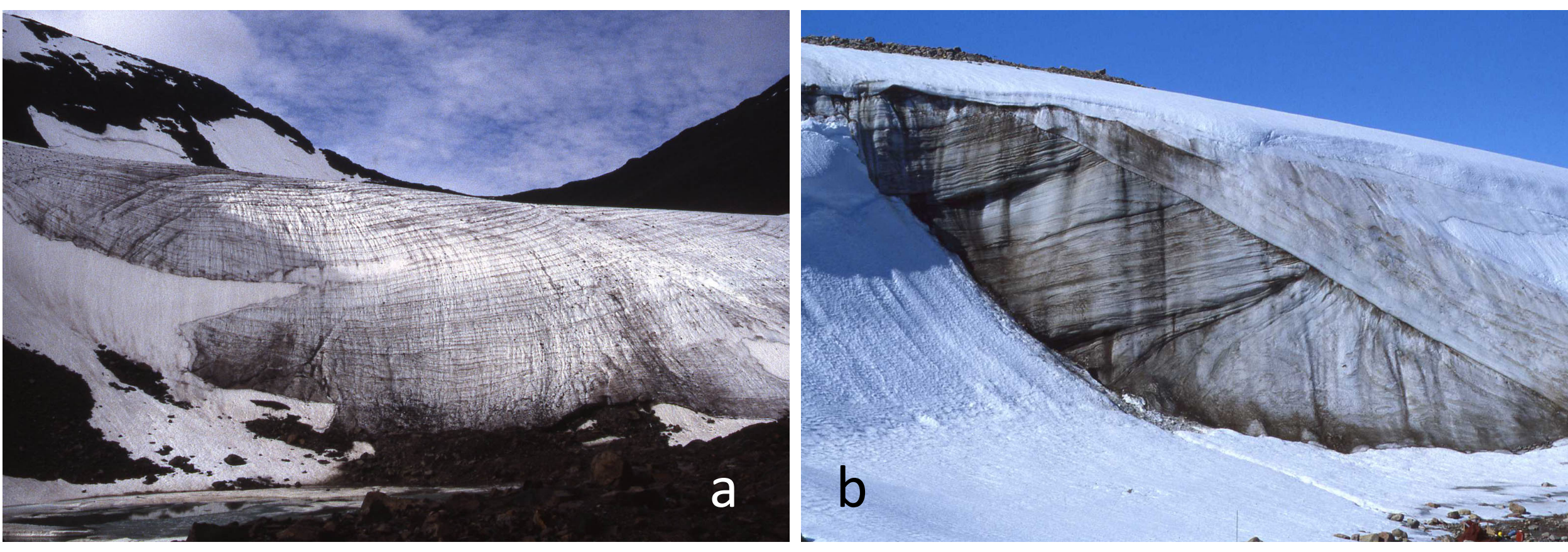

Fig. 9 


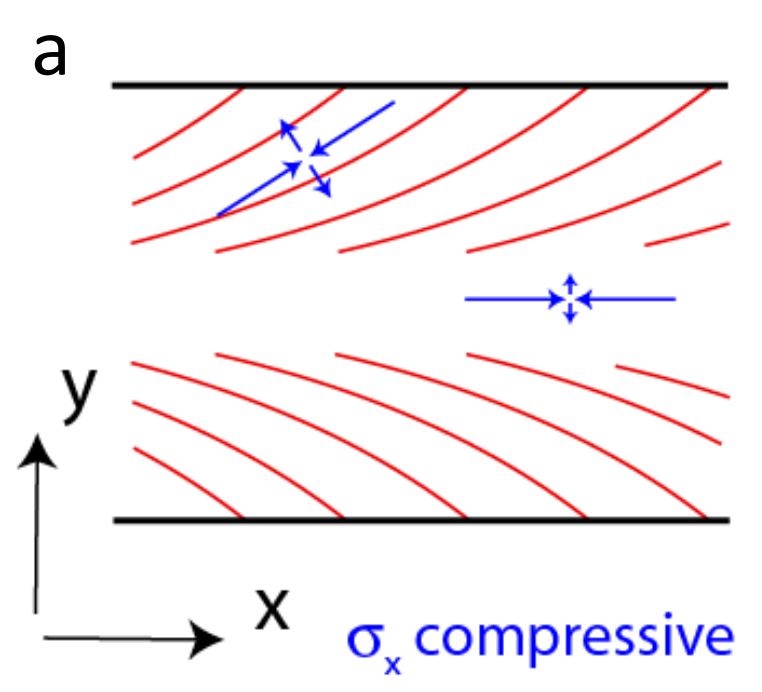

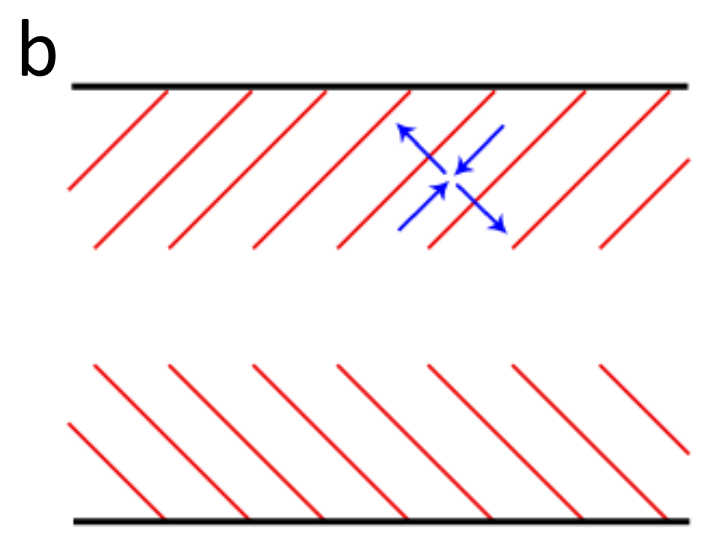

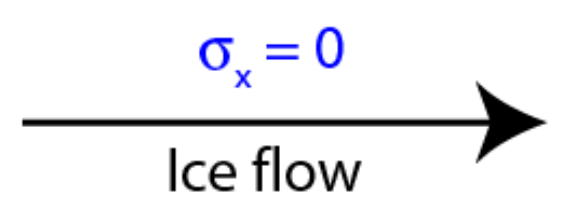

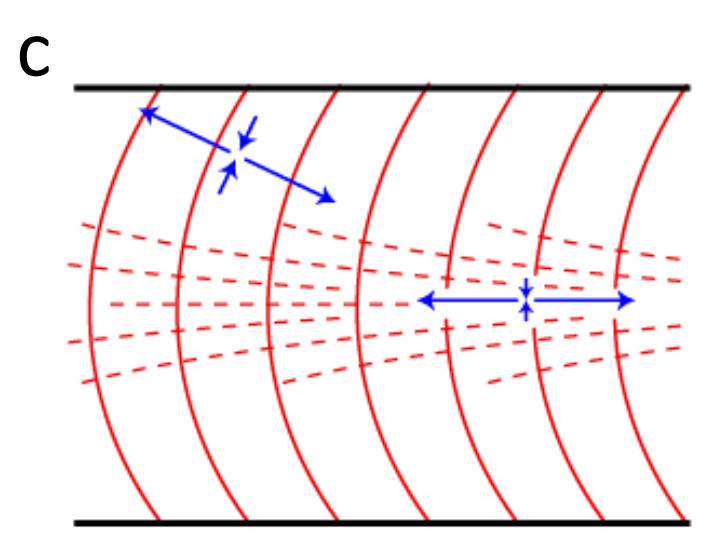

$\sigma_{x}$ tensile

Fig. 10 


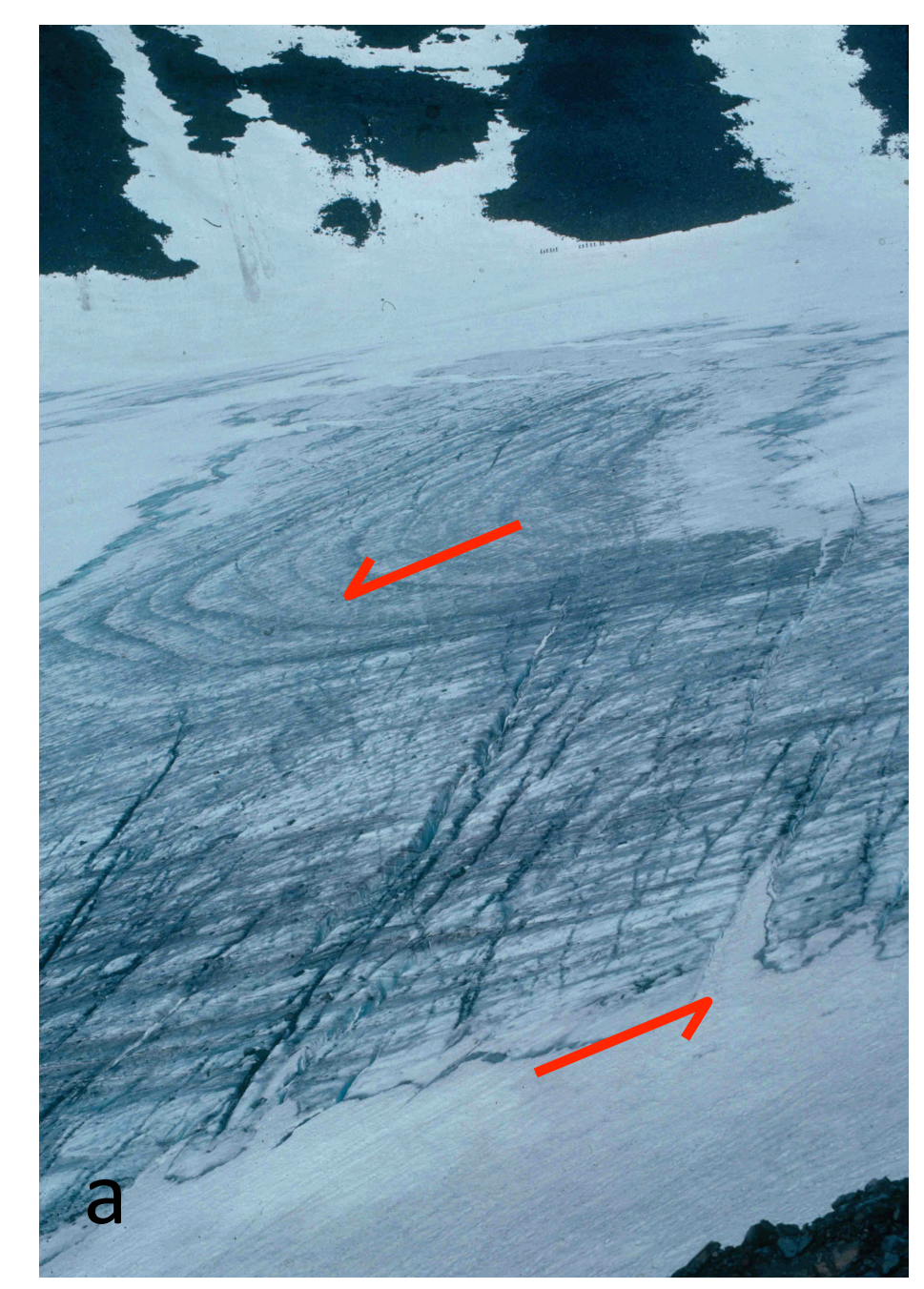

Fig. 11
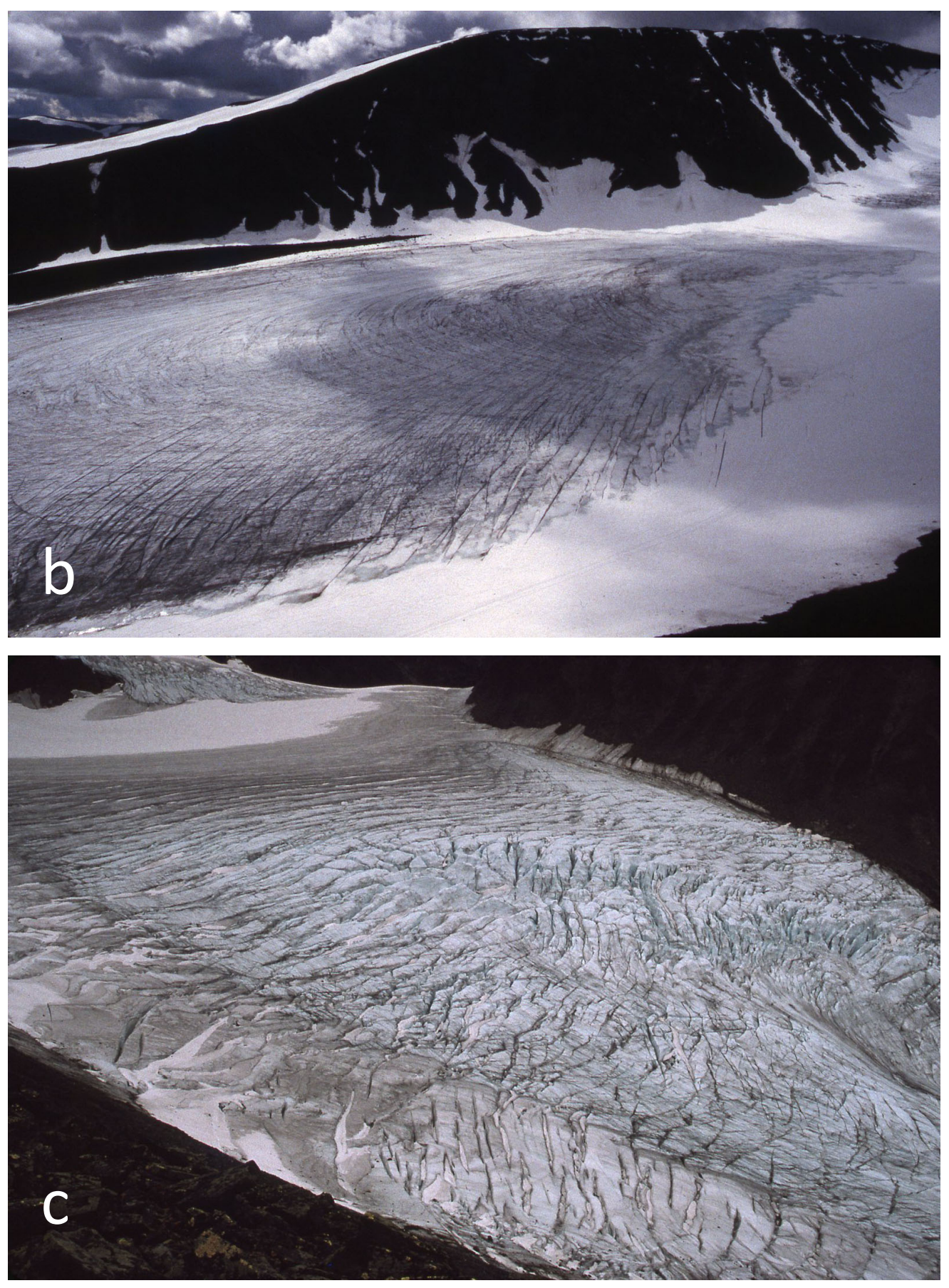
Fig. 12

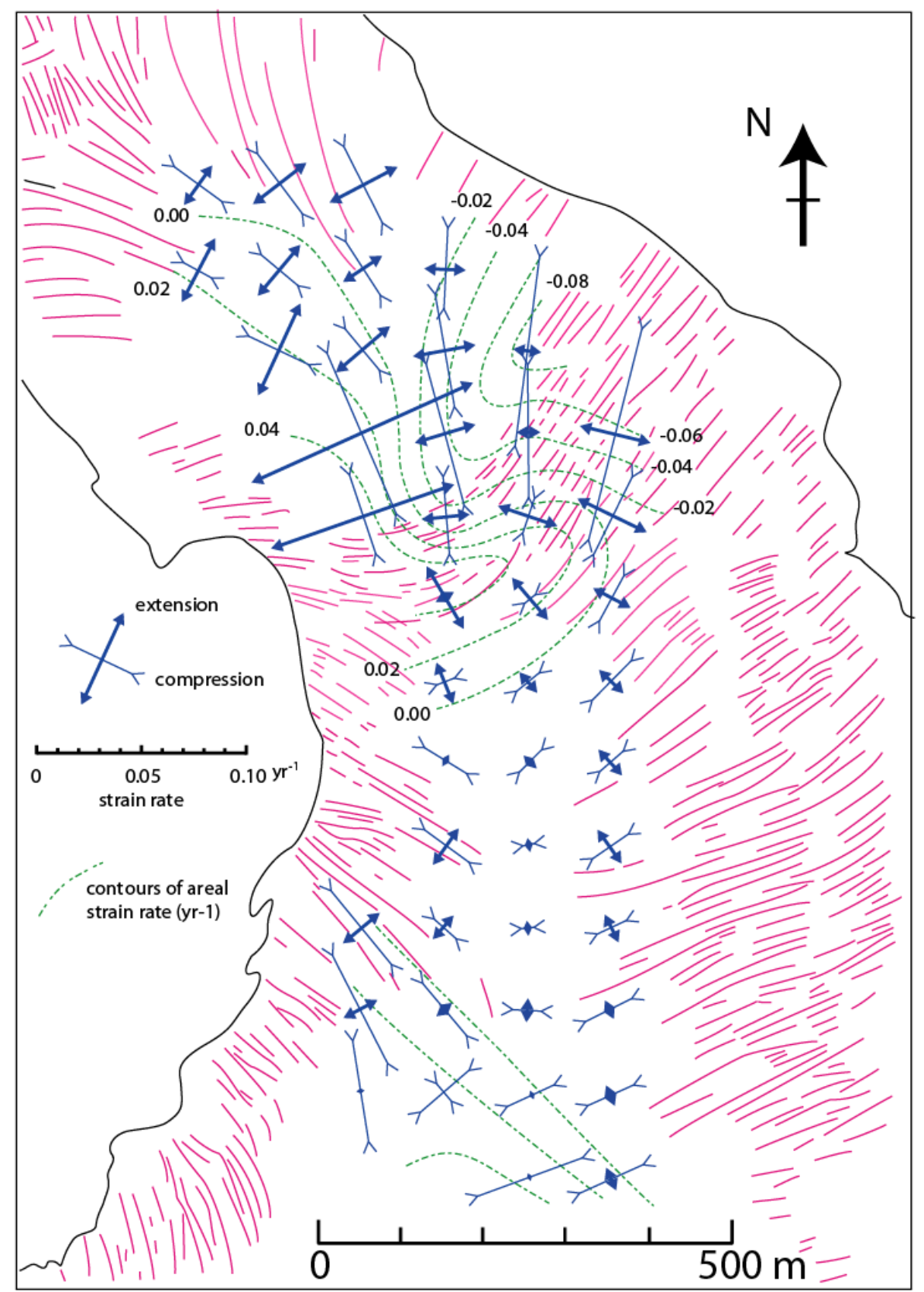




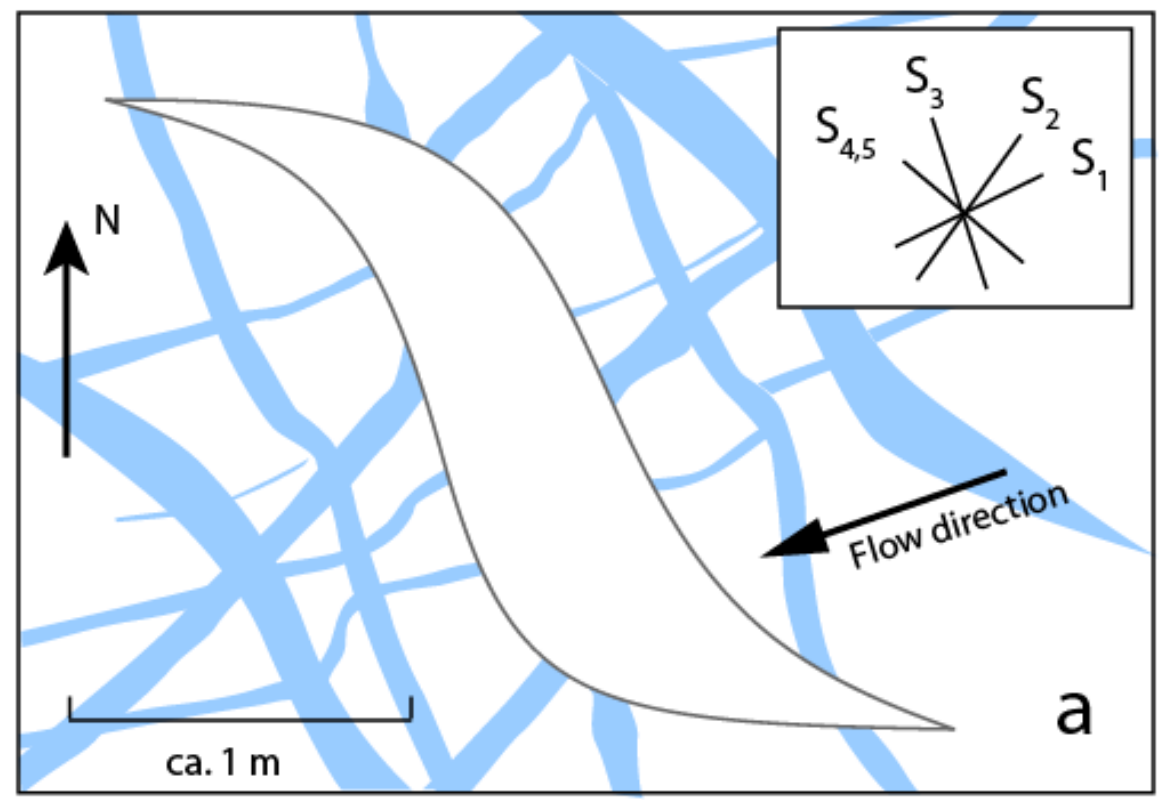

Fig. 14

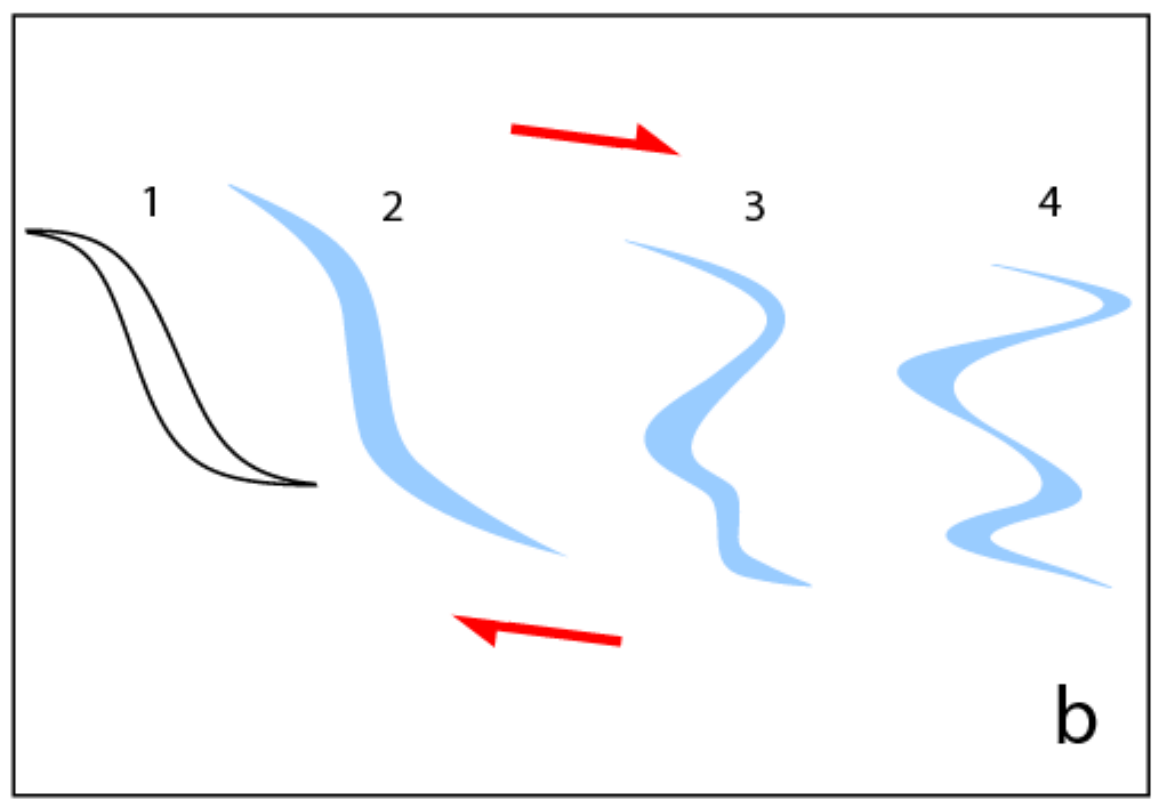




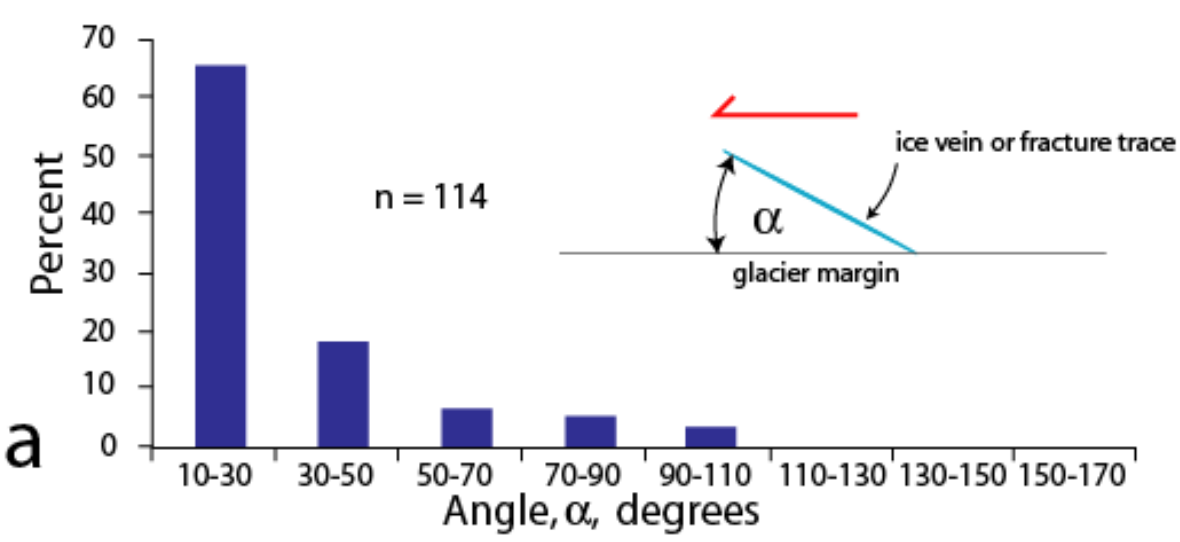

Fig. 15

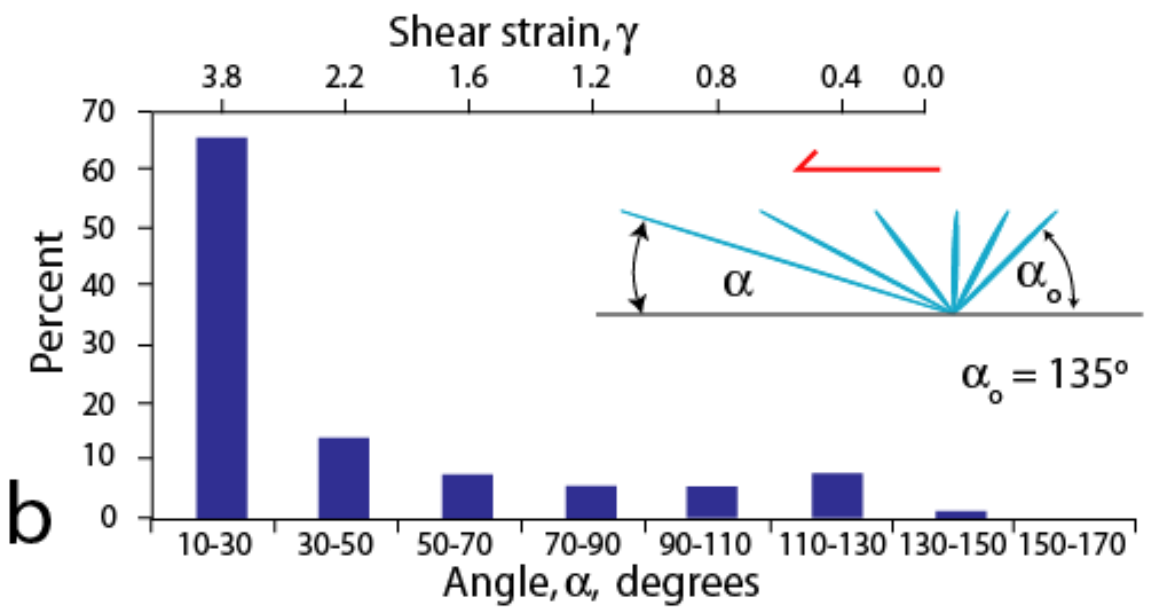

Shear strain, $\gamma$

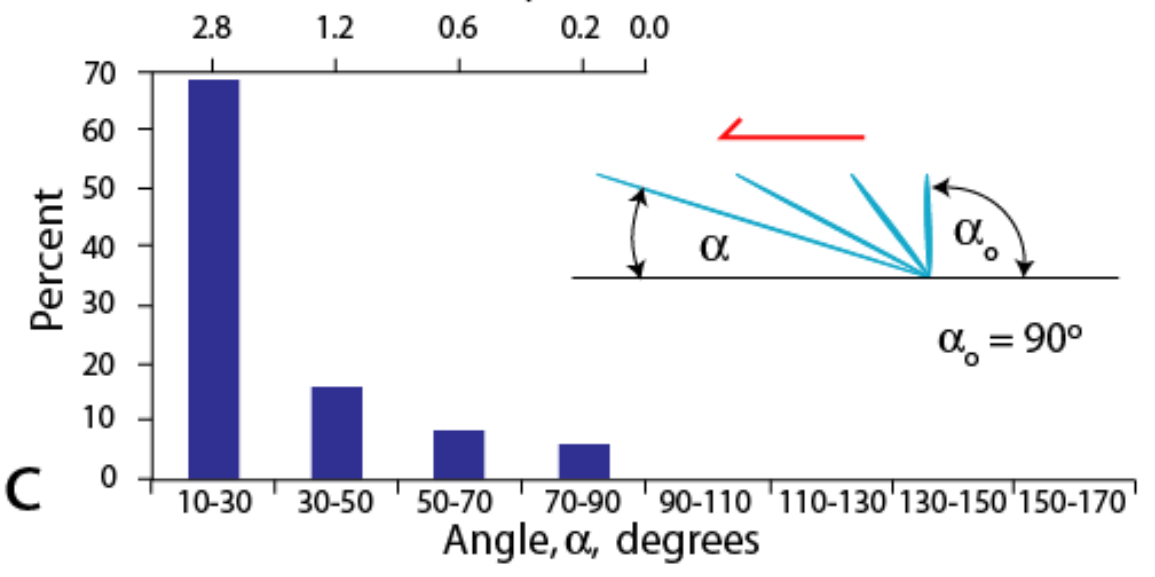




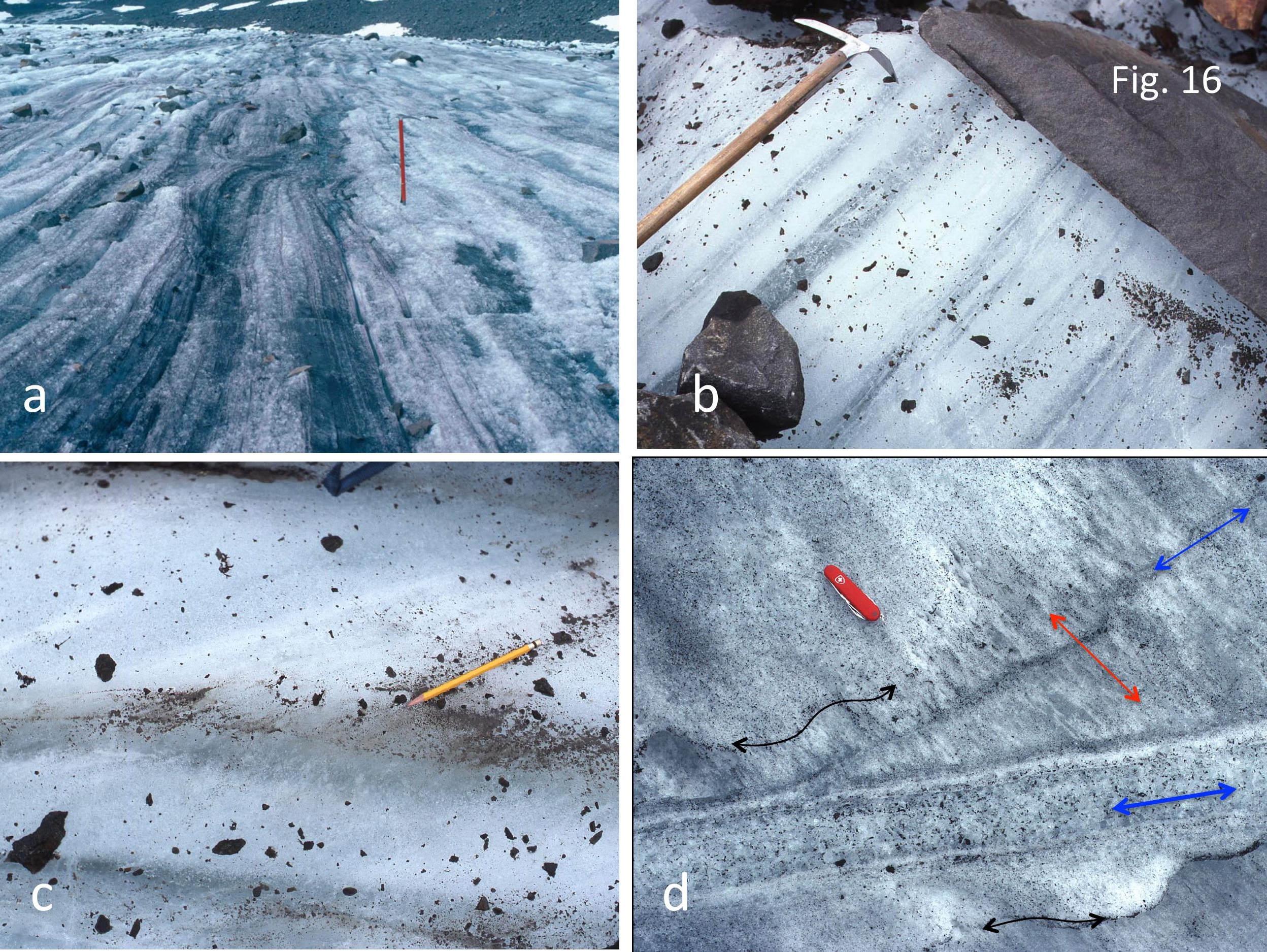



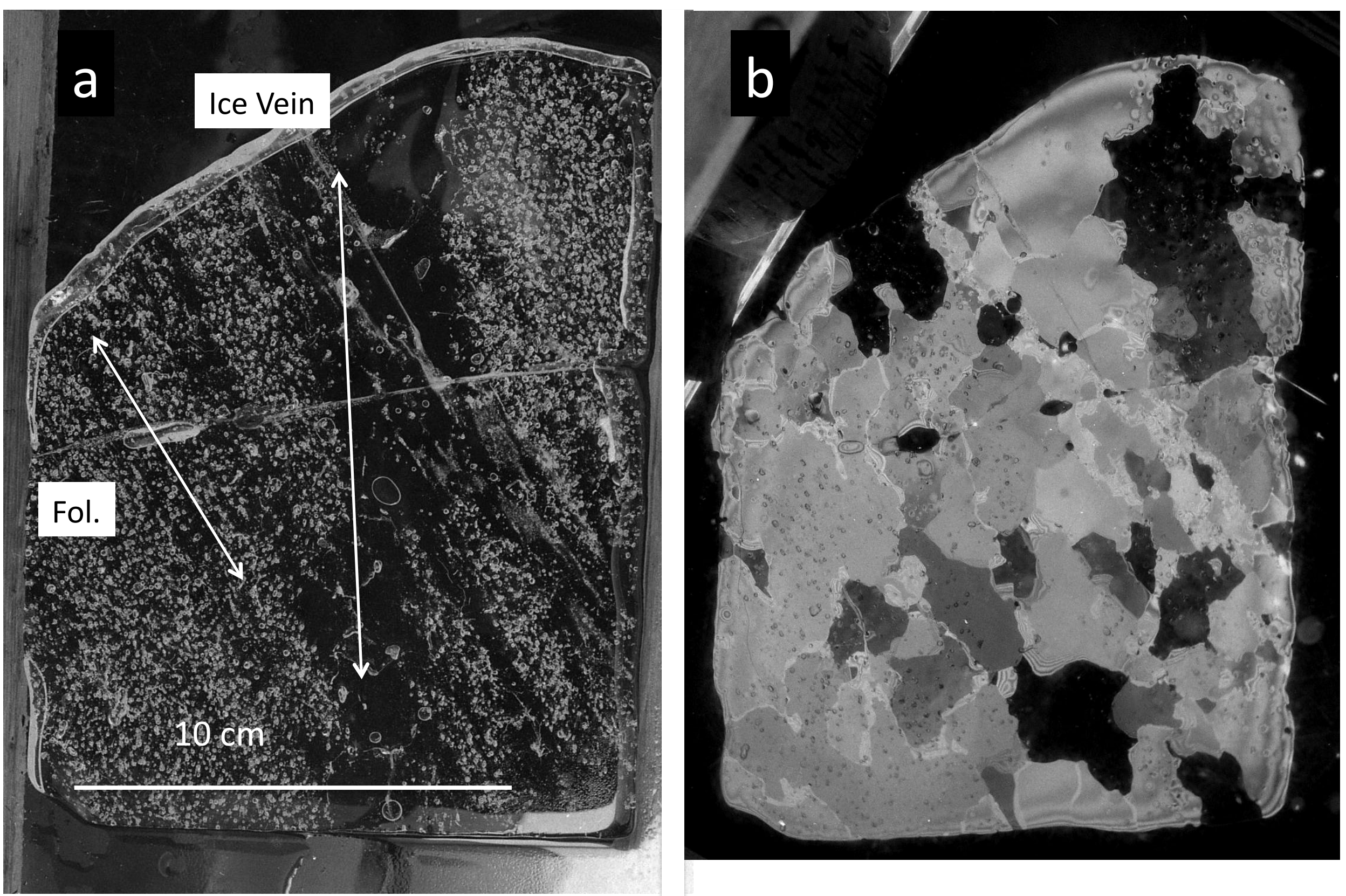

Fig. 17 


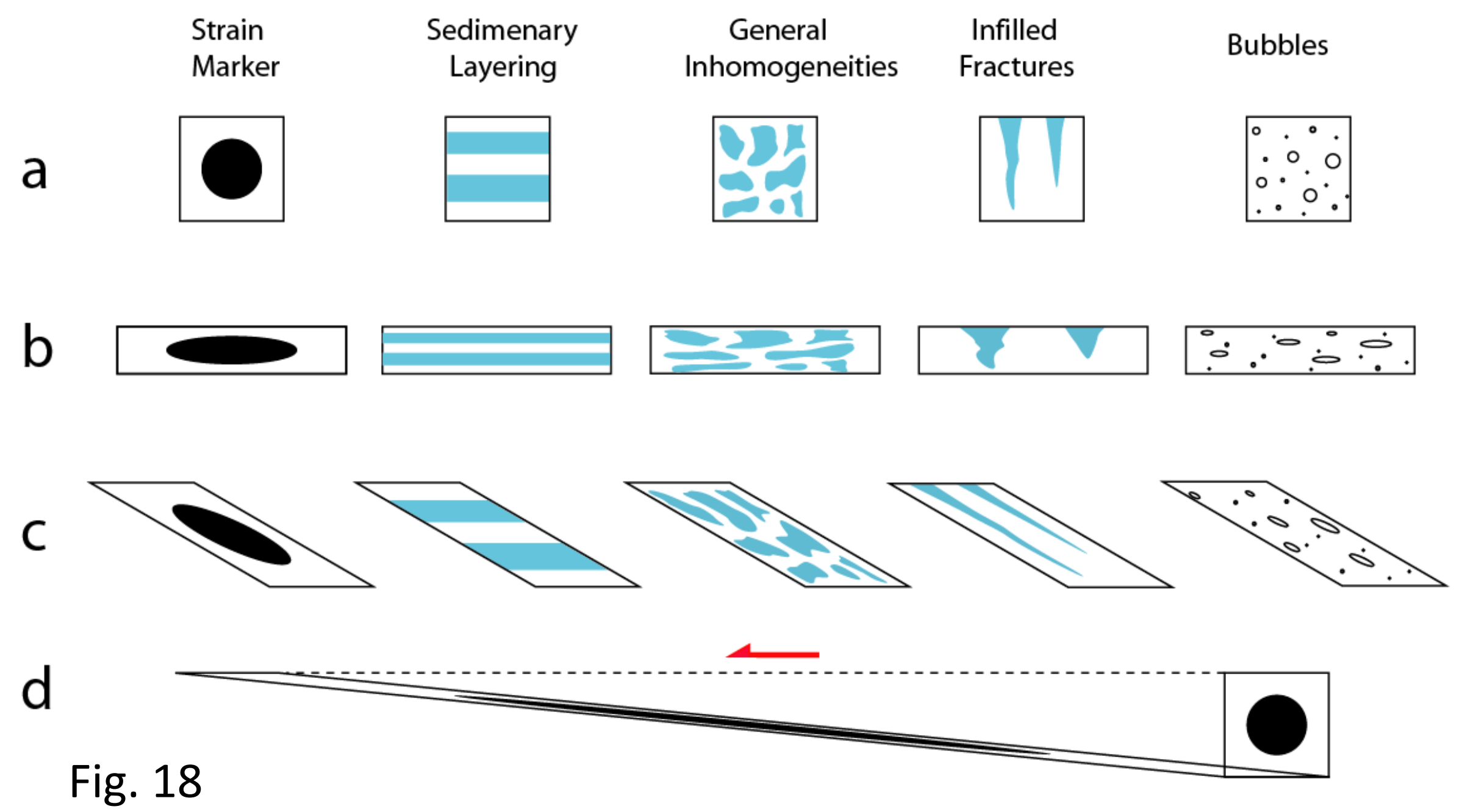



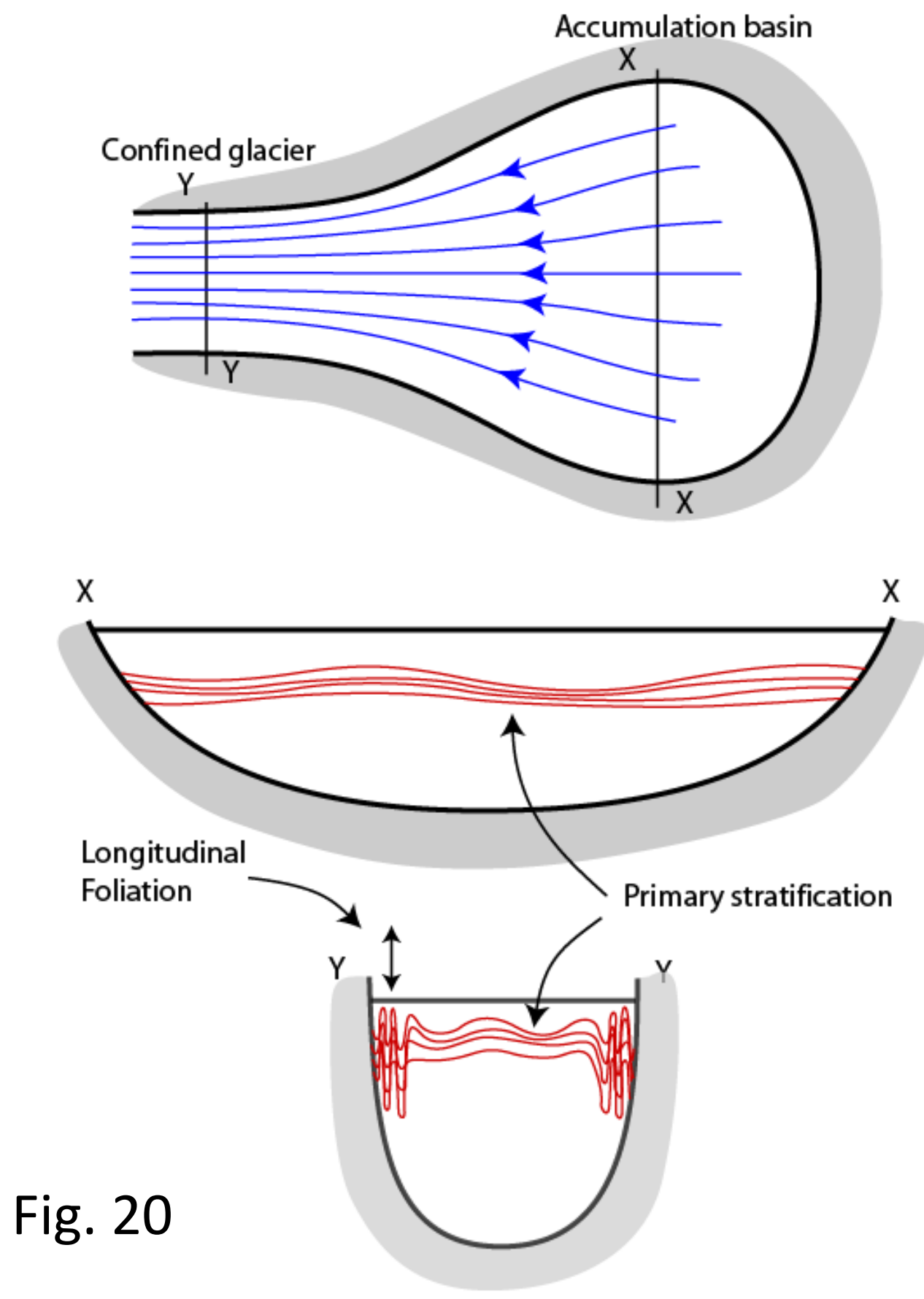


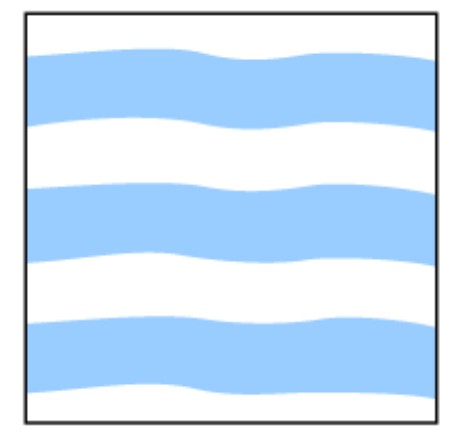

subhorizontal primary stratification

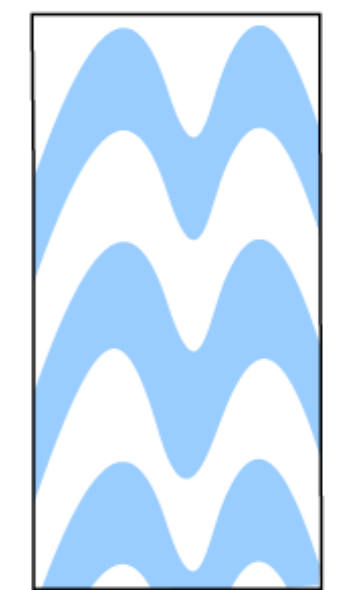

undulose stratification amplified to from folds

folds tighten and start to become dismembered as foliation develops

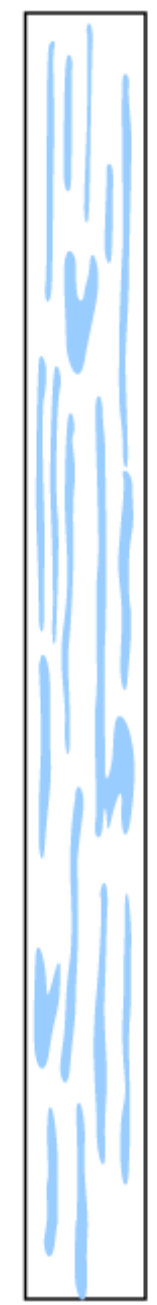

stratification

increased shortening

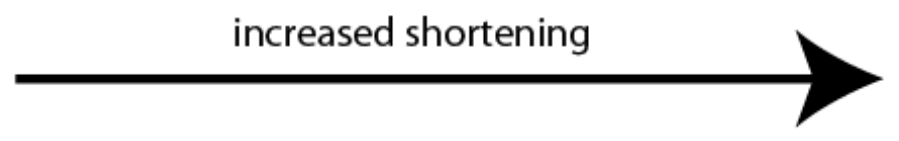

Fig. 21

mostly transposed into foliation 


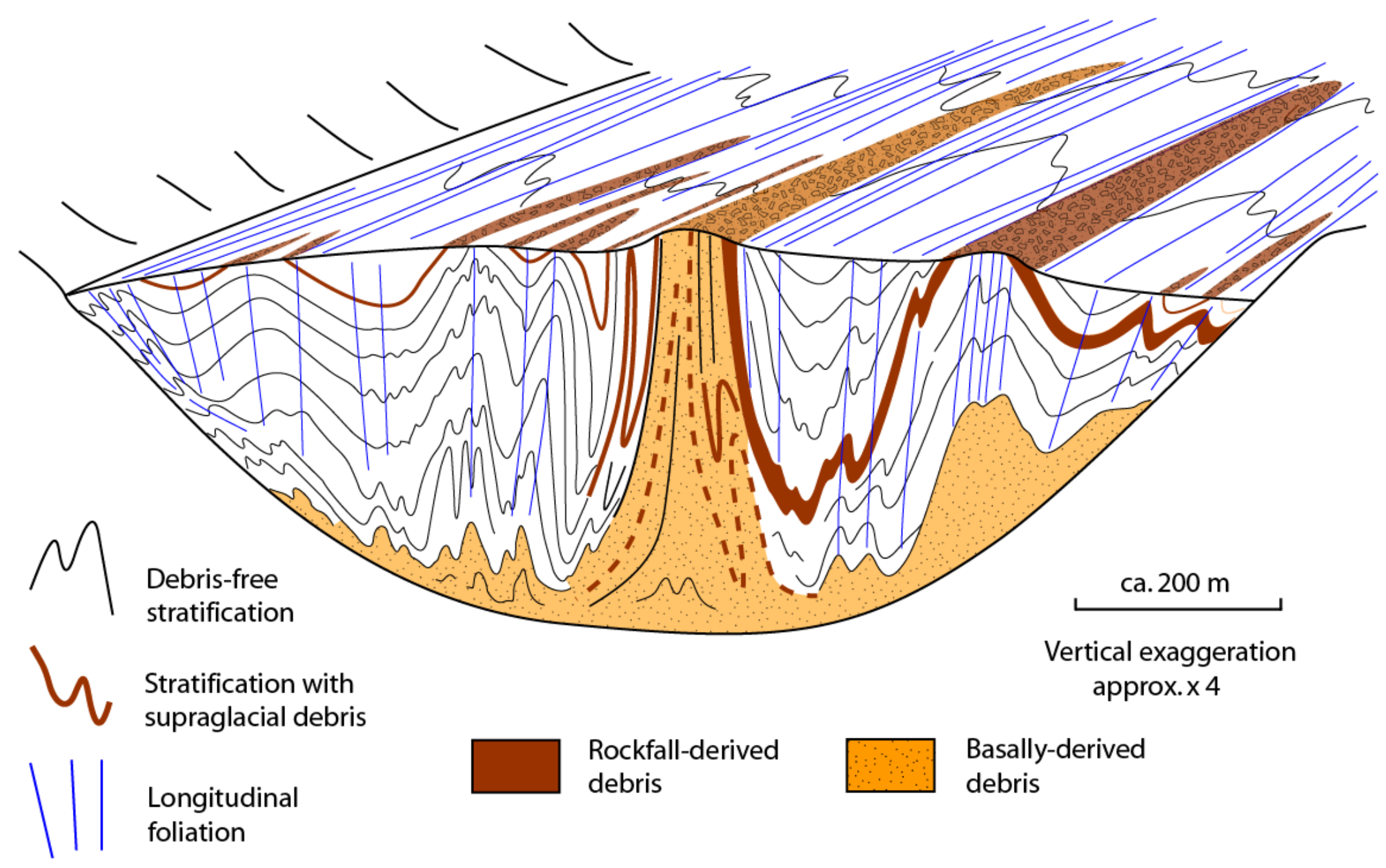

Fig. 22 


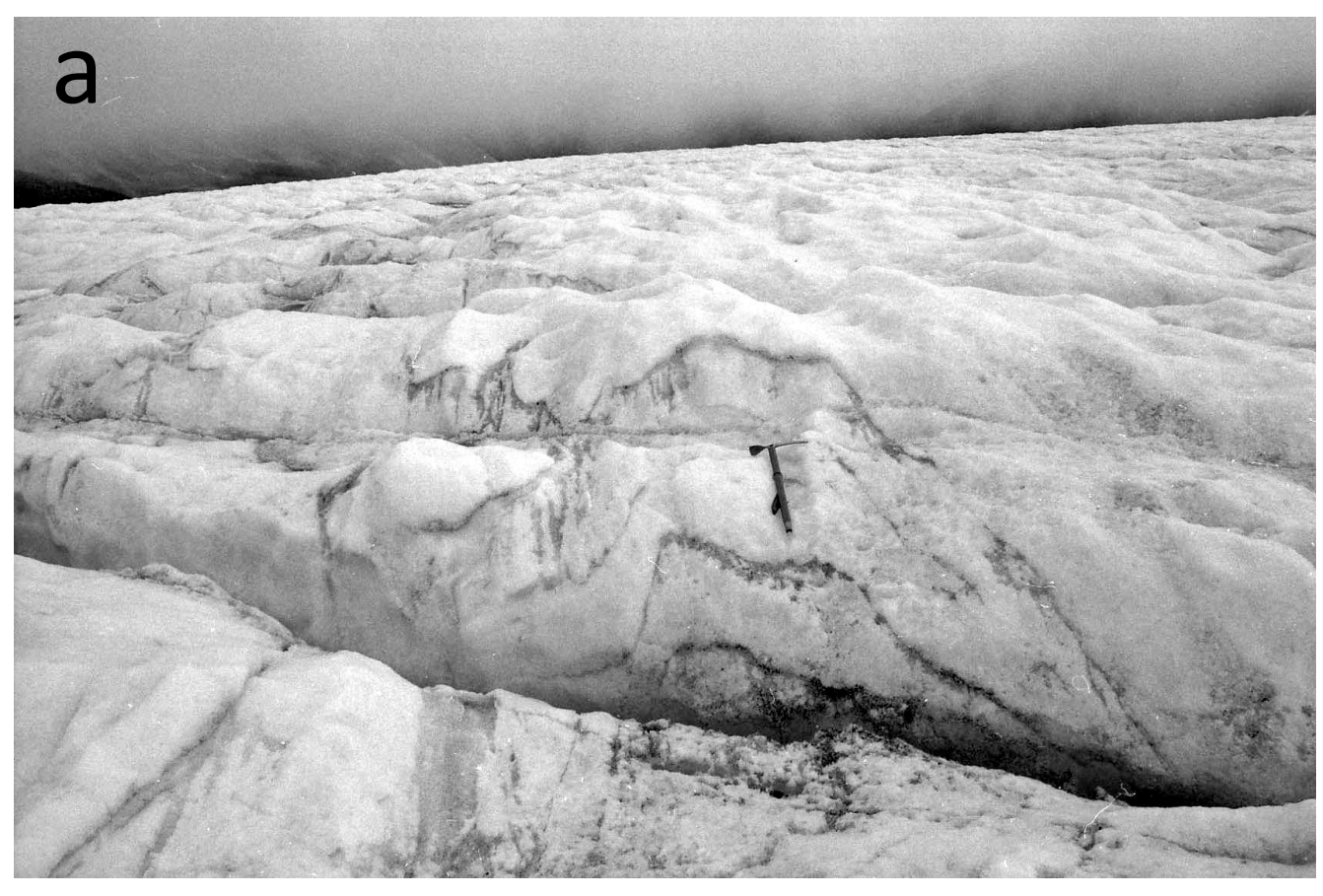

Fig. 23

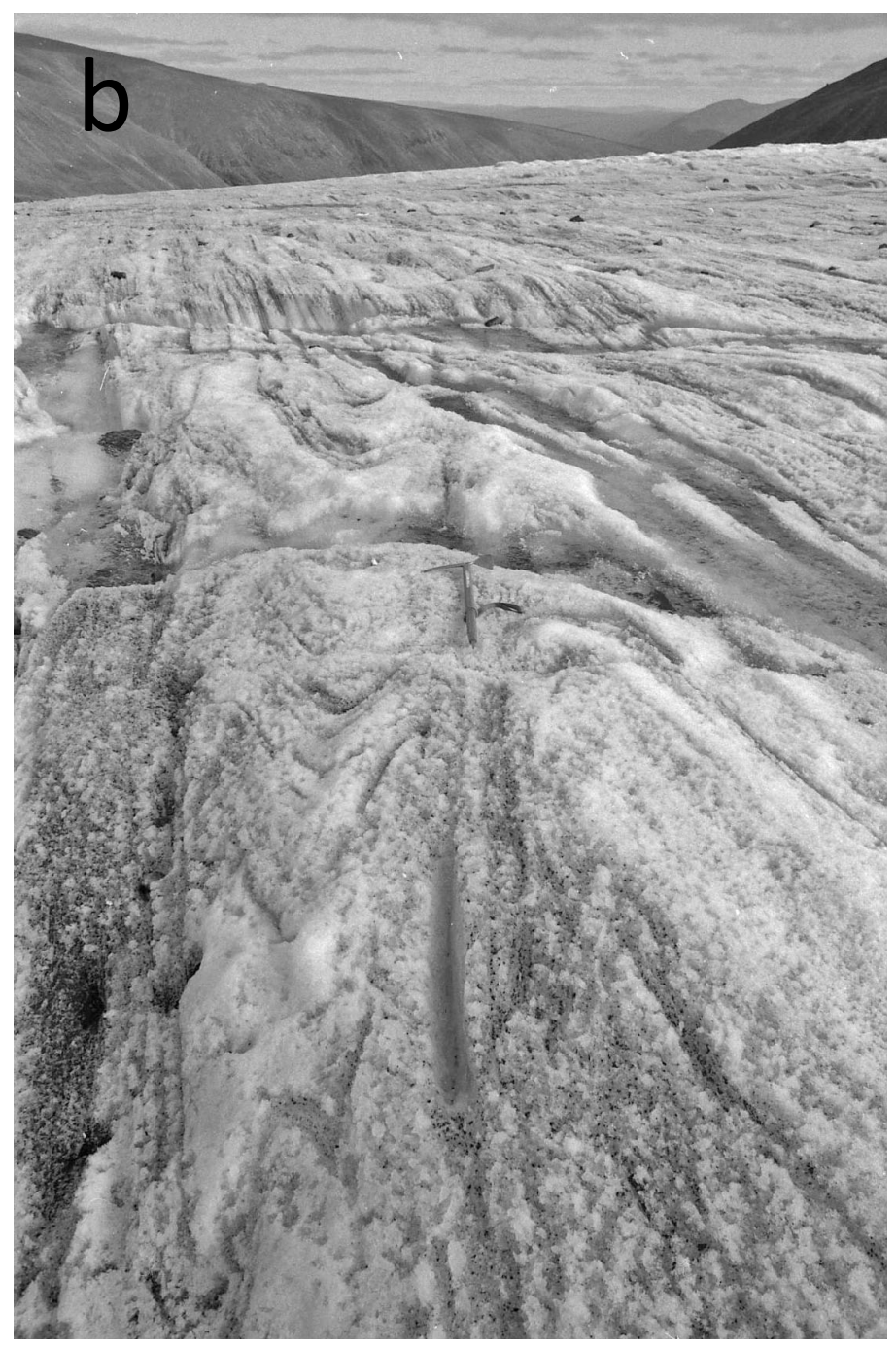




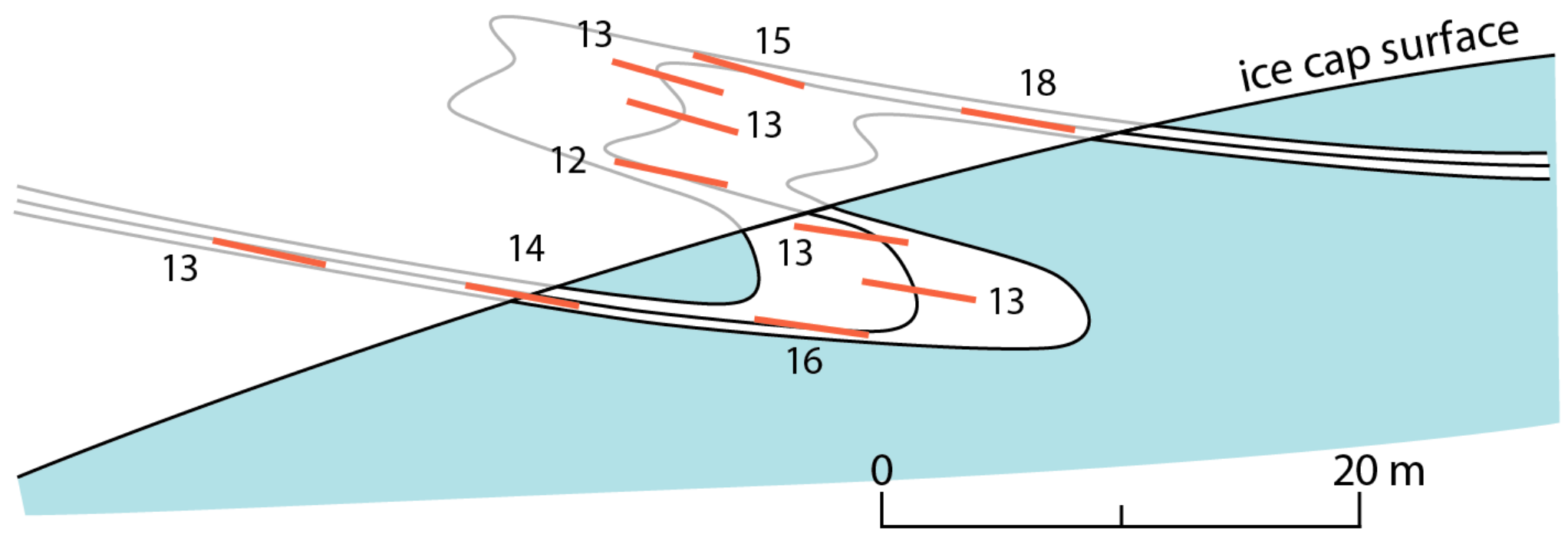

Fig. 24 


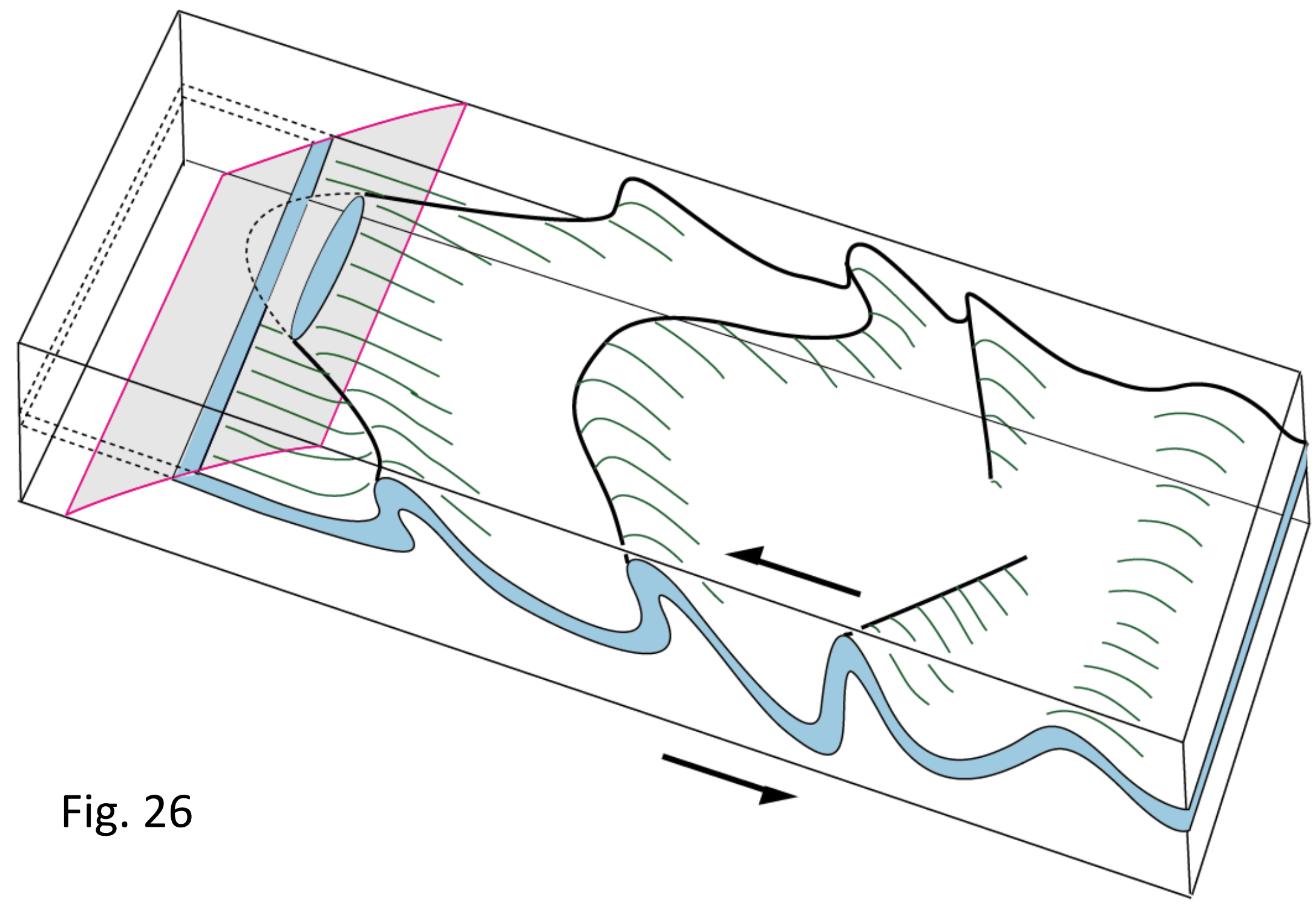




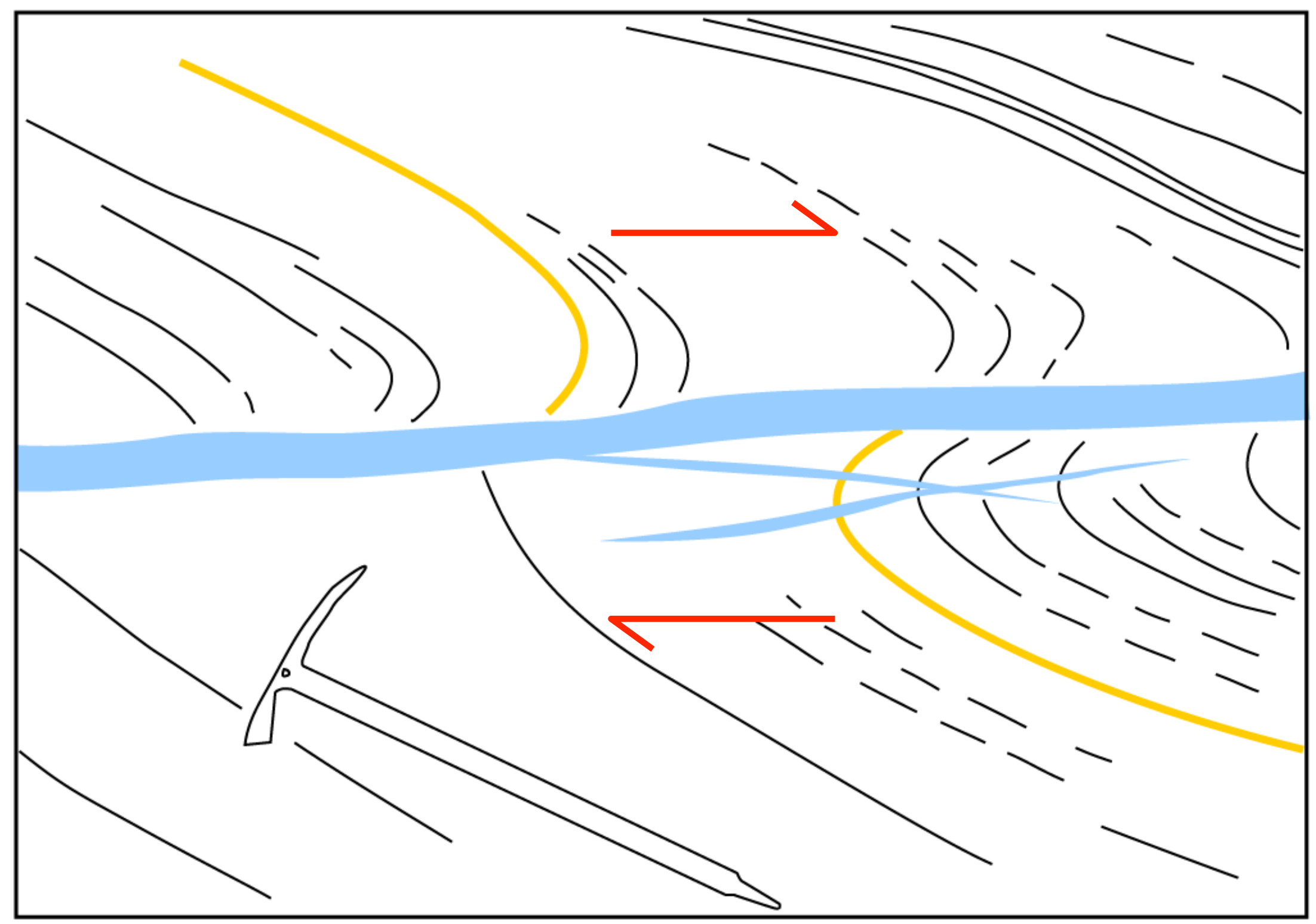

Fig. 27 


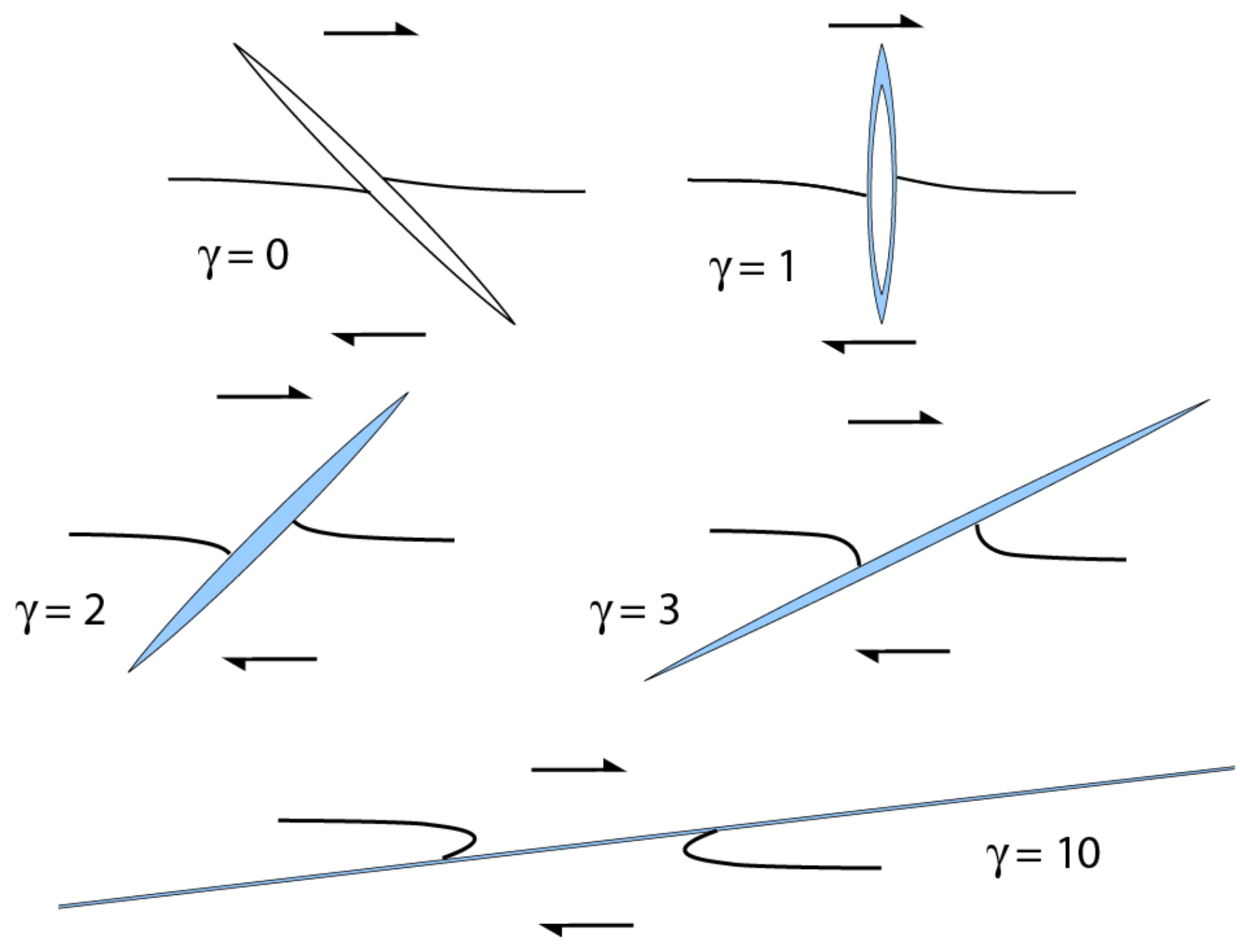

Fig. 28 


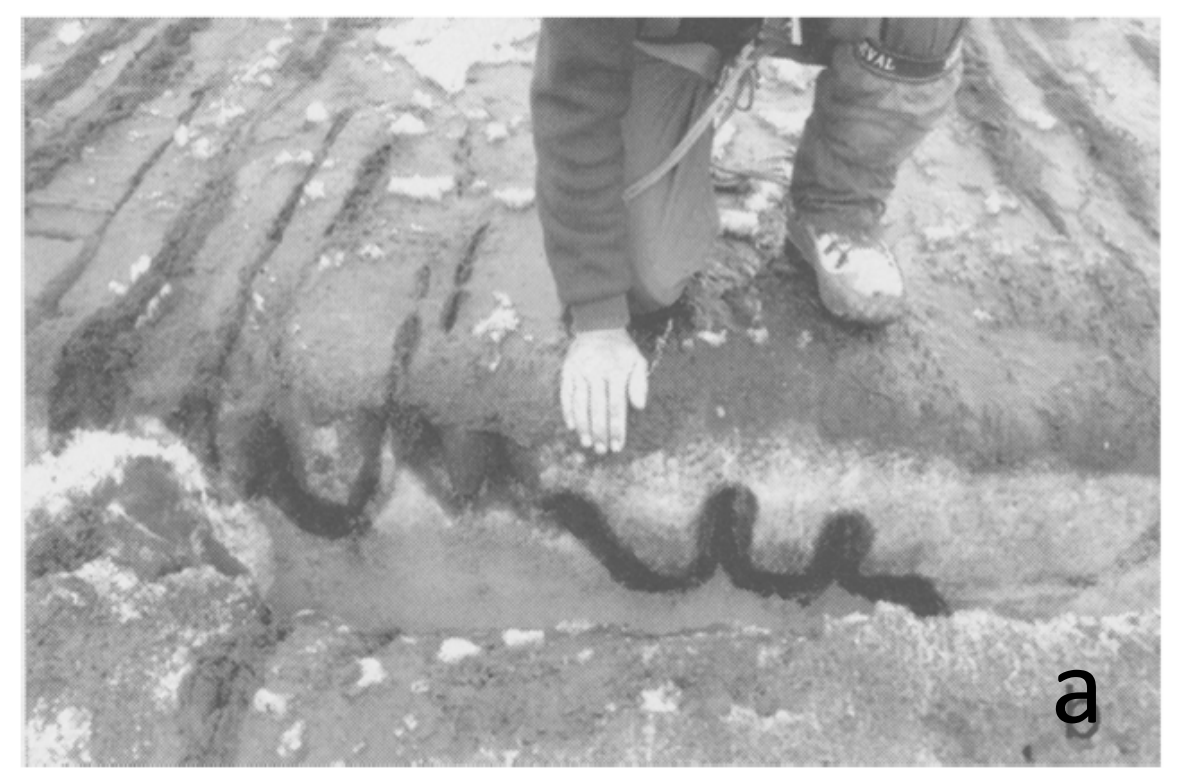

Fig. 29

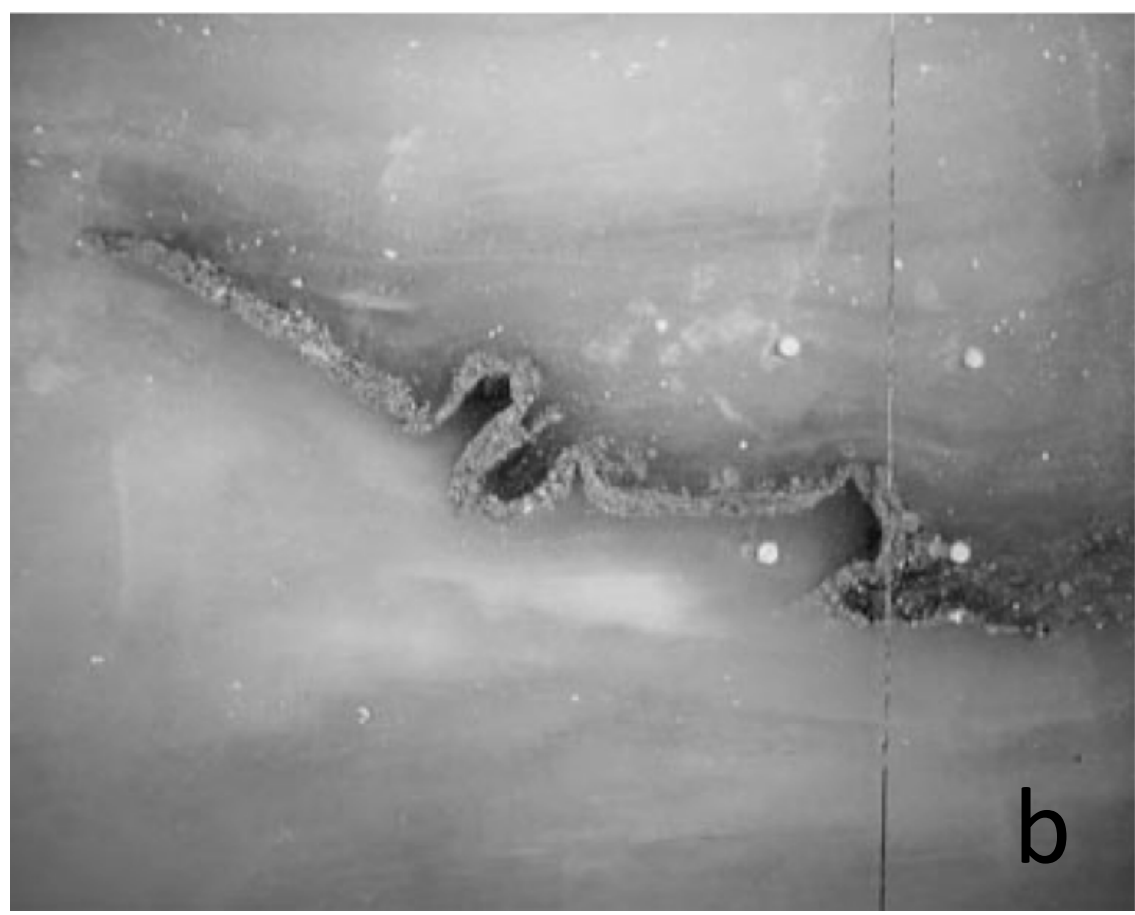


25

\section{$2 \mathrm{~cm}$}

$\ldots$

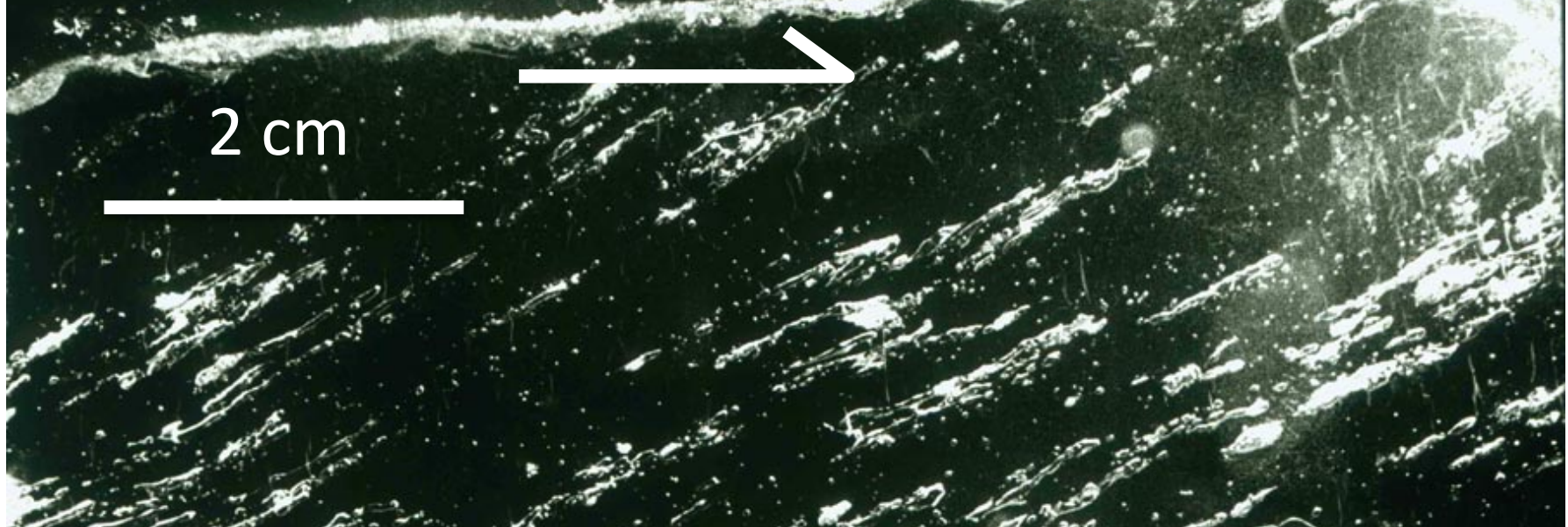
in

of 000 as

Fig. 30

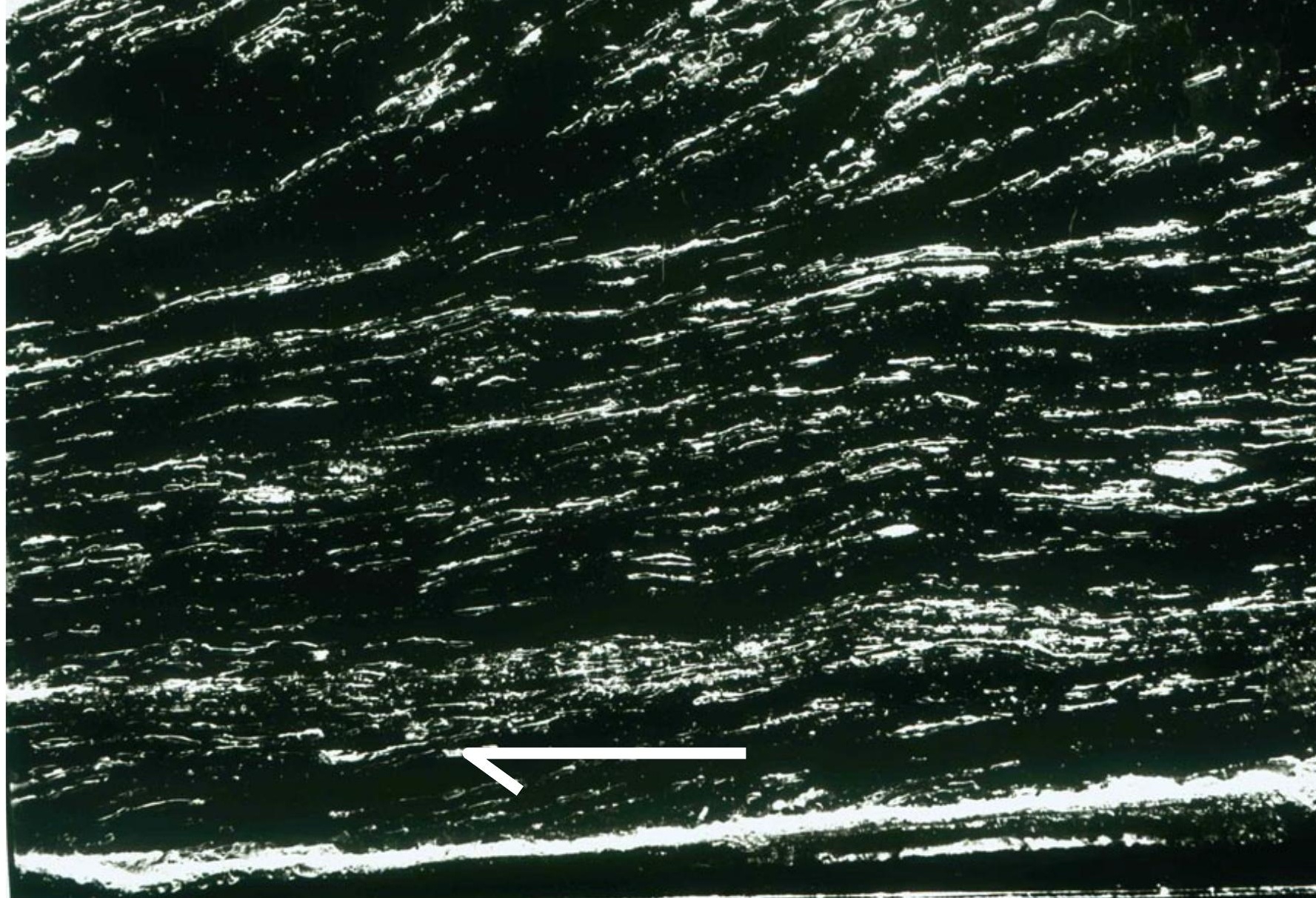




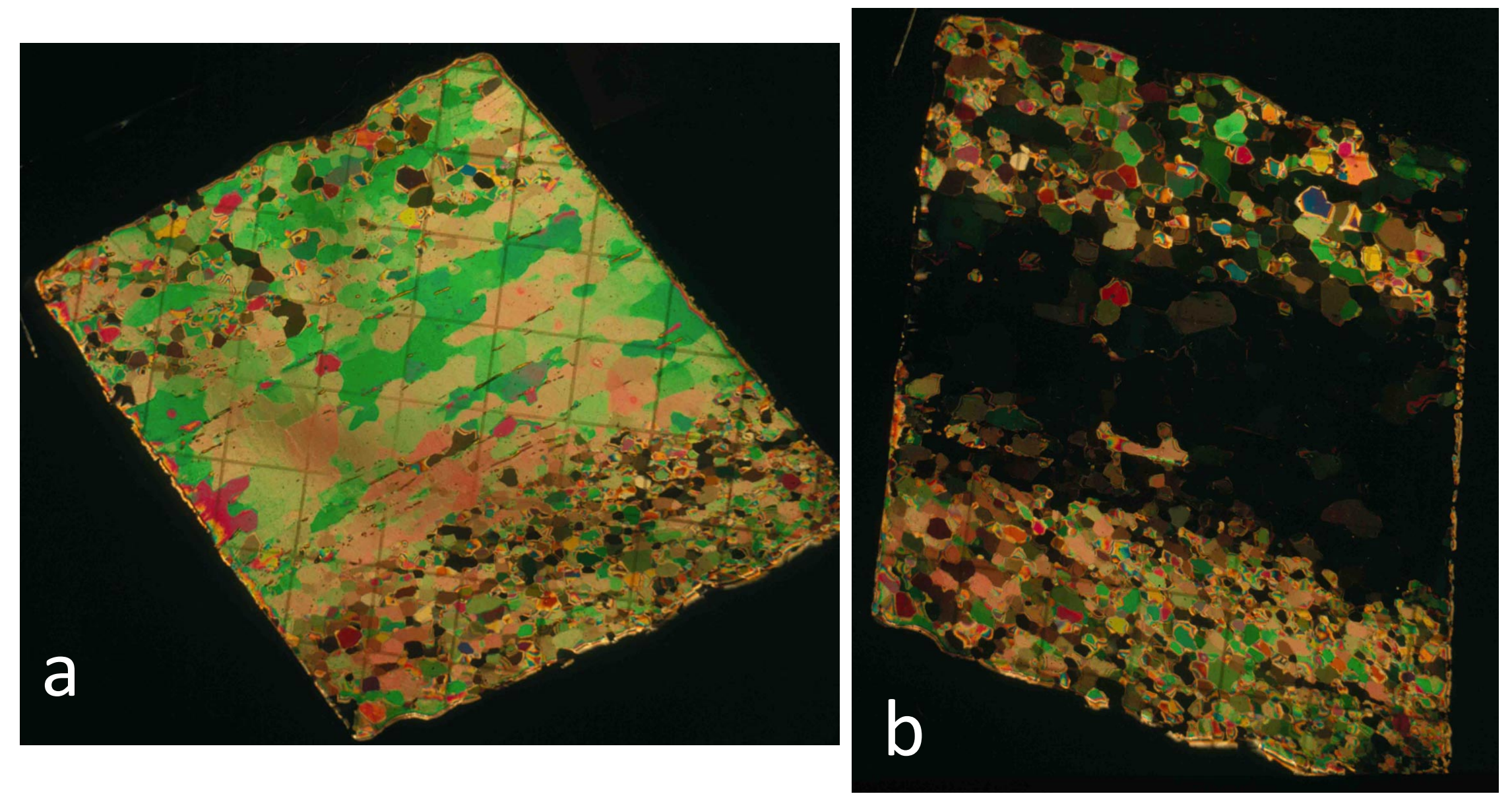

Fig. 31 

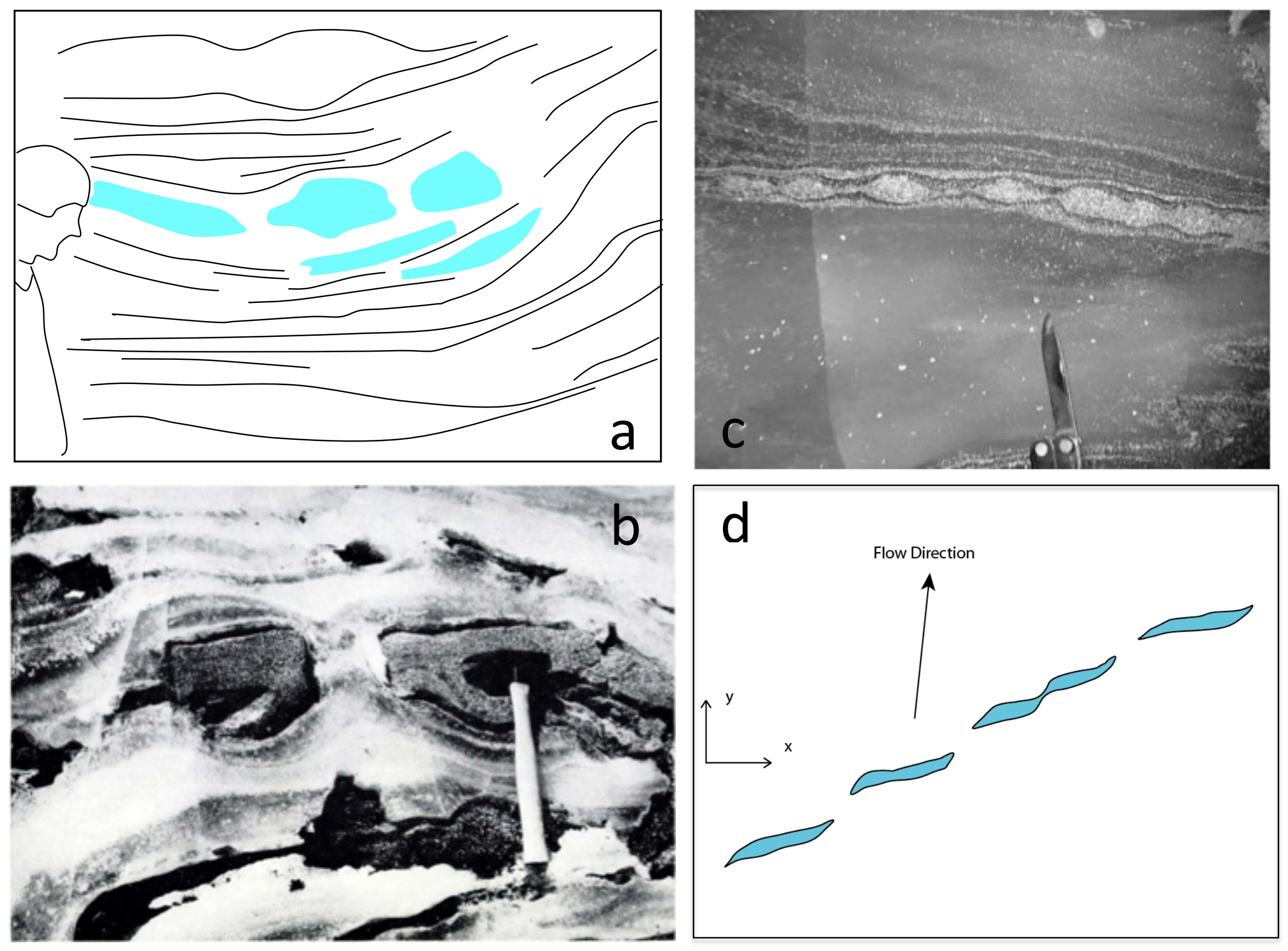

Fig. 32 


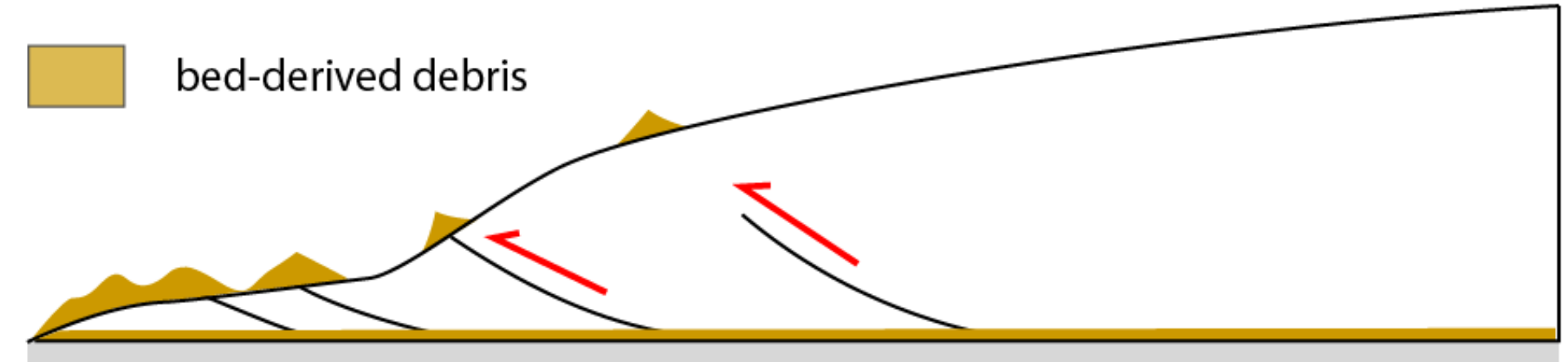

a

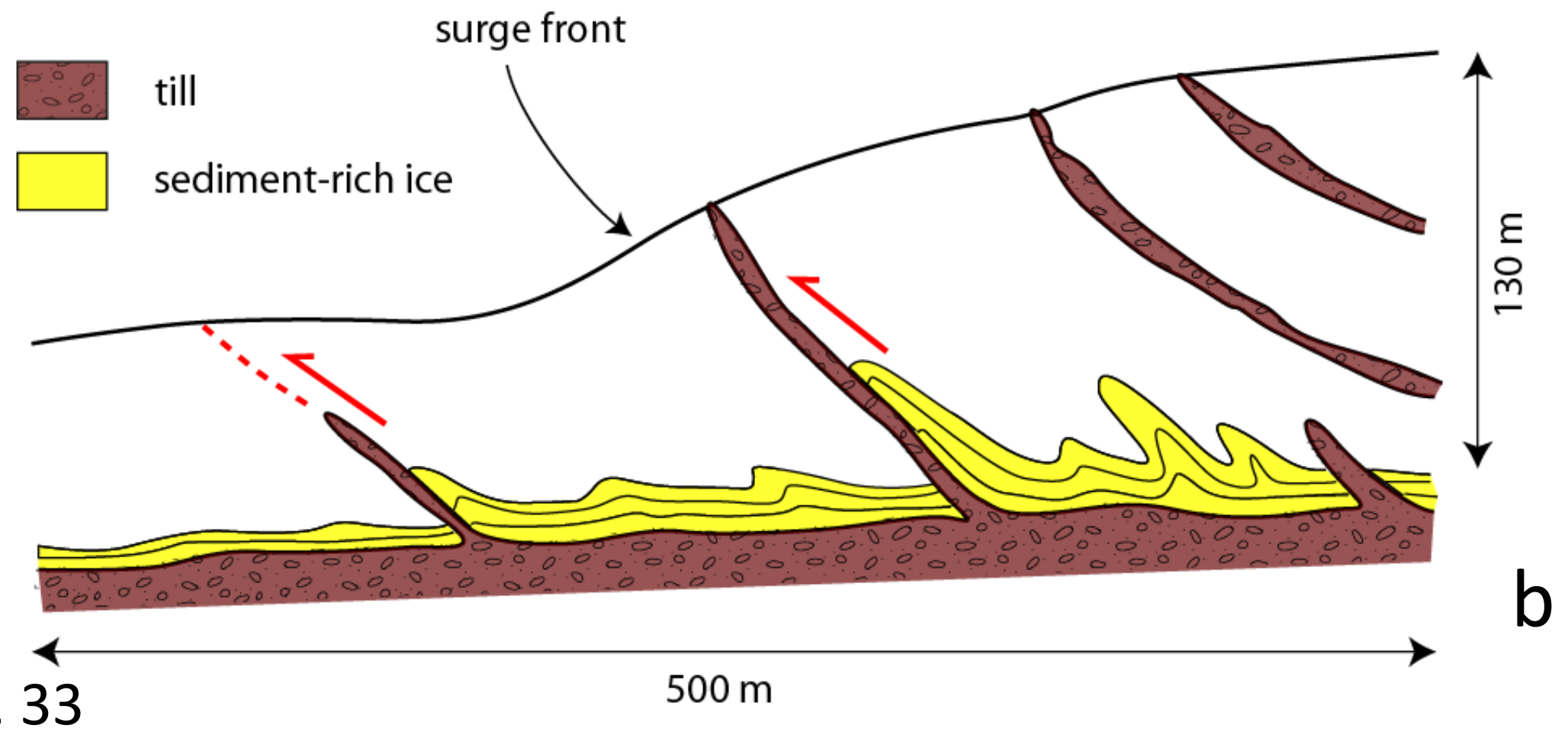



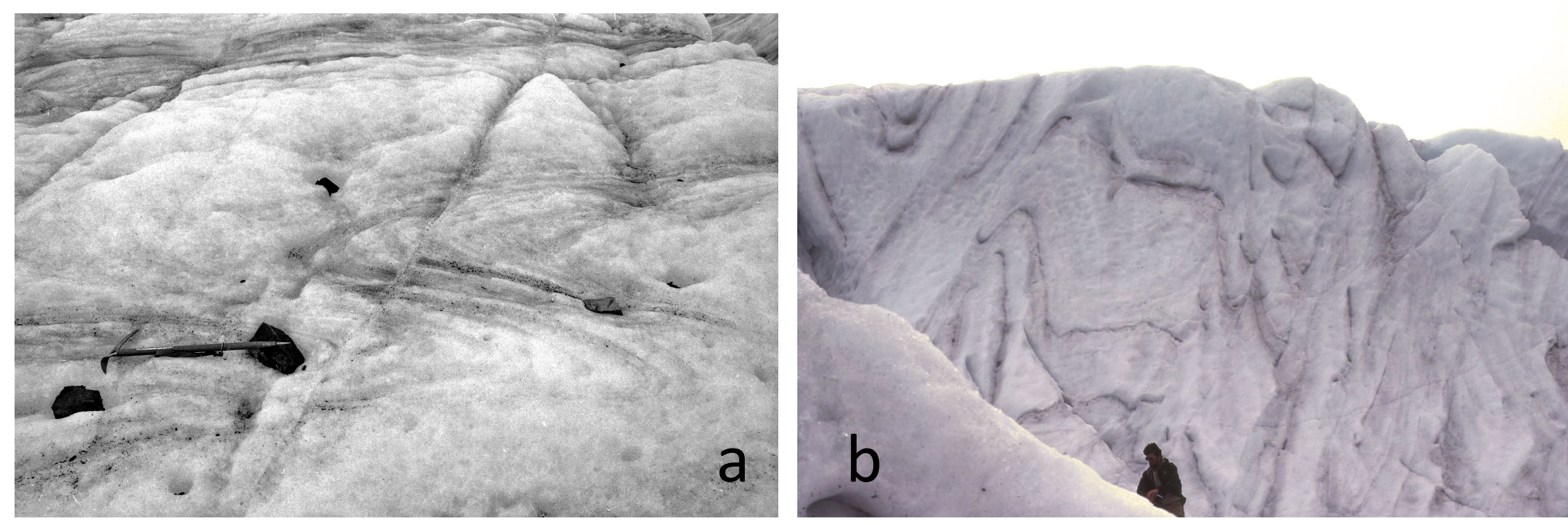

Fig. 34 

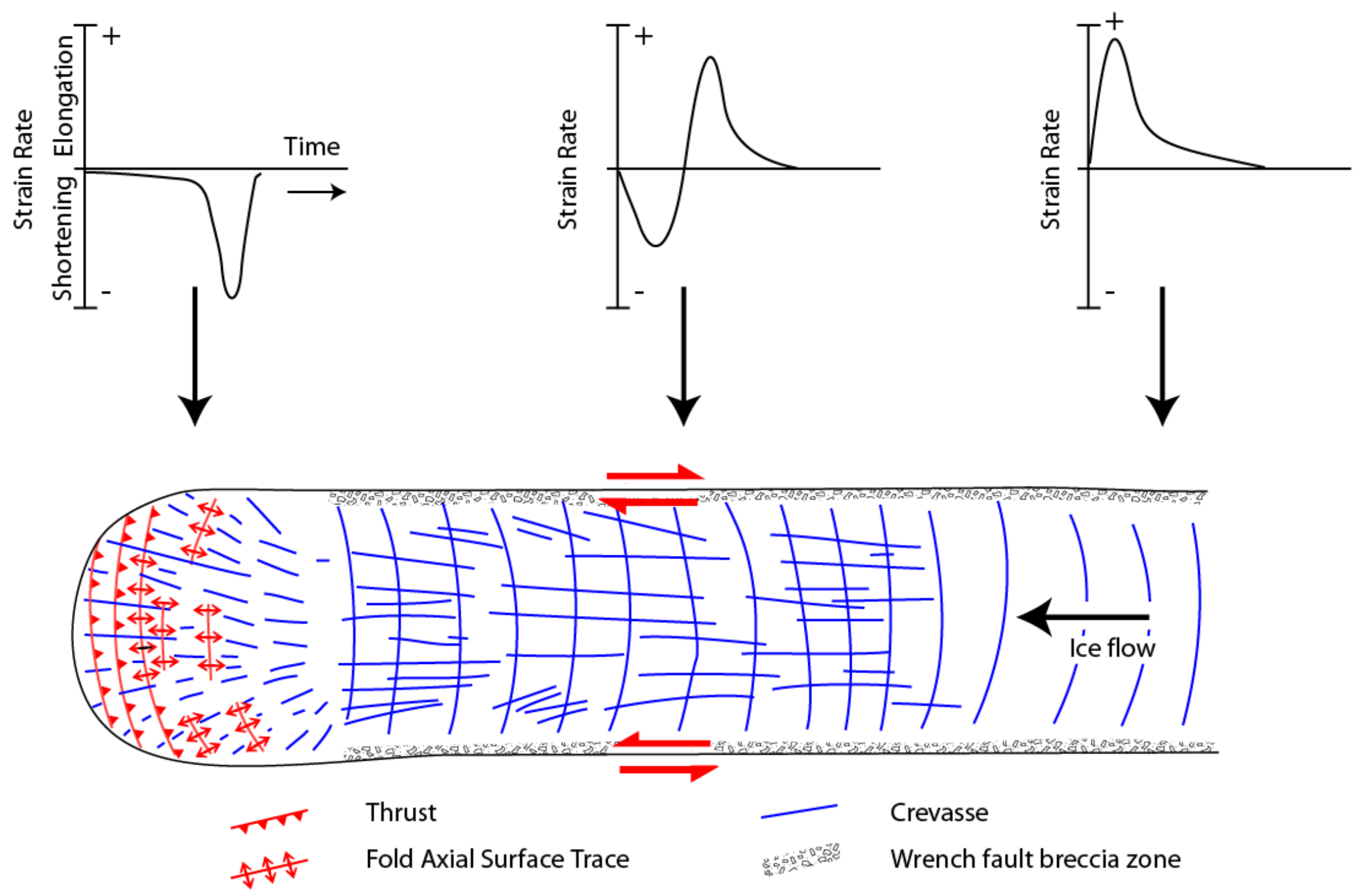

Fig. 35 

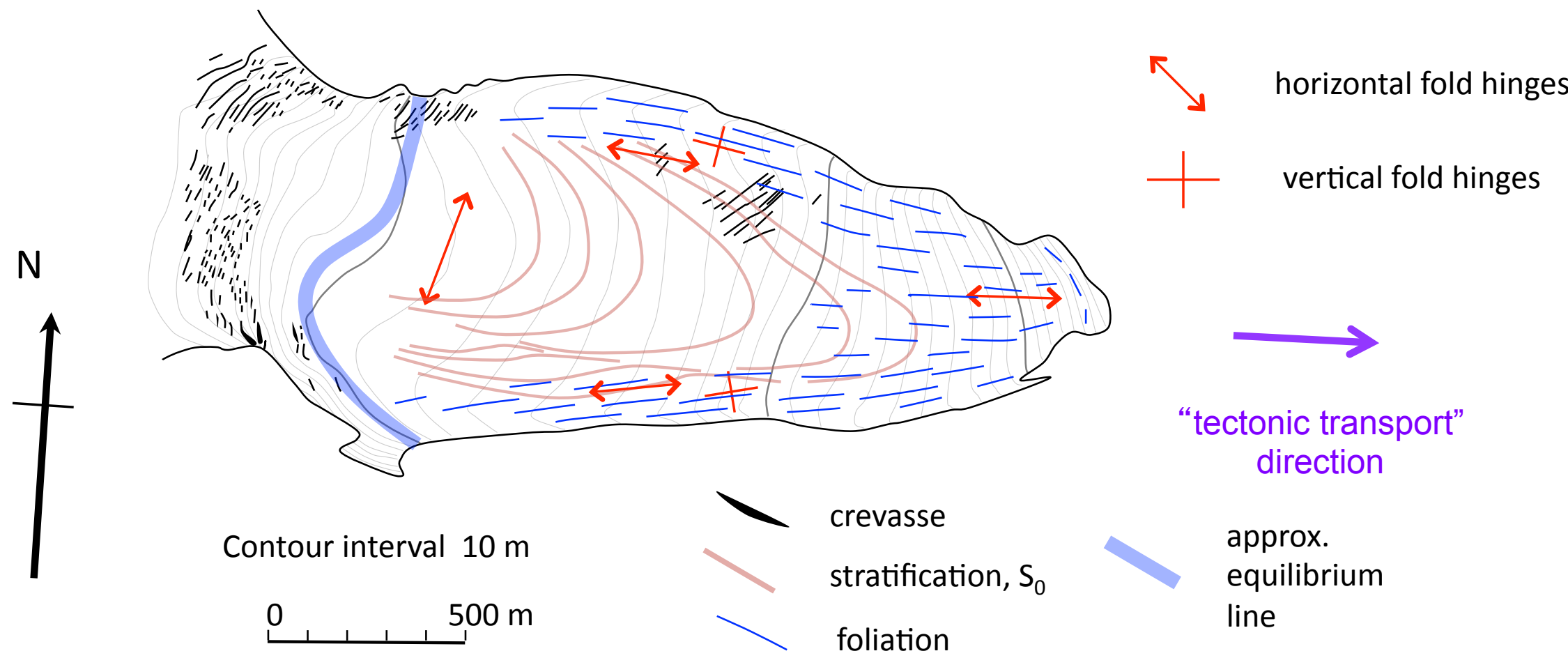

"tectonic transport" direction

approx.

equilibrium

line

Fig. 36 